\title{
Formation rates of complex organics in UV irradiated $\mathrm{CH}_{3} \mathrm{OH}$-rich ices
}

\section{Experiments ${ }^{\star}$}

\author{
K. I. Öberg ${ }^{1}$, R. T. Garrod ${ }^{2}$, E. F. van Dishoeck ${ }^{3,4}$, and H. Linnartz ${ }^{1}$ \\ 1 Raymond and Beverly Sackler Laboratory for Astrophysics, Leiden Observatory, Leiden University, PO Box 9513, 2300 RA Leiden, \\ The Netherlands \\ e-mail: oberg@strw.leidenuniv.nl \\ 2 Department of Astronomy, Cornell University, Ithaca, NY 14853, USA \\ e-mail: rgarrod@astro.cornell.edu \\ 3 Leiden Observatory, Leiden University, PO Box 9513, 2300 RA Leiden, The Netherlands \\ 4 Max-Planck-Institut für extraterrestrische Physik (MPE), Giessenbachstraat 1,85748 Garching, Germany
}

Received 23 May 2009 / Accepted 22 July 2009

\begin{abstract}
Context. Gas-phase complex organic molecules are commonly detected in the warm inner regions of protostellar envelopes, so-called hot cores. Recent models show that photochemistry in ices followed by desorption may explain the observed abundances. There is, however, a general lack of quantitative data on UV-induced complex chemistry in ices.

Aims. This study aims to experimentally quantify the UV-induced production rates of complex organics in $\mathrm{CH}_{3} \mathrm{OH}$-rich ices under a variety of astrophysically relevant conditions.

Methods. The ices are irradiated with a broad-band UV hydrogen microwave-discharge lamp under ultra-high vacuum conditions, at 20-70 K, and then heated to $200 \mathrm{~K}$. The reaction products are identified by reflection-absorption infrared spectroscopy (RAIRS) and temperature programmed desorption (TPD), through comparison with RAIRS and TPD curves of pure complex species, and through the observed effects of isotopic substitution and enhancement of specific functional groups, such as $\mathrm{CH}_{3}$, in the ice.

Results. Complex organics are readily formed in all experiments, both during irradiation and during the slow warm-up of the ices after the UV lamp is turned off. The relative abundances of photoproducts depend on the UV fluence, the ice temperature, and whether pure $\mathrm{CH}_{3} \mathrm{OH}$ ice or $\mathrm{CH}_{3} \mathrm{OH}: \mathrm{CH}_{4} / \mathrm{CO}$ ice mixtures are used. $\mathrm{C}_{2} \mathrm{H}_{6}, \mathrm{CH}_{3} \mathrm{CHO}, \mathrm{CH}_{3} \mathrm{CH}_{2} \mathrm{OH}, \mathrm{CH}_{3} \mathrm{OCH}_{3}, \mathrm{HCOOCH}_{3}, \mathrm{HOCH} \mathrm{CHO}$ and $\left(\mathrm{CH}_{2} \mathrm{OH}\right)_{2}$ are all detected in at least one experiment. Varying the ice thickness and the UV flux does not affect the chemistry. The derived product-formation yields and their dependences on different experimental parameters, such as the initial ice composition, are used to estimate the $\mathrm{CH}_{3} \mathrm{OH}$ photodissociation branching ratios in ice and the relative diffusion barriers of the formed radicals. At $20 \mathrm{~K}$, the pure $\mathrm{CH}_{3} \mathrm{OH}$ photodesorption yield is $2.1( \pm 1.0) \times 10^{-3}$ per incident UV photon, the photo-destruction cross section $2.6( \pm 0.9) \times 10^{-18} \mathrm{~cm}^{2}$.

Conclusions. Photochemistry in $\mathrm{CH}_{3} \mathrm{OH}$ ices is efficient enough to explain the observed abundances of complex organics around protostars. Some complex molecules, such as $\mathrm{CH}_{3} \mathrm{CH}_{2} \mathrm{OH}$ and $\mathrm{CH}_{3} \mathrm{OCH}_{3}$, form with a constant ratio in our ices and this can can be used to test whether complex gas-phase molecules in astrophysical settings have an ice-photochemistry origin. Other molecular ratios, e.g. HCO-bearing molecules versus $\left(\mathrm{CH}_{2} \mathrm{OH}\right)_{2}$, depend on the initial ice composition and temperature and can thus be used to investigate when and where complex ice molecules form.
\end{abstract}

Key words. astrochemistry - astrobiology - molecular processes - methods: laboratory - stars: circumstellar matter - ISM: molecules

\section{Introduction}

Organic molecules of increasing complexity are being detected in star-forming regions (Blake et al. 1987; Nummelin et al. 2000; Bisschop et al. 2007b; van Dishoeck et al. 1995; Cazaux et al. 2003; Bottinelli et al. 2004, 2007; Belloche et al. 2009); however, the origins of these complex molecules are the subject of debate. Commonly-suggested formation routes include various gas-phase reactions involving evaporated $\mathrm{CH}_{3} \mathrm{OH}$ ices, atom-addition reactions on dust grains, and UV- and cosmic rayinduced chemistry in the granular ices (Charnley et al. 1992; Nomura \& Millar 2004, Herbst \& van Dishoeck 2009). Recently,

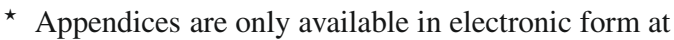
http://www . aanda. org
}

the focus has shifted to an ice formation pathway (e.g. Garrod et al. 2008), but due to the lack of quantitative experimental data, it is still not clear whether these molecules form in granular ices during the colder stages of star formation or in the warm gas close to the protostar. Nor has the relative importance of different grain formation routes been resolved. Establishing the main formation route is needed to predict the continued chemical evolution during star- and planet-formation and also to predict the amount of complex organics incorporated into comets and other planetesimals. In light of this, and the recent failures of gas phase chemistry to explain the observed complex molecules, we aim to quantify the formation of complex molecules through UVinduced chemistry in $\mathrm{CH}_{3} \mathrm{OH}$-rich ices. 
Simple ices, such as solid $\mathrm{H}_{2} \mathrm{O}, \mathrm{CO}, \mathrm{CO}_{2}, \mathrm{CH}_{4}$ and $\mathrm{NH}_{3}$, are among the most common species found in dark cloud cores and towards protostars. The ices form sequentially in the cloud, resulting in a bi-layered structure dominated by $\mathrm{H}_{2} \mathrm{O}$ and and $\mathrm{CO}$, respectively (Bergin et al. 2005; Knez et al. 2005; Pontoppidan 2006). Laboratory experiments suggest that $\mathrm{CH}_{3} \mathrm{OH}$ also forms in the ice during the pre-stellar phase, through hydrogenation of $\mathrm{CO}$ (Watanabe et al. 2003), although, as yet, $\mathrm{CH}_{3} \mathrm{OH}$ ice has only been detected toward protostars. Based on this formation route, $\mathrm{CH}_{3} \mathrm{OH}$ is probably present in a $\mathrm{CO}$-rich phase during most of its lifetime. More complex ices have been tentatively detected towards a few high-mass protostars (Schutte et al. 1999; Gibb et al. 2004), though specific band assignments are uncertain. Towards most other objects, derived upper limits on complex ices are too high to be conclusive.

Indirect evidence of complex molecule formation in ice mantles exists from millimeter observations of shocked regions and the innermost parts of low- and high-mass protostellar envelopes, so called hot cores and corinos. The observations by Arce et al. (2008) of $\mathrm{HCOOCH}_{3}, \mathrm{HCOOH}$ and $\mathrm{CH}_{3} \mathrm{CH}_{2} \mathrm{OH}$ at abundances of $\sim 10^{-2}$ with respect to $\mathrm{CH}_{3} \mathrm{OH}$ towards the lowmass molecular outflow L1157 are especially compelling; this outflow has been above $100 \mathrm{~K}$ for a period that is an order of magnitude shorter than is required for the gas-phase production of such complex molecules. Ice evaporation through sputtering is, in contrast, efficient in shocks (Jones et al. 1996). The observed abundances towards L1157 are remarkably similar to those observed in galactic-center clouds and high-mass protostars, suggesting a common formation route.

In hot cores and corinos, gas-phase production may still be a viable alternative for some of the detected molecules, because of the longer time scales compared to outflows. However, recent calculations and experiments suggest that some key gas-phase reactions are less efficient than previously thought; for example, the gas-phase formation of $\mathrm{HCOOCH}_{3}$ was found to be prohibitively inefficient (Horn et al. 2004). Furthermore, Bisschop et al. (2007b) recently showed that complex oxygen-bearing molecules and $\mathrm{H}_{2} \mathrm{CO}$ are equally well correlated with $\mathrm{CH}_{3} \mathrm{OH}$. Since $\mathrm{CH}_{3} \mathrm{OH}$ and $\mathrm{H}_{2} \mathrm{CO}$ are proposed to form together in the ice, this suggests that those complex oxygen-bearing molecules are also "first-generation" ice products.

One possible ice formation route for complex species is atomic accretion and recombination on grain surfaces, which appears efficient for smaller species. Charnley (2004) suggested that the hot-core molecules may form either through hydrogenation of molecules and radicals, such as $\mathrm{CO}$ and $\mathrm{HCCO}$, or through a combination of hydrogenation and oxidation starting with $\mathrm{C}_{2} \mathrm{H}_{2}$. Similar reaction schemes are suggested to explain observations by e.g. Bisschop et al. (2008) and Requena-Torres et al. (2008). Such formation mechanisms have not been comprehensively tested under astrophysically relevant conditions, although the models of Belloche et al. (2009) found them to be ineffective in the formation of nitriles up to ethyl cyanide, under hot core conditions. Experimental studies show that dissociative reactions may be the favored outcome of hydrogenating larger molecules and fragments (e.g. Bisschop et al. 2007a), hampering the build-up of large quantities of complex molecules. Quantitative experiments are, however, still lacking for most reactions.

The alternative grain-surface formation route, which is investigated in this study, is the energetic destruction of the observed simple ices and subsequent diffusion and recombination of the radicals into more complex species. Within this framework, Garrod \& Herbst (2006) and Garrod et al. (2008) modeled the formation of complex molecules during the slow warm-up of ices in an in-falling envelope, followed by ice evaporation in the hot core region. In the model, photodissociation of simple ices, especially $\mathrm{CH}_{3} \mathrm{OH}$, produces radicals in the ice. The lukewarm ices in the envelope $(20-100 \mathrm{~K})$ allow for the diffusion of "heavy" radicals like $\mathrm{CH}_{3}$ and $\mathrm{CH}_{2} \mathrm{OH}$, which recombine to form complex molecules. The model continues until all the ice is evaporated and the resulting gas phase abundances reproduce some of the abundance ratios and temperature structures seen in the galactic center and towards hot cores. Improvement of these model predictions is mainly limited by lack of quantitative experimental data on $\mathrm{CH}_{3} \mathrm{OH}$ photodissociation branching ratios in ices, diffusion barriers of the formed radicals and binding energies of most complex molecules. The ultimate objective of the present study is to provide these numbers by experimental investigation of the photochemistry in $\mathrm{CH}_{3} \mathrm{OH}$-rich ices, followed by quantitative modeling (Paper II, Garrod \& Öberg, in preparation).

There have been multiple studies of photochemistry in ices containing organic molecules, stretching back to the $1960 \mathrm{~s}$ (e.g. Stief et al. 1965). Most studies provide only a limited amount of the kind of quantitative data needed for astrochemical models and instead focus on the qualitative assignment of final photochemistry products, following irradiation of ice mixtures that are proposed to mimic ice compositions in star forming regions. To produce enough detectable products, deposition and irradiation were typically simultaneous in the early experiments, rather than a sequential deposition, irradiation and warm-up scheme. This was the approach of, for example, Hagen et al. (1979) and D'Hendecourt et al. (1982). Allamandola et al. (1988) included $\mathrm{CH}_{3} \mathrm{OH}$ in ice mixtures in similar experiments and found that $\mathrm{CH}_{3} \mathrm{OH}$ mainly photodissociates into smaller fragments at $10 \mathrm{~K}$, while several new unidentified features appear following the warm-up of the irradiated ice, indicating an efficient diffusion of radicals. Gerakines et al. (1996) investigated the photochemistry of pure $\mathrm{CH}_{3} \mathrm{OH}$ ice more quantitatively at $10 \mathrm{~K}$, and determined the $\mathrm{CH}_{3} \mathrm{OH}$ photolysis cross section, and the $\mathrm{H}_{2} \mathrm{CO}$ and $\mathrm{CH}_{4} \mathrm{UV}$ formation cross sections averaged over the lamp wavelength range at a specific flux setting. Gerakines et al. (1996) also detected $\mathrm{HCOOCH}_{3}$, and several other complex species have also been identified in $\mathrm{CH}_{3} \mathrm{OH}$-rich ices following UV-irradiation, though some peaks have been assigned to different carriers in different studies. The difficulty in identifying most complex products is discussed by e.g. Hudson \& Moore (2000) who investigated the production of complex molecules in $\mathrm{CH}_{3} \mathrm{OH}: \mathrm{H}_{2} \mathrm{O}$ and $\mathrm{CH}_{3} \mathrm{OH}: \mathrm{CO}$ ice mixtures both following UV irradiation and ion bombardment in a number of studies, most recently in Moore \& Hudson (2005) and Hudson et al. (2005).

A few studies exist on the formation of complex molecules from ion bombardment of pure $\mathrm{CH}_{3} \mathrm{OH}$ ice, though similarly to the UV photolysis experiments, the formation of more complex molecules than $\mathrm{CH}_{3} \mathrm{OH}$ is in general not quantified (Baratta et al. 2002; Bennett et al. 2007). Bennett et al. (2007) identified $\mathrm{HCOOCH}_{3}, \mathrm{HOCH}_{2} \mathrm{CHO}$ and $\left(\mathrm{CH}_{2} \mathrm{OH}\right)_{2}$, mainly based on comparison with calculated spectra and desorption patterns following irradiation, but provided only upper limits of their formation rates. The quantitative data from both studies include formation rates of small molecules and $\mathrm{CH}_{3} \mathrm{OH}$ and $\mathrm{H}_{2} \mathrm{CO}$ ionbombardment dissociation rates. In a separate study Bennett \& Kaiser (2007) determined the formation rate of $\mathrm{HCOOCH}_{3}$ and $\mathrm{HOCH}_{2} \mathrm{CHO}$ in a $\mathrm{CO}: \mathrm{CH}_{3} \mathrm{OH}$ ice mixture for the ionbombardment flux used in their experiment.

The aim of this study and its follow-up paper is to combine experiments with kinetic modeling to completely quantify 
the photochemistry of $\mathrm{CH}_{3} \mathrm{OH}$ rich ices. This includes determining the $\mathrm{CH}_{3} \mathrm{OH}$ photodesorption yield, the $\mathrm{CH}_{3} \mathrm{OH}$ dissociation branching ratios upon UV irradiation, the diffusion barriers of the formed radicals and reaction barriers to form more complex molecules, where present. Here, we present the experiments on $\mathrm{CH}_{3} \mathrm{OH}$ ice chemistry under a large range of astrophysically relevant conditions and quantify the formation of all possible first generation complex molecules. To ensure that reaction products are correctly assigned, we also present RAIR spectra and temperature-programmed desorption experiments of all stable expected complex products, together with their derived binding energies.

The paper is organized as follows. Section 2 presents the experimental and data analysis methods. Section 3 reports on both qualitative and quantitative results of the experiments. Discussion follows in Sect. 4, and includes estimates of photodissociation branching ratios and diffusion barriers. Preliminary astrophysical implications are discussed in Sect. 5. A summary of results and concluding remarks are given in Sect. 6.

\section{Experiments and analysis}

All experiments are carried out under ultra-high vacuum conditions $\left(\sim 10^{-10}\right.$ mbar $)$ in the CRYOPAD set-up, which is described in detail in Fuchs et al. (2006) and Öberg et al. (2009b). The ices are grown in situ with monolayer precision at thicknesses between 3 and $66 \mathrm{ML}$, by exposing a cold substrate at the center of the vacuum chamber to a steady flow of gas, directed along the surface normal. The substrate is temperature controlled between 20 and $200 \mathrm{~K}$. The relative temperature uncertainty is less than a degree, while the absolute uncertainty is about two degrees. All UV-irradiation experiments are performed with $\mathrm{CH}_{3} \mathrm{OH}$ from Sigma-Aldrich with a minimum purity of $99.8 \%$. The mixed ice experiments contain $\mathrm{CH}_{4}$ or $\mathrm{CO}$ gas of $99 \%$ purity (Indogas). Pure, complex ice experiments with $\mathrm{C}_{2} \mathrm{H}_{6}, \mathrm{CH}_{3} \mathrm{CHO}, \mathrm{CH}_{3} \mathrm{OCH}_{3}, \mathrm{CH}_{3} \mathrm{CH}_{2} \mathrm{OH}, \mathrm{HCOOH}$, $\mathrm{HCOOCH}_{3}, \mathrm{CH}_{3} \mathrm{COOH}, \mathrm{HOCH}_{2} \mathrm{CHO}$ and $\left(\mathrm{CH}_{2} \mathrm{OH}\right)_{2}$ are carried out with chemicals of 99-99.9\% purity from Sigma-Aldrich. All liquid samples are further purified with several freeze-thaw cycles to remove any volatile gas from the sample. The dominant source of contaminants is from the vacuum inside of the chamber once the ice is deposited; during each experiment, up to $0.5 \mathrm{ML}$ of $\mathrm{H}_{2} \mathrm{O}$ adsorbs onto the substrate from the small $\mathrm{H}_{2} \mathrm{O}$ contamination always present in the chamber. This has no measurable impact on the photochemistry from test experiments with $\mathrm{CH}_{3} \mathrm{OH}$ isotopologues.

The set-up is equipped with a Fourier transform infrared (FTIR) spectrometer in reflection-absorption mode (ReflectionAbsorption InfraRed Spectroscopy or RAIRS). The FTIR covers $750-4000 \mathrm{~cm}^{-1}$, which includes vibrational bands of all investigated molecules, and is operated with a spectral resolution of $1 \mathrm{~cm}^{-1}$. To increase the signal to noise the spectra are frequently binned when this can be done without reducing the absorbance of sharp features. RAIRS is employed both to acquire infrared spectra of complex molecules and to quantify the changing ice composition during UV irradiation of $\mathrm{CH}_{3} \mathrm{OH}$-rich ices. All spectra are corrected with a linear baseline alone, to avoid distorting any spectral profiles.

Temperature Programmed Desorption (TPD) is another analytical tool, which is employed in this study to identify ice photoproducts. In a TPD experiment, ice evaporation is induced by linear heating of the ice, here with a heating rate of $1 \mathrm{~K} \mathrm{~min}^{-1}$. The evaporated gas phase molecules are detected by a Quadrupole
Mass Spectrometer (QMS). The resulting TPD curves depend on the evaporation energy of the ice, which can be uniquely identified for most of the investigated species. For mixed ices the TPD curve also depends on such quantities as ice trapping, mixing and segregation. The QMS software allows for the simultaneous detection of up to 60 different $\mathrm{m} / \mathrm{z}$ values (the molecular mass divided by the charge). Hence in the TPD experiments of irradiated ices, all possible reaction-product masses, which contain at most two oxygen and two carbon atoms, are monitored.

In the $\mathrm{CH}_{3} \mathrm{OH}$ photochemistry experiments, the ice films are irradiated at normal or $45^{\circ}$ incidence with UV light from a broadband hydrogen microwave-discharge lamp, which peaks around Ly $\alpha$ at $121 \mathrm{~nm}$ and covers $115-170 \mathrm{~nm}$ or $7-10.5 \mathrm{eV}$ (Muñoz Caro \& Schutte 2003). The lamp flux was calibrated against a NIST calibrated silicate photodiode prior to the experimental series and is monitored during each experiment using the photoelectric effect in a gold wire in front of the lamp. The lamp emission resembles the spectral distribution of the UV interstellar radiation field that impinges externally on all clouds. It is also consistent with the UV radiation produced locally inside clouds by the decay of electronic states of $\mathrm{H}_{2}$, following excitation by energetic electrons resulting from cosmic-ray induced ionization of hydrogen, see e.g. Sternberg et al. (1987). Each irradiation experiment is followed by a TPD experiment, where RAIR spectra are acquired every $10 \mathrm{~K}$ up to $200 \mathrm{~K}$.

Supporting experiments consist of RAIR spectra and TPD curves of nine complex organic ices, which are potential photoproducts of $\mathrm{CH}_{3} \mathrm{OH}$ ices. Spectra of these ices have been reported previously in the literature in transmission, but because of known band shifts in RAIRS compared to transmission spectroscopy, their RAIR spectra are also presented here.

The identification process is complicated by spectral overlaps of most of the potential photochemistry products. Thus great care is taken in securing each assignment, especially where they disagree with previous work or where disagreements between previous studies exist. To call an identification secure we test it to be consistent with up to seven criteria. These identification tools are described in detail in Sect. 3.5.

Following the spectral band identification, RAIR spectroscopy is used to determine the initial $\mathrm{CH}_{3} \mathrm{OH}$ ice abundance and the formed simple and complex ice abundances as a function of fluence during each photochemistry experiment. This requires known band strengths. The absolute RAIRS band strengths have been estimated previously in our set-up for $\mathrm{CO}$ and $\mathrm{CO}_{2}$ ice (Öberg et al. 2009a,b). Using the same method, new measurements on $\mathrm{CH}_{3} \mathrm{OH}$ are consistent with the $\mathrm{CO}$ and $\mathrm{CO}_{2}$ results; i.e. the determined band strengths have the same relative values compared to the transmission band strength ratios reported in the literature, within $20 \%$. The relative ice band strengths from transmission are thus still valid, with some exceptions, and most experimental objectives only require knowing the ice fraction that has been converted into products. The main caveat is that ices thicker than a few monolayers are not guaranteed to have a linear relationship between the absorbance of strong bands and ice thickness due to RAIRS effects (Teolis et al. 2007). This is circumvented by selecting weak enough bands, especially for $\mathrm{CH}_{3} \mathrm{OH}$, whose absorbance remains linear with respect to the amount of deposited ice at all the investigated ice thicknesses. The transmission band strength of $\mathrm{CH}_{3} \mathrm{OCH}_{3}$ is not present in the literature and its band strength is estimated by deposition of a dilute $\mathrm{CH}_{3} \mathrm{OCH}_{3}: \mathrm{CH}_{3} \mathrm{OH}$ 1:10 mixture and assuming a constant sticking coefficient and that the $\mathrm{CH}_{3} \mathrm{OCH}_{3}$ is "dragged" along with the $\mathrm{CH}_{3} \mathrm{OH}$ to reach the substrate at a similar deposition rate. 
Table 1. Experimental parameters for UV-irradiation experiments.

\begin{tabular}{lcccc}
\hline \hline Exp. & Species & $\begin{array}{c}\text { Temp }^{a} \\
(\mathrm{~K})\end{array}$ & $\begin{array}{c}\text { Thick. } \\
(\mathrm{ML})\end{array}$ & $\begin{array}{c}\text { UV flux } \\
\left(10^{13} \mathrm{~cm}^{-2} \mathrm{~s}^{-1}\right)\end{array}$ \\
\hline 1 & $\mathrm{CH}_{3} \mathrm{OH}$ & 20 & 21 & 1.1 \\
2 & $\mathrm{CH}_{3} \mathrm{OH}$ & 30 & 19 & 1.1 \\
3 & $\mathrm{CH}_{3} \mathrm{OH}$ & 50 & 20 & 1.1 \\
4 & $\mathrm{CH}_{3} \mathrm{OH}$ & 70 & 22 & 1.1 \\
5 & $\mathrm{CH}_{3} \mathrm{OH}$ & 20 & 19 & 4.3 \\
6 & $\mathrm{CH}_{3} \mathrm{OH}$ & 50 & 15 & 4.3 \\
7 & $\mathrm{CH}_{3} \mathrm{OH}: \mathrm{CO}$ & 20 & $12: 17$ & 1.1 \\
8 & $\mathrm{CH}_{3} \mathrm{OH}: \mathrm{CO}$ & 30 & $12: 11$ & 1.1 \\
9 & $\mathrm{CH}_{3} \mathrm{OH}: \mathrm{CO}$ & 50 & $16: 7$ & 1.1 \\
10 & $\mathrm{CH}_{3} \mathrm{OH}: \mathrm{CH}$ & 30 & $11: 27$ & 1.1 \\
11 & $\mathrm{CH}_{3} \mathrm{OH}: \mathrm{CH}$ & 50 & $11: 6$ & 1.1 \\
12 & $\mathrm{CH}_{3} \mathrm{OH}: \mathrm{CO}$ & 20 & $6: 60$ & 1.1 \\
13 & $\mathrm{CH}_{3} \mathrm{OH}$ & 20 & 6 & 1.1 \\
14 & $\mathrm{CH}_{3} \mathrm{OH}$ & 50 & 6 & 1.1 \\
15 & $\mathrm{CH}_{3} \mathrm{OH}$ & 20 & 4 & 4.3 \\
16 & $\mathrm{CH}_{3} \mathrm{OH}$ & 50 & 8 & 4.3 \\
$17^{b}$ & $\mathrm{CH}_{3} \mathrm{OH}$ & 20 & 18 & 1.1 \\
$18^{c}$ & $\mathrm{CH}_{3} \mathrm{OH}$ & 20 & 20 & 1.1 \\
19 & $\mathrm{CH}_{3} \mathrm{OD}$ & 20 & $\sim 20$ & 1.1 \\
20 & $\mathrm{CH}_{3} \mathrm{OD}$ & 50 & $\sim 20$ & 1.1 \\
21 & $\mathrm{CD}_{3} \mathrm{OH}$ & 20 & $\sim 20$ & 1.1 \\
22 & $\mathrm{CD}_{3} \mathrm{OH}$ & 50 & $\sim 20$ & 1.1 \\
\hline
\end{tabular}

${ }^{a}$ The ice-deposition and -irradiation temperature.

${ }^{b}$ Following irradiation the ice is quickly heated to $50 \mathrm{~K}$ for $2 \mathrm{~h}$.

${ }^{c}$ Following irradiation the ice is quickly heated to $70 \mathrm{~K}$ for $2 \mathrm{~h}$.

Table 1 lists the $\mathrm{CH}_{3} \mathrm{OH}, \mathrm{CH}_{3} \mathrm{OH}: \mathrm{CO}$ and $\mathrm{CH}_{3} \mathrm{OH}: \mathrm{CH}_{4}$ photochemistry experiments. The experiments are designed to study the impact of ice temperature, ice thickness, UV flux, UV fluence and mixed-in $\mathrm{CO}$ and $\mathrm{CH}_{4}$ on the reaction-product abundances. Each ice is irradiated for $\sim 6 \mathrm{~h}$ at the reported flux. The high flux/fluence experiments are also used to determine the $\mathrm{CH}_{3} \mathrm{OH}$ photodesorption rate using the same procedure as reported by Öberg et al. (2009b). In two experiments (17 and 18) the irradiation is followed by fast heating to a specified temperature to investigate the impact of the heating rate for radical diffusion. Table 2 lists the investigated complex organics for which RAIR spectra and TPD experiments have been acquired.

In addition to the experiments listed in Table 1 and 2, two experiments were performed to test the $\mathrm{CO}$ accretion rate due to UV-induced out-gassing from chamber walls and the life time of spectral features in the ice when diffusion is slow. In the first experiment a blank substrate was irradiated for the typical experiment time of six hours and a build-up of 0.2 CO ML was recorded. In the second experiment a photolyzed $\mathrm{CH}_{3} \mathrm{OH}$ ice was monitored for five hours at $17 \mathrm{~K}$ after the UV lamp was turned off; the spectra of complex products did not change measurably during this period.

In all experiments, systematic uncertainties dominate and include the absolute calibration of the temperature $(\sim 2 \mathrm{~K})$, the UV flux $(\sim 30 \%)$ and the conversion between transmission and RAIRS band strengths used to determine the absolute ice abundances $(\sim 50 \%)$, while the relative RAIRS band strengths are more accurate ( $\sim 20 \%$ uncertainty from comparison between different trannsmission spectroscopy studies). The conversion between transmission and RAIRS band strengths will not affect the uncertainty of the photochemistry rates, since these depend only on the fraction of the ice that is converted into products. The determined diffusion barriers in Paper II are furthermore not affected by the uncertainty in UV flux because these only depend on which species the produced radicals react with, not on how
Table 2. Pure ice spectroscopy and TPD experiments.

\begin{tabular}{|c|c|c|c|c|}
\hline Species & Formula & Mass (amu) & Thick. $^{a}$ (ML) & $E_{\mathrm{des}}^{a}(\mathrm{~K})$ \\
\hline Ethane & $\mathrm{C}_{2} \mathrm{H}_{6}$ & 30 & $5[3]$ & $2300[300]$ \\
\hline Methanol & $\mathrm{CH}_{3} \mathrm{OH}$ & 32 & 25 [10] & $4700[500]$ \\
\hline Acetaldehyde & $\mathrm{CH}_{3} \mathrm{CHO}$ & 44 & $4[2]$ & 3800 [400] \\
\hline Dimethyl ether & $\mathrm{CH}_{3} \mathrm{OCH}_{3}$ & 46 & $\sim 4$ & 3300 [400] \\
\hline Ethanol & $\mathrm{CH}_{3} \mathrm{CH}_{2} \mathrm{OH}$ & 46 & $5[2]$ & $5200[500]$ \\
\hline Formic acid & $\mathrm{HCOOH}$ & 46 & $5[2]$ & $5000[500]$ \\
\hline Methyl formate & $\mathrm{HCOOCH}_{3}$ & 60 & $3[1]$ & 4000 [400] \\
\hline Acetic acid & $\mathrm{CH}_{3} \mathrm{COOH}$ & 60 & $3[1]$ & $6300[700]$ \\
\hline Glycolaldehyde & $\mathrm{HOCH}_{2} \mathrm{CHO}$ & 60 & $3[1]$ & $5900[600]$ \\
\hline Ethylene glycol & $\left(\mathrm{CH}_{2} \mathrm{OH}\right)_{2}$ & 62 & $7[3]$ & $7500[800]$ \\
\hline
\end{tabular}

${ }^{a}$ Values in brackets indicate uncertainties.

many of them are produced per UV photon. Another source of error is the local baseline determination, which results in relative abundance uncertainties of up to $30 \%$ for a couple of the detected products, which is reported in detail in Sect. 3.6 for each species. Thus the formation yield of products relative to the original ice abundance has a total uncertainty of $35-50 \%$.

\section{Experimental results}

This section begins with experimental results that quantify $\mathrm{CH}_{3} \mathrm{OH}$ bulk photolysis (Sect. 3.1) and surface photodesorption (Sect. 3.2). Section 3.3 qualitatively describes how the $\mathrm{CH}_{3} \mathrm{OH}$ photoproducts are affected by different experimental variables for the experiments listed in Table 1. This information, together with RAIR spectra and TPD data on pure complex organics in Sect. 3.4, is used in Sect. 3.5 to identify the $\mathrm{CH}_{3} \mathrm{OH}$ photoproducts. Following identification, the formation of all identified products from pure $\mathrm{CH}_{3} \mathrm{OH}$ ice photochemistry are shown quantitatively in Sect. 3.6. Section 3.7 describes quantitatively the formation and desorption of molecules during warm-up of the irradiated ices. Finally, Sect. 3.8 summarizes the effects of different experimental parameters on the final ice composition after irradiation and during warm-up.

\subsection{The $\mathrm{CH}_{3} \mathrm{OH}$ UV photolysis cross-section}

The UV-destruction cross-section of $\mathrm{CH}_{3} \mathrm{OH}$ ice, averaged over the lamp spectrum, determines the total amount of radicals available for diffusion and subsequent reaction. The cross section is calculated from the measured loss of $\mathrm{CH}_{3} \mathrm{OH}$ ice band intensity with fluence. The initial UV destruction of $\mathrm{CH}_{3} \mathrm{OH}$, i.e. before back-reactions to reform $\mathrm{CH}_{3} \mathrm{OH}$ become important, in an optically thin ice is given by

$N(\phi)=N(0) \exp \left(-\phi \times \sigma_{\mathrm{ph}}\right)$,

where $N$ is the $\mathrm{CH}_{3} \mathrm{OH}$ column density in $\mathrm{cm}^{-2}, \phi$ is the UV fluence in photons $\mathrm{cm}^{-2}$ and $\sigma_{\mathrm{ph}}$ is the UV-photolysis cross section in $\mathrm{cm}^{2}$. Figure 1 shows that photodestruction during the first $10^{17}$ photons is well described by this equation for $\sim 20$ ML thick ices at different temperatures. The loss of $\mathrm{CH}_{3} \mathrm{OH}$ is calculated from the combination band around $2550 \mathrm{~cm}^{-1}$ and the resulting photodissociation cross sections are 2.6[0.9], 2.4[0.8], 3.3[1.1] and $3.9[1.3] \times 10^{-18} \mathrm{~cm}^{2}$ at $20,30,50$ and $70 \mathrm{~K}$ respectively. The uncertainties in brackets are the absolute errors; the relative uncertainties are $10-20 \%$. The increasing cross section with temperature is indicative of significant immediate recombination of dissociated $\mathrm{CH}_{3} \mathrm{OH}$ at low temperatures when diffusion is slow. 


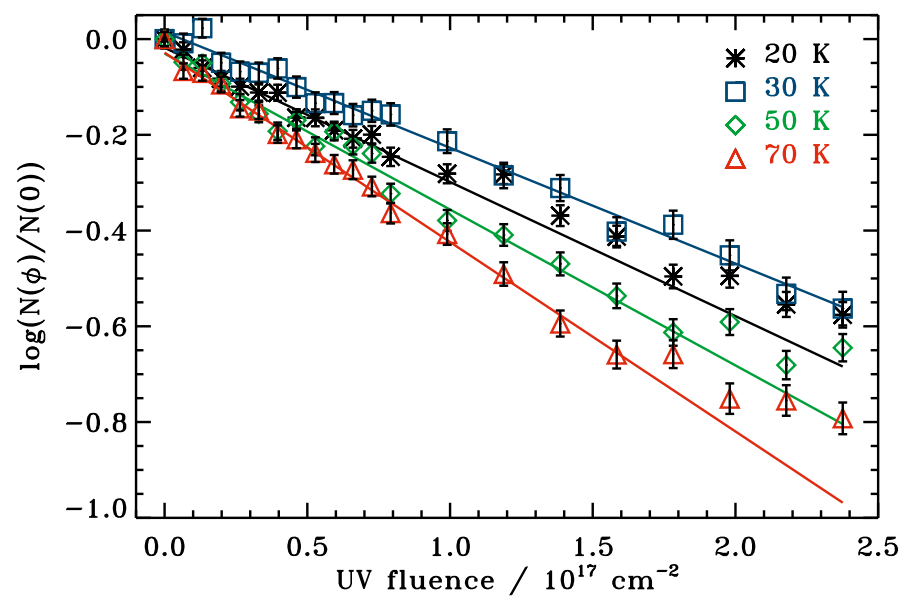

Fig. 1. The logarithm of the normalized $\mathrm{CH}_{3} \mathrm{OH}$ abundance as a function of UV fluence at 20,30,50 and $70 \mathrm{~K}$. The lines are exponential fits to the first $10^{17}$ photons in each experiment.

The measured effective $\mathrm{CH}_{3} \mathrm{OH}$-ice cross sections thus underestimate the actual photodissociation rate. This is consistent with the higher gas-phase $\mathrm{CH}_{3} \mathrm{OH} \mathrm{UV}$-absorption cross section; convolving the absorption spectra from Nee et al. (1985) with our lamp spectra results in a factor of three higher absorption rate than the observed photodissociation rate in the ice at $20 \mathrm{~K}$.

The measured photolysis cross sections also depend on whether a "clean" $\mathrm{CH}_{3} \mathrm{OH}$ band is used to calculate the $\mathrm{CH}_{3} \mathrm{OH}$ loss. The $v_{11} \mathrm{CH}_{3} \mathrm{OH}$ band around $1050 \mathrm{~cm}^{-1}$ is commonly used in the literature (Gerakines et al. 1996; Cottin et al. 2003). This band overlaps with strong absorptions of several complex photoproducts and using it results in a $30 \%$ underestimate of the $\mathrm{CH}_{3} \mathrm{OH}$ destruction cross section at $20 \mathrm{~K}$. This explains the higher cross-section value obtained in these experiments compared to Gerakines et al. (1996) and Cottin et al. (2003), who recorded $1.6 \times 10^{-18} \mathrm{~cm}^{2}$ and $6 \times 10^{-19} \mathrm{~cm}^{2}$, respectively. These destruction cross sections were also measured after greater fluences, $\sim 1.8 \times 10^{17}$ and $\sim 6 \times 10^{17} \mathrm{UV}$ photons $\mathrm{cm}^{-2}$, respectively, when back reactions to form $\mathrm{CH}_{3} \mathrm{OH}$ confuse the measurements. The measurements in this paper thus demonstrates the importance of a high fluence resolution and of picking a "clean" band when determining the photodestruction cross section of an ice.

\section{2. $\mathrm{CH}_{3} \mathrm{OH}$ photodesorption yields}

Previous experiments show that several ices (pure $\mathrm{CO}, \mathrm{CO}_{2}$ and $\mathrm{H}_{2} \mathrm{O}$ ) are efficiently photodesorbed upon UV irradiation. To constrain the photodesorption of $\mathrm{CH}_{3} \mathrm{OH}$ ice and thus determine the loss of $\mathrm{CH}_{3} \mathrm{OH}$ molecules into the gas phase rather than into photoproducts in the ice, the same procedure is followed as reported by Öberg et al. (2009b). This method is based on the fact that photodesorption from a multilayer ice is a zeroth order process with respect to photon fluence, since it only depends on the amount of molecules in the surface layer. The photodesorption yield will thus not change with fluence as long as the original ice is sufficiently thick. In contrast ice photolysis is a first order process, since it depends on the total amount of ice. Through simultaneous modeling of the ice loss with an exponential decay and a linear function, these two processes can be separated and the photodesorption yield determined (Fig. 2). The resulting yields are $2.1[1.0] \times 10^{-3}$ and $2.4[1.2] \times 10^{-3}$ desorbed molecules per incident UV photon at 20 and $50 \mathrm{~K}$, respectively. There is thus

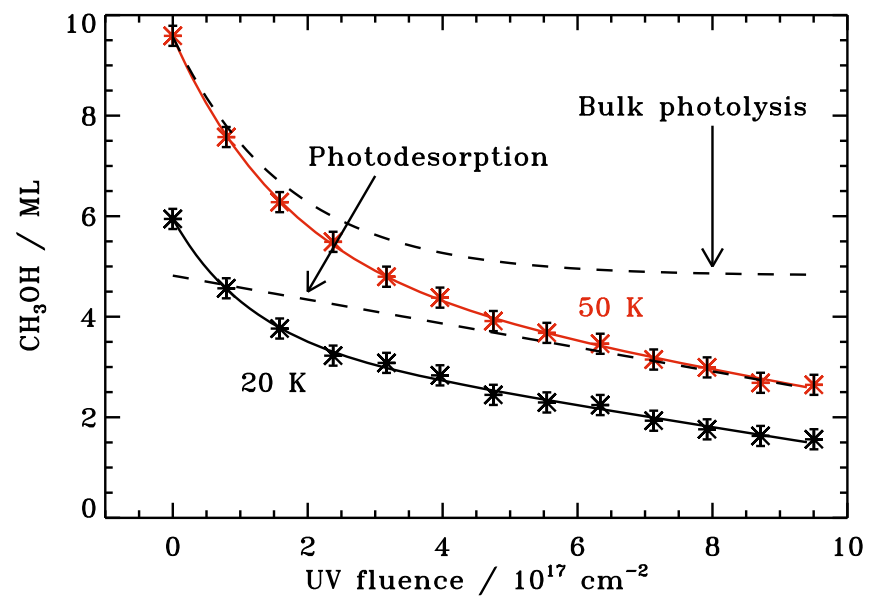

Fig. 2. The loss of $\mathrm{CH}_{3} \mathrm{OH}$ ice through photolysis and photodesorption at 20 and $50 \mathrm{~K}$ as a function of UV fluence. The curves are fitted with $A_{0}+A_{1} \times \phi+A_{2}(1-\exp (-\phi \times \sigma))$. The thin dashed lines show the offset decomposition of the function belonging to the $50 \mathrm{~K}$ experiment into its exponential photolysis part and its linear photodesorption part.

no evidence for a temperature dependence of the photodesorption yield within the investigated temperature range.

These yields agree with previous photodesorption studies of other molecules (Westley et al. 1995; Öberg et al. 2007, 2009a,b) and confirms the assumption in several observational and model papers that most ice molecules have similar photodesorption yields, around $10^{-3}$ per incident UV photon. The $\mathrm{CH}_{3} \mathrm{OH}$ photodesorption mechanism is suggested to be similar to $\mathrm{H}_{2} \mathrm{O}$ and $\mathrm{CO}_{2}$, i.e. a photodesorption event is initiated by photodissociation of a surface $\mathrm{CH}_{3} \mathrm{OH}$ molecule. The fragments contain excess energy and either desorb directly or recombine and desorb. The insensitivity to temperature suggest that longer range diffusion is comparatively unimportant and that most molecules desorb through the escape of the produced photodissociation fragments or through immediate recombination, in the same site, and desorption of the fragments following photodissociation. A more complete study including different ice thicknesses and temperatures is however required to confirm the proposed photodesorption pathway.

Another conceivable indirect photodesorption mechanism is desorption due to release of chemical heat following recombination of two thermalized radicals, first suggested by Williams (1968) and more recently investigated theoretically by Garrod et al. (2007). Its quantification requires more sensitive QMS measurements than is possible with this setup. The temperature independence suggests, however, that this is a minor desorption pathway in this setup, compared to direct photodesorption.

\subsection{Dependence of photo-product spectra on experimental variables}

The influence, if any, of different experimental variables on the resulting infrared spectra of irradiated $\mathrm{CH}_{3} \mathrm{OH}$ ice is investigated in detail below. These dependences are then used in the following sections to identify absorption bands and to subsequently quantify reaction rates, diffusion barriers and photodissociation branching ratios. The results are also independently valuable, since many of these experimental variables also vary between different astrophysical environments. 


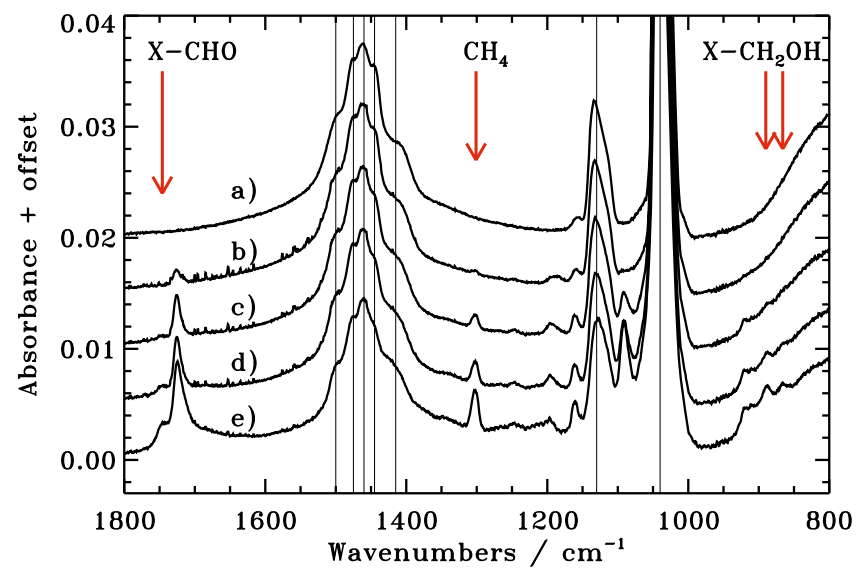

Fig. 3. The different growth rates of spectral features in a $\mathrm{CH}_{3} \mathrm{OH}$ ice at $50 \mathrm{~K}$ a) before UV irradiation and after a UV fluence of b) $7 \times 10^{15}$, c) $4 \times 10^{16}$, d), $8 \times 10^{16}$ and e) $2.4 \times 10^{17} \mathrm{~cm}^{-2}$. The $\mathrm{CH}_{3} \mathrm{OH}$ features are marked with thin lines. New features are present at 1750-1700, $1400-1150,1100-1050$ and $950-850 \mathrm{~cm}^{-1}$, including the bands belonging to $\mathrm{CH}_{4}$, complex aldehydes and acids (X-CHO), and complex alcohols $\left(\mathrm{X}-\mathrm{CH}_{2} \mathrm{OH}\right)$, where $\mathrm{X} \neq \mathrm{H}$.

\subsubsection{UV fluence}

In most experiments, the ices are exposed to a total UV fluence (i.e. total flux integrated over the time of the experiment) of $\sim 2.4 \times 10^{17} \mathrm{~cm}^{-2}$, which is comparable to the UV fluence in a cloud core after a million years with a UV flux of $10^{4} \mathrm{~cm}^{-2} \mathrm{~s}^{-1}$ (Shen et al. 2004). This agreement is important since the composition of photoproducts changes with UV fluence in all experiments. This is illustrated in Fig. 3, which shows spectra of an originally $20 \mathrm{ML}$ thick $\mathrm{CH}_{3} \mathrm{OH}$ ice at $50 \mathrm{~K}$ after different fluences. This effect is demonstrated numerically below for three of the bands representing complex $\mathrm{OH}$ bearing molecules $\left(\mathrm{X}-\mathrm{CH}_{2} \mathrm{OH}\right)$ at $866 / 890 \mathrm{~cm}^{-1}$, simple photoproducts $\left(\mathrm{CH}_{4}\right)$ at $1301 \mathrm{~cm}^{-1}$, and $\mathrm{HCO} / \mathrm{COOH}$ bearing complex molecules (shortened to $\mathrm{X}-\mathrm{CHO}$ in most figures for convenience) at $1747 \mathrm{~cm}^{-1}$. These molecular class assignments agree with previous studies and are discussed specifically in Sect. 3.5. After a fluence of $\sim 7 \times 10^{16} \mathrm{~cm}^{-2}$ the relative importance of the integrated bands at $866 / 890,1301$ and $1747 \mathrm{~cm}^{-1}$ is 0:90:10. After a fluence of $\sim 2.2 \times 10^{17} \mathrm{~cm}^{-2}$ this has changed significantly to $35: 34: 31$. The product composition after a particular fluence cannot therefore be linearly scaled to a lower or a higher fluence.

\subsubsection{UV flux}

The flux levels in the laboratory $\left(\sim 10^{13} \mathrm{UV}\right.$ photons $\left.\mathrm{cm}^{-2} \mathrm{~s}^{-1}\right)$ are several orders of magnitude higher than those found in most astrophysical environments - the interstellar irradiation field is $\sim 10^{8}$ photons $\mathrm{cm}^{-2} \mathrm{~s}^{-1}$ (Mathis et al. 1983). Hence the product dependence on flux, if any, is required before translating laboratory results into an astrophysical setting. Figure 4 shows that two spectra acquired after the same fluence, but irradiated with a factor of four different flux, are identical within the experimental uncertainties. Numerically, the relative importance of the integrated bands at 866/890, 1301 and the $1747 \mathrm{~cm}^{-1}$ are 15:56:29 in the low flux experiment and 24:51:25 for the high flux experiment after a total fluence of $2.2 \times 10^{17} \mathrm{~cm}^{-2}$. Including a 10-20\% uncertainty in the band intensities (the higher value for the $866 / 890 \mathrm{~cm}^{-1}$ band), there is thus no significant dependence on flux within the explored flux range at $20 \mathrm{~K}$. The same holds

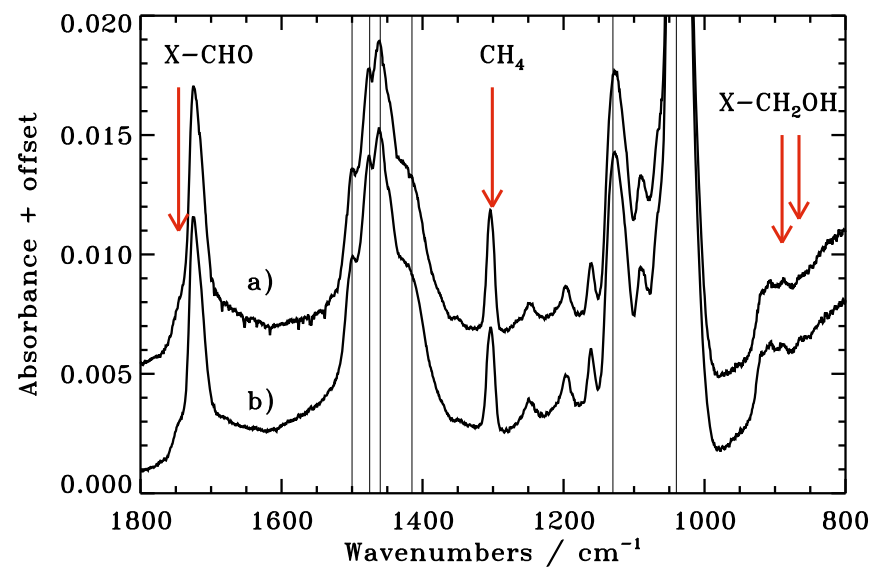

Fig. 4. The spectra of originally a) 21 and b) $19 \mathrm{ML}$ thick $\mathrm{CH}_{3} \mathrm{OH}$ ice irradiated with a UV flux of a) $1.1 \times 10^{13} \mathrm{~cm}^{-2} \mathrm{~s}^{-1}$ and b) $4.3 \times$ $10^{13} \mathrm{~cm}^{-2} \mathrm{~s}^{-1}$ at $20 \mathrm{~K}$ achieve the same fluence of $2.2 \times 10^{17} \mathrm{~cm}^{-2}$. The $\mathrm{CH}_{3} \mathrm{OH}$ features and some product bands are marked as in Fig. 3 .

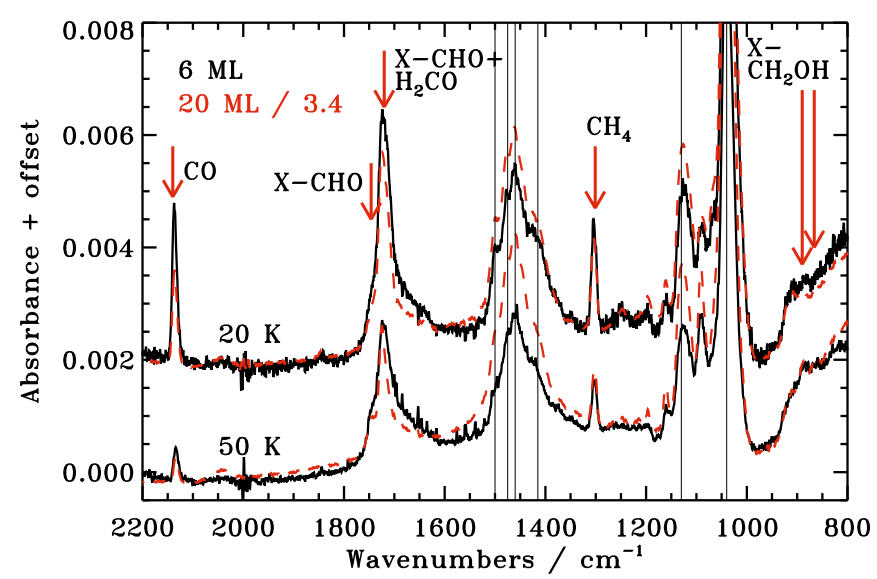

Fig. 5. The differences in the photolyzed $\mathrm{CH}_{3} \mathrm{OH}$ spectra of two different original thicknesses after the same fluence of $\sim 2.4 \times 10^{17} \mathrm{~cm}^{-2}$. The $20 \mathrm{ML}$ (red dashed lines) ice spectrum is normalized to have the same $\mathrm{CH}_{3} \mathrm{OH}$ absorbance as the $6 \mathrm{ML}$ (black solid lines) ice experiment before irradiation to facilitate comparison of fractional photoproduct rates. $\mathrm{CO}$ and $\mathrm{H}_{2} \mathrm{CO}$ bands are marked in addition to the spectral features focused on in previous figures.

for similar experiments at $50 \mathrm{~K}$ (not shown). This does not exclude a flux dependence at astronomical time scales, but it does provide a benchmark for models aiming to translate laboratory results into astrophysical ones.

\subsubsection{Ice thickness}

Figure 5 shows that both the fractional $\mathrm{CH}_{3} \mathrm{OH}$ destruction, as evidenced by e.g. the $v_{7}$ band intensity, decrease around $1130 \mathrm{~cm}^{-1}$, and the fractional formation of a few new spectral features are enhanced in thin ices ( $\sim 6 \mathrm{ML})$ compared to the standard $20 \mathrm{ML}$ experiment. However, this does not necessarily imply a different chemistry in thinner ices. Rather the difference in $\mathrm{CH}_{3} \mathrm{OH}$ destruction may be explained by an increased escape probability of photoproducts in the thinner ice and by the greater importance of direct photodesorption. Similarly, the observed relative enhancements of the $\mathrm{CO}$ band at $2150 \mathrm{~cm}^{-1}$ and the $1700 \mathrm{~cm}^{-1}$ band in the $20 \mathrm{~K}$ experiment are probably due to the constant freeze-out of $\mathrm{CO}$ during the experiment, up to 


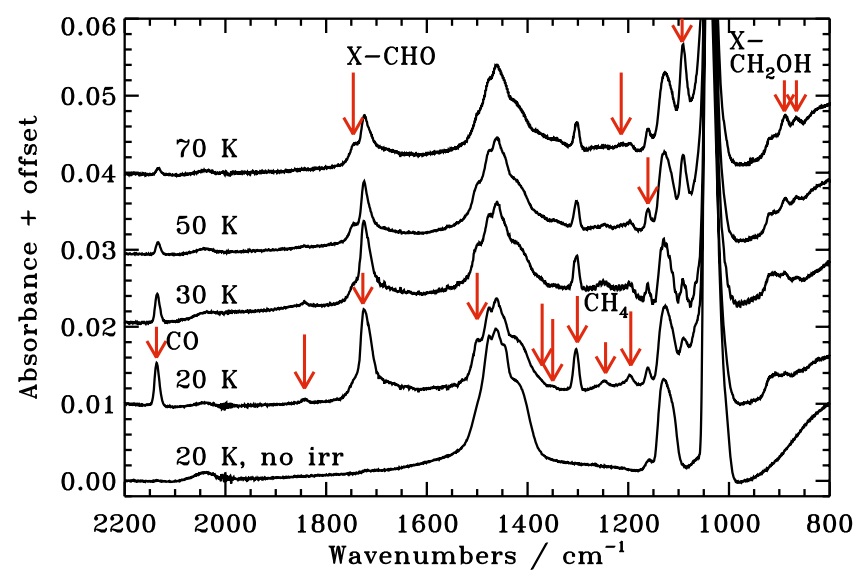

Fig. 6. The photolyzed $\mathrm{CH}_{3} \mathrm{OH}$ spectra at different temperatures after the same fluence of $\sim 2.4 \times 10^{17} \mathrm{~cm}^{-2}$ for 19-22 ML thick ices. The arrows mark new bands at the temperature at which they are most abundantly produced and some key features are also named.

0.2 ML out of 0.5 ML CO ice detected at the end of the $6 \mathrm{ML}$ experiment, and its reactions to form more HCO-bearing carriers of the $1700 \mathrm{~cm}^{-1}$ band. Therefore, despite the apparent dependence of the spectral features on ice thickness, there is no significant evidence for different formation yields in 6 and $20 \mathrm{ML}$ thick ices. This means that bulk reactions still dominate over the potentially more efficient surface reactions in ices as thin as $6 \mathrm{ML}$, at these fluences.

\subsubsection{Ice temperature during irradiation}

The photolyzed ice spectra depend on the ice temperature, illustrating the different temperature dependencies of different photochemistry products (Fig. 6). The $1727\left(\mathrm{H}_{2} \mathrm{CO}+\mathrm{X}-\mathrm{CHO}\right)$ and $1300\left(\mathrm{CH}_{4}\right) \mathrm{cm}^{-1}$ features are most abundantly produced at the lowest investigated temperature of $20 \mathrm{~K}$, while the $866 / 890 \mathrm{~cm}^{-1}$ bands increase in strength with temperature and the 1747 (X-CHO) $\mathrm{cm}^{-1}$ feature is barely affected by temperature changes. The different temperature dependencies can be used to infer the size of the main contributor to each band; photolysis fragments and molecules that form through hydrogenation of such fragments are expected to be most abundant at $20 \mathrm{~K}$, while molecules that form from two larger fragments will be more efficiently produced at higher temperatures where diffusion is facilitated. This is complicated by competition between different reaction pathways, which may inhibit the formation of some complex molecules at higher temperatures where new reaction channels become possible. Nevertheless, the dependence on temperature of different bands can aid in identifying their molecular contributors. All formed bands are thus classified according to the temperature at which they are most abundantly produced (Fig. 6), except for a few bands, where the dependence on temperature is too weak to assign them to a certain temperature bin. This information is summarized in Table 3.

\subsubsection{Pure $\mathrm{CH}_{3} \mathrm{OH}$ ice versus $\mathrm{CH}_{3} \mathrm{OH}: \mathrm{CO} 1: 1$ and $\mathrm{CH}_{3} \mathrm{OH}: \mathrm{CH}_{4}$ 1:2 ice mixtures}

In the set of experiments where $\mathrm{CH}_{3} \mathrm{OH}$ is mixed with $\mathrm{CH}_{4}$ or $\mathrm{CO}$ at $\sim 1: 1$ ratio, the resulting photoproduct compositions are significantly different compared to those obtained from pure $\mathrm{CH}_{3} \mathrm{OH}$ ice experiments. This is illustrated in Fig. 7 for ices

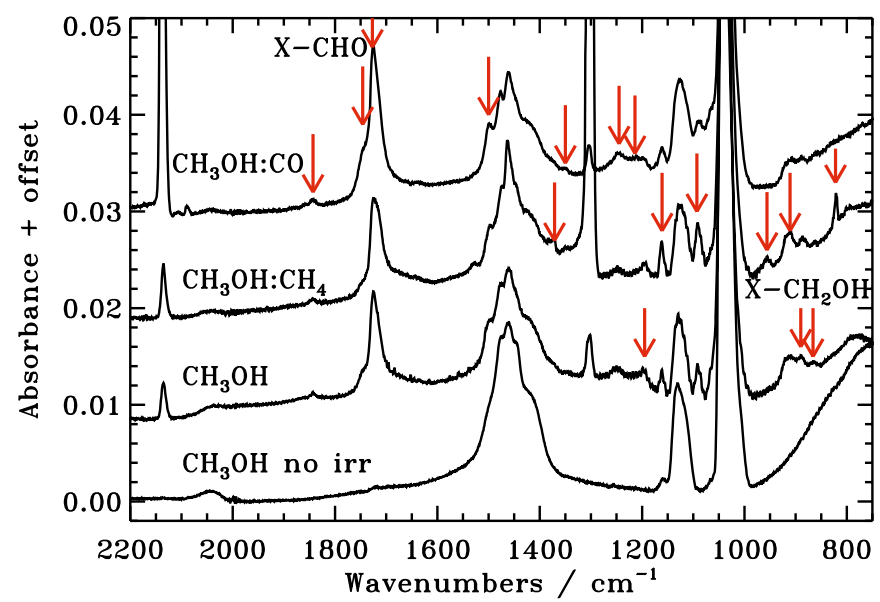

Fig. 7. The changes in the photolyzed ice spectra for pure $\mathrm{CH}_{3} \mathrm{OH}$ (19 ML), and 1:1 $\mathrm{CH}_{3} \mathrm{OH}: \mathrm{CO}$ and 1:2 $\mathrm{CH}_{3} \mathrm{OH}: \mathrm{CH}_{4}$ ice mixtures at $30 \mathrm{~K}$ (23 and $38 \mathrm{ML}$, respectively) after the same fluence of $\sim 2.4 \times 10^{17} \mathrm{~cm}^{-2}$. The spectra have been scaled to correspond to the same initial $\mathrm{CH}_{3} \mathrm{OH}$ abundance. The arrows mark new bands in the ice mixture where they are most abundantly produced.

irradiated at $30 \mathrm{~K}$. In the $\mathrm{CH}_{3} \mathrm{OH}: \mathrm{CH}_{4}$ mixture, bands corresponding to complex molecules at 822, 890, 956, 1161, 1350 and $1382 \mathrm{~cm}^{-1}$ are enhanced, while in the $\mathrm{CH}_{3} \mathrm{OH}$ : $\mathrm{CO}$ mixtures, the $1214,1245,1350,1498,1727,1746$ and $1843 \mathrm{~cm}^{-1}$ bands grow faster compared to pure $\mathrm{CH}_{3} \mathrm{OH}$ ice. A few bands are most prominent when no other species is added to the $\mathrm{CH}_{3} \mathrm{OH}$ ice, for example the 866 and $1195 \mathrm{~cm}^{-1}$ bands. The $1726-1747 \mathrm{~cm}^{-1}$ band excess in the CO-containing ices shows that molecules that contain an $\mathrm{HCO}$ group can be overproduced by adding $\mathrm{CO}$. Similarly, the band enhancements in the $\mathrm{CH}_{4}$-containing ices are expected to arise from overproduction of $\mathrm{CH}_{3}$-containing molecules. These observations are used below for band identifications and later to explain variations in abundances of different complex molecules in star-forming regions.

\subsection{6. $\mathrm{CH}_{3} \mathrm{OH}$ deuteration level}

In the partially deuterated ices $\left(\mathrm{CH}_{3} \mathrm{OD}\right.$ and $\left.\mathrm{CD}_{3} \mathrm{OH}\right)$ some band positions do not change compared to regular $\mathrm{CH}_{3} \mathrm{OH}$, while others are either shifted or completely missing (Fig. 8). Bands that are present in the $\mathrm{CH}_{3} \mathrm{OH}$ ice and missing in the $\mathrm{CH}_{3} \mathrm{OD}$ experiments must originate from either $\mathrm{OH}(\mathrm{D})$-containing molecules with the $\mathrm{H}$ involved in the vibrational mode in question or from simple hydrogenated species. These two groups of molecules are seldom confused and thus comparison between the photolyzed $\mathrm{CH}_{3} \mathrm{OH}$ spectra and the photolyzed $\mathrm{CH}_{3} \mathrm{OD}$ spectra can be used to assign some alcohol-bands. The band positions that are constant between the $\mathrm{CH}_{3} \mathrm{OH}$ and $\mathrm{CH}_{3} \mathrm{OD}$ do not however exclude the contributions of $\mathrm{OH}$-containing molecules to these bands, since the $\mathrm{OH}$ group can be present in the molecule without involvement in the vibration in question. Comparing the $\mathrm{CH}_{3} \mathrm{OH}$ and $\mathrm{CH}_{3} \mathrm{OD}$ experiments, the bands at 866 and $890 \mathrm{~cm}^{-1}$ are obviously affected. The $1700 \mathrm{~cm}^{-1}$ band is somewhat reduced in the $\mathrm{CH}_{3} \mathrm{OD}$ experiment, suggesting that one of the carriers is $\mathrm{HOCH}_{2} \mathrm{CHO}$. An underlying broad feature around $1600 \mathrm{~cm}^{-1}$ is also reduced in the $\mathrm{CH}_{3} \mathrm{OD}$ experiment.

As expected, few of the bands in the $\mathrm{CH}_{3} \mathrm{OH}$ experiments are still present in the UV-irradiated $\mathrm{CD}_{3} \mathrm{OH}$ ice. The complex at $900-860 \mathrm{~cm}^{-1}$ and some of the X-CHO features are exceptions, though the bands are shifted. The only bands expected to 
Table 3. Detected bands between 700 and $2200 \mathrm{~cm}^{-1}$ and identifications.

\begin{tabular}{|c|c|c|c|c|c|c|}
\hline Wavenumber $\left(\mathrm{cm}^{-1}\right)$ & $T_{\text {form }}(\mathrm{K})^{a}$ & $\overline{T_{\text {des }}(\mathrm{K})^{b}}$ & $\mathrm{CO}$ & $\overline{\mathrm{C} \mathrm{CH}_{3}}$ & $\overline{\mathrm{OH}}$ & Candidates \\
\hline 2135 & 20 & 30 & $\mathrm{y}$ & & & $\mathrm{CO}$ \\
\hline 1843 & 20 & 30 & $\mathrm{y}$ & & & $\mathrm{HCO}$ \\
\hline 1746 & 70 & $140-190$ & $\mathrm{y}$ & & $\mathrm{y} /-$ & $\mathrm{HOCH}_{2} \mathrm{CHO}+\mathrm{HCOOH}+\mathrm{CH}_{3} \mathrm{CHO}$ \\
\hline 1727 & 20 & $70 / 110 / 150$ & $\mathrm{y}$ & & & $\mathrm{H}_{2} \mathrm{CO}+\mathrm{CH}_{3} \mathrm{CHO}+\mathrm{HCOOCH}_{3}$ \\
\hline 1498 & 20 & 70 & $\mathrm{y}$ & & & $\mathrm{H}_{2} \mathrm{CO}$ \\
\hline 1382 & 20 & 140 & & $\mathrm{y}$ & & $\mathrm{CH}_{3} \mathrm{CH}_{2} \mathrm{OH}$ \\
\hline 1372 & 30 & 40 & & $\mathrm{y}$ & & $\mathrm{C}_{2} \mathrm{H}_{6}$ \\
\hline 1350 & 20 & 100 & $\mathrm{y}$ & $\mathrm{y}$ & & $\mathrm{CH}_{3} \mathrm{CHO}$ \\
\hline 1301 & 20 & 40 & & $\mathrm{y}$ & & $\mathrm{CH}_{4}$ \\
\hline 1245 & 20 & 70 & $\mathrm{y}$ & & & $\mathrm{H}_{2} \mathrm{CO}$ \\
\hline 1214 & 70 & 130 & $\mathrm{y}$ & & & $\mathrm{HCOOCH}_{3}$ \\
\hline 1195 & 20 & 50 & & & $\mathrm{y}$ & $\mathrm{CH}_{2} \mathrm{OH}$ \\
\hline 1161 & 50 & 90 & & $\mathrm{y}$ & & $\mathrm{CH}_{3} \mathrm{OCH}_{3}$ \\
\hline 1093 & 70 & $110 / 130 / 180$ & & & & $\left(\mathrm{CH}_{2} \mathrm{OH}\right)_{2}+\mathrm{CH}_{3} \mathrm{OCH}_{3}+\mathrm{CH}_{3} \mathrm{CH}_{2} \mathrm{OH}$ \\
\hline 956 & 30 & 70 & & $\mathrm{y}$ & & \\
\hline 921 & $?$ & 110 & & $\mathrm{y}$ & & $\mathrm{CH}_{3} \mathrm{OCH}_{3}$ \\
\hline 911 & $?$ & 150 & & & & $\mathrm{HCOOCH}_{3}$ \\
\hline 890 & 70 & 180 & & & $\mathrm{y}$ & $\left(\mathrm{CH}_{2} \mathrm{OH}\right)_{2}$ \\
\hline 885 & $?$ & 130 & & $\mathrm{y}$ & $\mathrm{y}$ & $\mathrm{CH}_{3} \mathrm{CH}_{2} \mathrm{OH}$ \\
\hline 866 & 70 & $150 / 180$ & & & $\mathrm{y}$ & $\left(\mathrm{CH}_{2} \mathrm{OH}\right)_{2}\left(+\mathrm{HOCH}_{2} \mathrm{CHO}\right)^{c}$ \\
\hline 822 & 30 & 50 & & $\mathrm{y}$ & & $\mathrm{C}_{2} \mathrm{H}_{6}$ \\
\hline
\end{tabular}

${ }^{a}$ The temperature at which the band carrier is most efficiently produced.

${ }^{b}$ The temperature at which the band starts to disappear during warm-up with $1 \mathrm{~K} \mathrm{~min}^{-1}$.

${ }^{c}$ Minor contributor in most experiments.

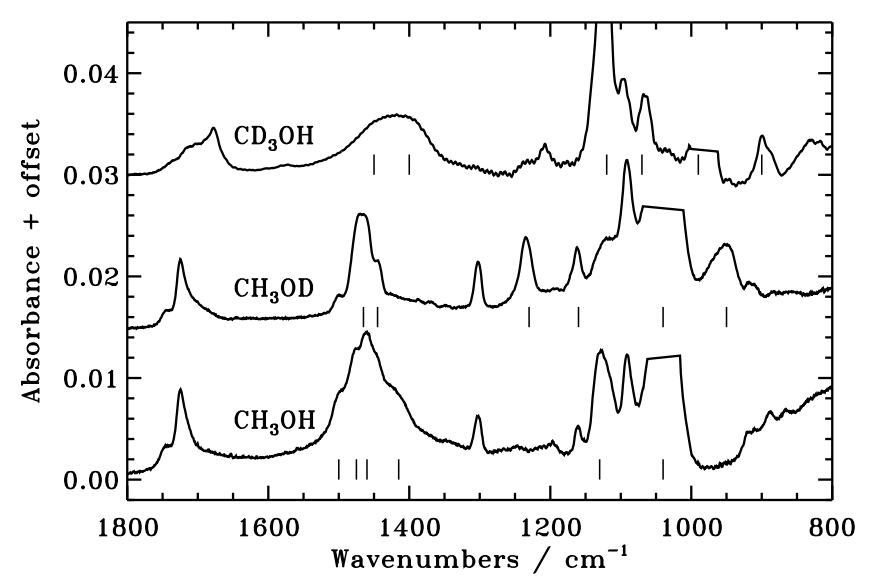

Fig. 8. The resulting spectra of photolyzed pure $\mathrm{CH}_{3} \mathrm{OH}, \mathrm{CH}_{3} \mathrm{OD}$ and $\mathrm{CD}_{3} \mathrm{OH}$ ices at $50 \mathrm{~K}$ after the same fluence of $\sim 2.4 \times 10^{17} \mathrm{~cm}^{-2}$. The thin lines below each spectra mark the original $\mathrm{CH}_{3} \mathrm{OH}, \mathrm{CH}_{3} \mathrm{OD}$ and $\mathrm{CD}_{3} \mathrm{OH}$ features. The strongest band in each spectrum is blanked out for visibility.

appear at their normal positions come from $\mathrm{H}_{2} \mathrm{O}_{2}$ and possible $\mathrm{H}_{2} \mathrm{O}$ dependent on the main source of hydrogen in the ice; neither species is obviously present in the ice from the photolyzed $\mathrm{CD}_{3} \mathrm{OH}$-ice spectra.

\subsubsection{Spectral changes during warm-up}

Following irradiation at the specified temperatures, the ices are heated by $1 \mathrm{~K} \mathrm{~min}^{-1}$ to $200 \mathrm{~K}$ and spectra acquired every $10 \mathrm{~min}$. Figure 9 shows the irradiated $\mathrm{CH}_{3} \mathrm{OH}$ ice between 20 and $190 \mathrm{~K}$. The UV lamp is turned off during the warm-up and thus the ice composition only depends on thermal desorption and reactions of previously produced radicals. As the ice is heated (Fig. 9), several new spectral bands appear, while others increase or decrease in strength with temperature.

The 866,890 and $1090 \mathrm{~cm}^{-1}$ bands increase most dramatically in intensity during warm-up of the $20 \mathrm{~K}$ pure $\mathrm{CH}_{3} \mathrm{OH}$ ice. Simultaneously the $1195 \mathrm{~cm}^{-1}$ feature loses intensity. The 866 and $890 \mathrm{~cm}^{-1}$ bands remain until $170 \mathrm{~K}$ and are the last sharp features to disappear. The 1747 and $1214 \mathrm{~cm}^{-1}$ bands also increase in intensity with temperature. In contrast the bands at $1245,1300,1727$ and $1850 \mathrm{~cm}^{-1}$ only lose intensity during warm-up. Most of these bands only disappear completely at the desorption temperature of $\mathrm{CH}_{3} \mathrm{OH}, 120-130 \mathrm{~K}$, indicating significant trapping of molecules inside the $\mathrm{CH}_{3} \mathrm{OH}$ ice. Significant bulk chemistry is thus required to explain the results (see also Sect. 3.3.3). At $190 \mathrm{~K}$ there are still some shallow bands left, which only disappear after the substrate has been heated to room temperature.

Experiments 17 and 18 show that the warm-up rate matters somewhat for the final ice composition. The quantification and discussion of this effect is saved for Paper II.

\subsection{Reference RAIR spectra and TPD experiments of pure complex ices}

Photolysis of $\mathrm{CH}_{3} \mathrm{OH}$ ice and recombination of the fragments can theoretically result in a large number of new species. To facilitate the identification of these species, this section briefly presents new RAIR spectra and TPD time series of all stable, complex photoproducts considered in this study. Radicals are expected to form in the photolyzed ice, but these cannot be produced in pure form in ices and thus comparison spectra are difficult to obtain.

Figure 10 shows the RAIR spectra of $\mathrm{C}_{2} \mathrm{H}_{6}$ (ethane), $\mathrm{CH}_{3} \mathrm{CHO}$ (acetaldehyde), $\mathrm{CH}_{3} \mathrm{OCH}_{3}$ (dimethyl ether), $\mathrm{CH}_{3} \mathrm{CH}_{2} \mathrm{OH}$ (ethanol), $\mathrm{HCOOH}$ (formic acid), $\mathrm{HCOOCH}_{3}$ (methyl formate), $\mathrm{CH}_{3} \mathrm{COOH}$ (acetic acid) and $\mathrm{HOCH}_{2} \mathrm{CHO}$ 


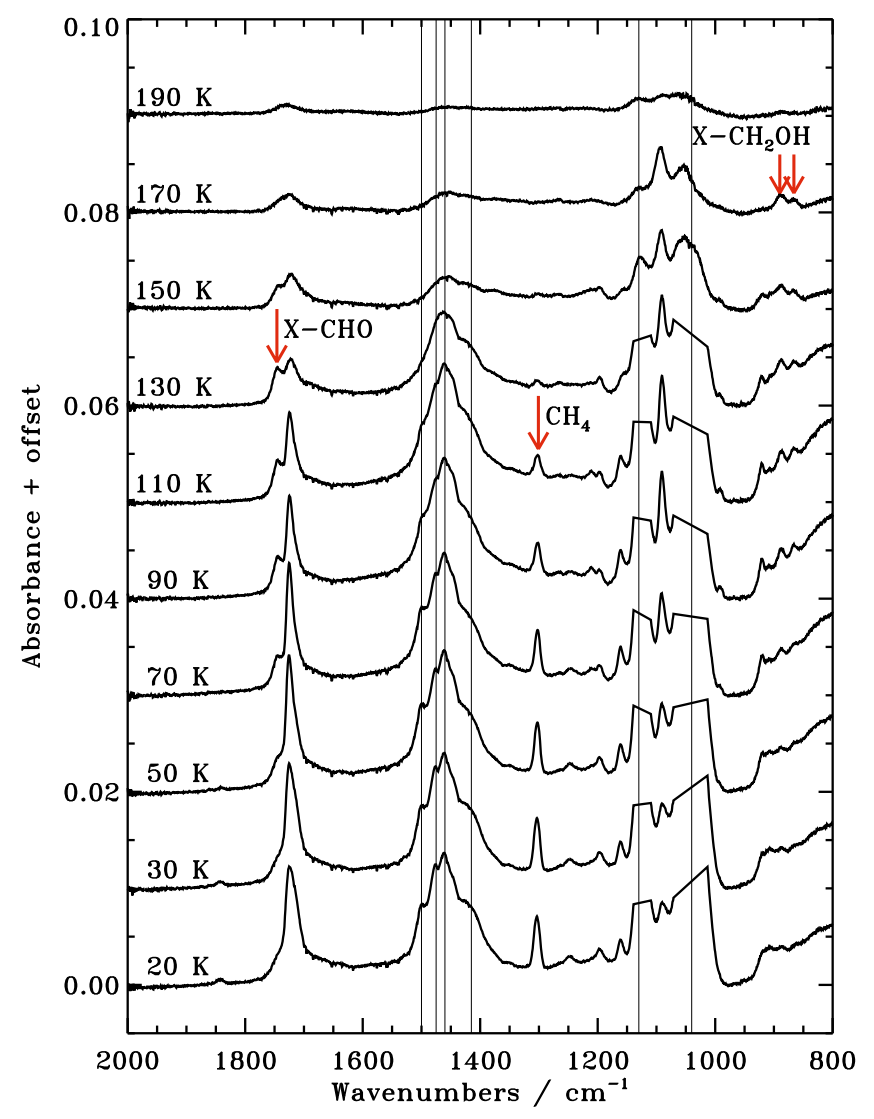

Fig. 9. The photolyzed ice spectra during warm-up following irradiation at $20 \mathrm{~K}$ with a fluence of $\sim 2.4 \times 10^{17} \mathrm{~cm}^{-2}-$ the UV lamp is turned off during the warm-up. The thin lines mark $\mathrm{CH}_{3} \mathrm{OH}$ features with the two strongest bands blanked out for visibility.

(glycolaldehyde) at $20 \mathrm{~K}$ and $\left(\mathrm{CH}_{2} \mathrm{OH}\right)_{2}$ (ethylene glycol) at $150 \mathrm{~K}$. Below $150 \mathrm{~K}$ the $\left(\mathrm{CH}_{2} \mathrm{OH}\right)_{2}$ spectrum contains $\mathrm{CH}_{3} \mathrm{OH}$ features despite the high stated purity (99\%) of the sample. The spectral bands above $2000 \mathrm{~cm}^{-1}$ are not shown since all complex molecule spectral features in that region overlap with strong $\mathrm{CH}_{3} \mathrm{OH}$ features and thus cannot be used for identification. The figure illustrates that most bands overlap with at least one band from another complex molecule or with bands of $\mathrm{H}_{2} \mathrm{CO}$ and/or $\mathrm{CH}_{3} \mathrm{OH}$, which is expected for complex molecules with the same or similar functional groups (e.g. absorption by $\mathrm{HCO} / \mathrm{COOH}$ stretches at $\left.1700-1750 \mathrm{~cm}^{-1}\right)$. The red arrows indicate the bands mainly used for identification of each species. These bands are chosen to overlap as little as possible with strong absorption features of other species. For $\mathrm{HCOOH}, \mathrm{CH}_{3} \mathrm{COOH}, \mathrm{HCOOCH}_{3}$ and $\mathrm{HOCH}_{2} \mathrm{CHO}$ there are no suitable bands for determining the produced abundances in most experiments, i.e. the isolated bands are too weak to provide detections or strict upper limits. For these molecules the red arrows indicate the bands used to derive upper limits, while the $1700 \mathrm{~cm}^{-1}$ band is used to derive the sum of their abundances once the $\mathrm{H}_{2} \mathrm{CO}$ contribution has been subtracted. Where bands are partly overlapping only the low- or high-frequency half of the band is used for identification.

Figure 11 displays the TPD curves for the same complex molecules as shown in Fig. 10. The QMS signal belonging to the molecular mass is plotted for each TPD experiment. The $\mathrm{m} / \mathrm{z}$ values of all possible fragments have also been gathered, and are used to separate TPD curves of molecules of the same molecular mass that desorb in a similar temperature interval.

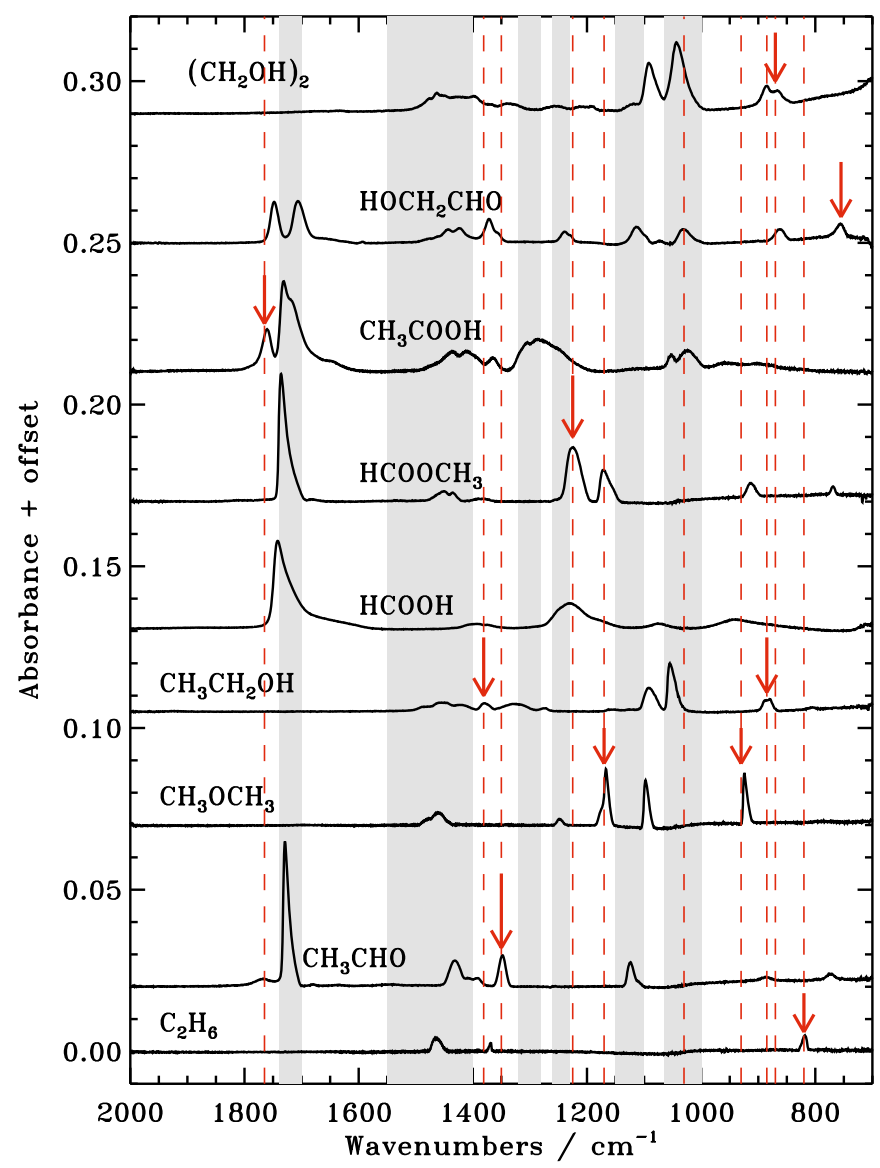

Fig. 10. RAIR spectra of 3-9 ML thick pure complex organic ices at $20 \mathrm{~K}$ (except for $\left(\mathrm{CH}_{2} \mathrm{OH}\right)_{2}$ at $150 \mathrm{~K}$ ) used to identify stable photoproducts. The red arrows indicate the bands mainly used for identification and abundance determinations - $\mathrm{HCOOH}$ has no sharp isolated feature. The dashed lines follow the arrows through all spectra to visualize overlaps with other spectral bands. The shaded regions show the wavelength regions where fundamental modes of $\mathrm{CH}_{4}, \mathrm{H}_{2} \mathrm{CO}$ and $\mathrm{CH}_{3} \mathrm{OH}$ absorb.

For example, $\mathrm{CH}_{3} \mathrm{COOH}$ and $\mathrm{HCOOCH}_{3}$ both have a molecular mass of 60 , but $\mathrm{CH}_{3} \mathrm{COOH}$ frequently loses an $\mathrm{OH}$ group in the QMS, resulting in $m / z=17$ and 43, while $\mathrm{HCOOCH}_{3}$ does not. The TPD curves were modeled using the IDL routine MPFIT under the assumption of zeroth order desorption behavior, which is expected for multilayer ices. The desorption rate is then $v \times N_{\text {sites }} \times \exp \left(-E_{\mathrm{des}} / T\right)$. The vibrational frequency $v$ is defined as a function of the desorption energy $E_{\mathrm{des}}$ :

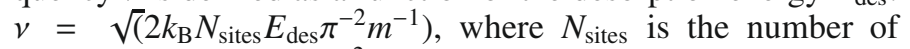
molecular sites per $\mathrm{cm}^{-2}$ and $m$ is the molecular mass $-N_{\text {sites }}$ is a constant and assumed to be $10^{15} \mathrm{~cm}^{-2}$ in line with previous studies. The resulting desorption energies are reported in Table 2. The uncertainties include both model uncertainty and experimental errors. The values agree with those published by Garrod \& Herbst (2006), based on experiments on water rich ice mixtures by Collings et al. (2004), within 20\%, except for $\mathrm{HCOOCH}_{3}$ where the discrepancy is larger. This may however be due to experimental differences, i.e. pure ices here versus their ice mixtures, rather than experimental errors.

\subsection{Identification of $\mathrm{CH}_{3} \mathrm{OH}$ ice UV photoproducts}

In addition to the complex molecules described in the previous section, smaller molecules and radicals that form via $\mathrm{CH}_{3} \mathrm{OH}$ 


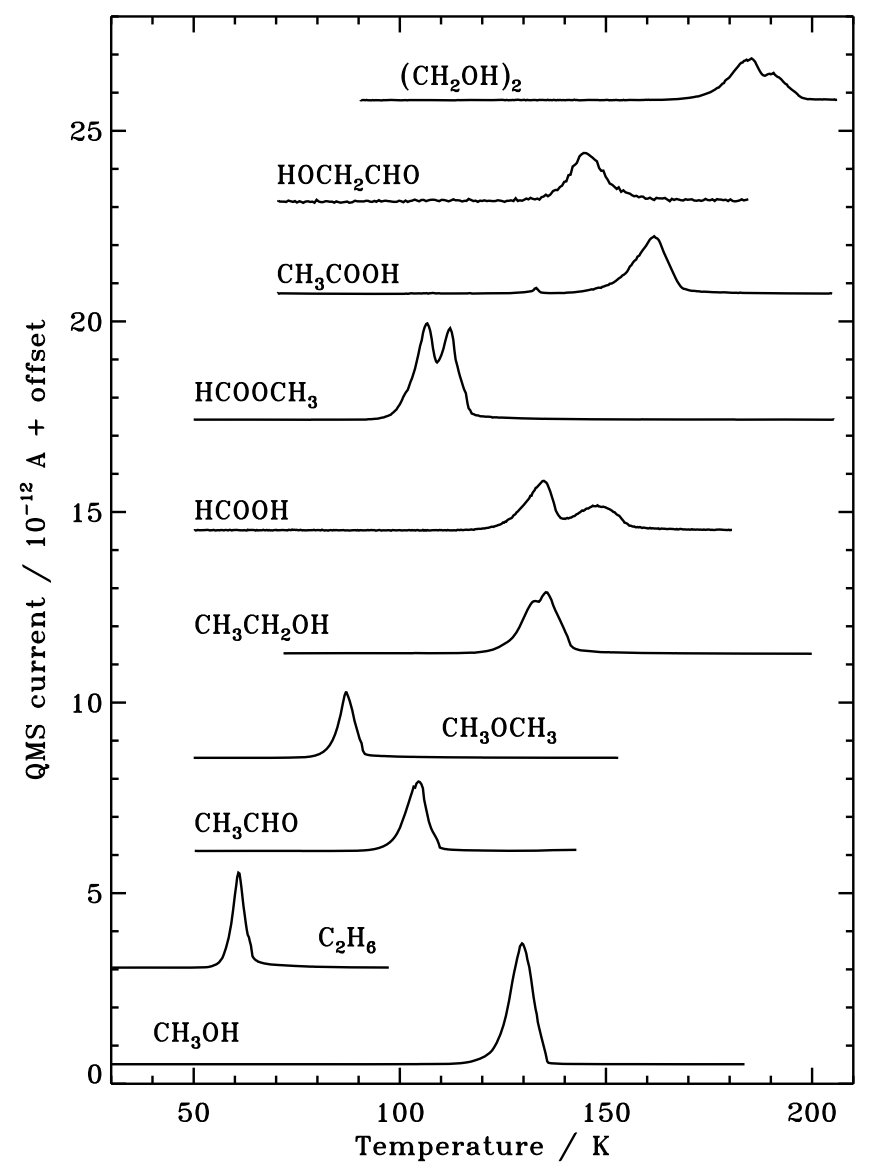

Fig. 11. TPD spectra of pure complex organic ices used to identify photoproducts together with a $\mathrm{CH}_{3} \mathrm{OH}$ TPD curve.

photodissociation are also considered when assigning spectral bands following $\mathrm{CH}_{3} \mathrm{OH}$ ice photolysis. Identification of all photoproducts is a two-step process where the first step is the comparison between new band positions and experimentally or calculated band positions of molecules and fragments to establish a list of possible carriers to each observed band. In the second step the behavior of the band when changing experimental variables, as described in Sect. 3.3, is employed together with QMS data (Fig. 12) to determine which ones(s) of the possible candidates is the most important contributor to the formed band. Combining all information, a band identification is considered secure when consistent with the list of criteria below:

1. the spectral band position in the photolysis spectra must agree within $15 \mathrm{~cm}^{-1}$ of a measured pure ice band (e.g. Hudson et al. 2005) or within $50 \mathrm{~cm}^{-1}$ of a calculated band position for the species in question to be considered a candidate carrier of the observed band. In each case all spectral features within the spectrometer range are checked for consistency even if only one band is used for identification;

2. the temperature at which the band starts to disappear during warm-up is compared for consistency with the observed desorption temperatures of different complex molecules in pure-ice TPD experiments;

3. the mass signature in the TPD experiment following UV irradiation is checked at each temperature where a tentatively assigned band disappears during warm-up (Fig. 12);

4. the band positions of new carriers in UV-irradiated $\mathrm{CH}_{3} \mathrm{OH}$ and partly-deuterated $\mathrm{CH}_{3} \mathrm{OH}$ experiments are compared

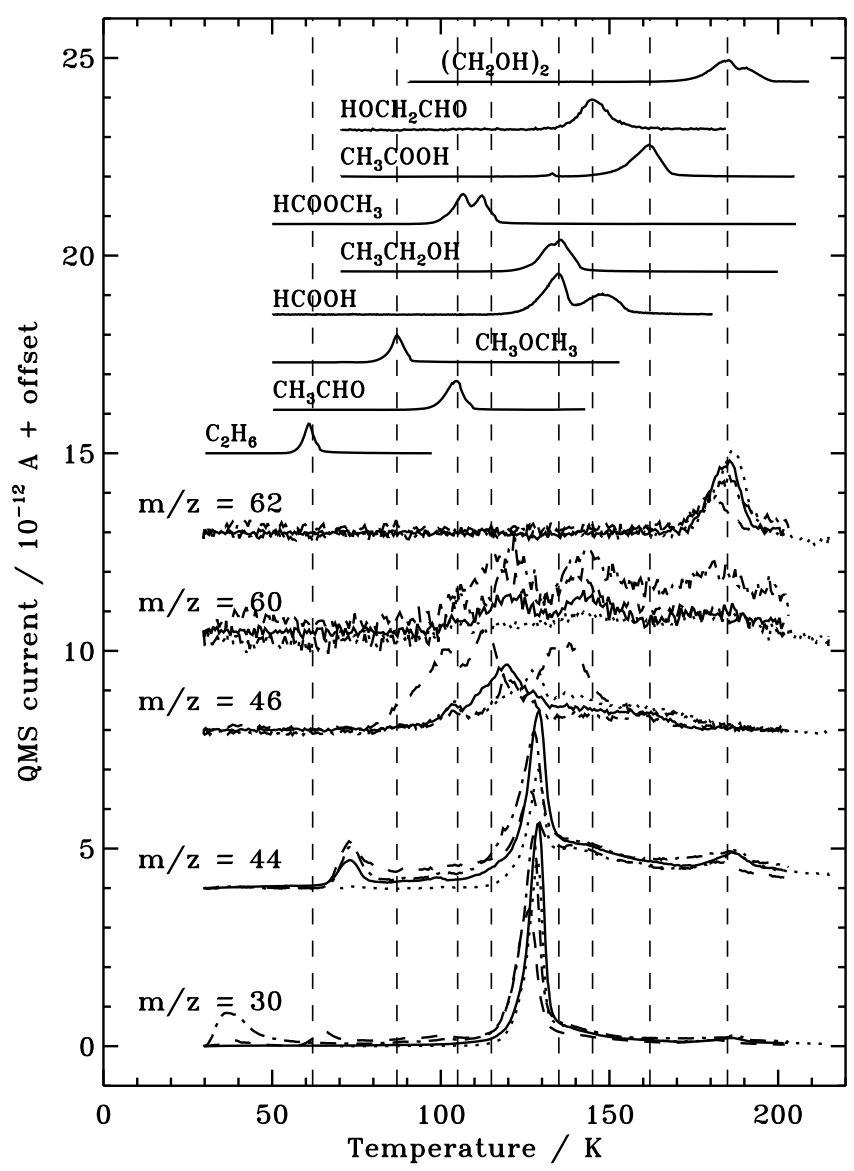

Fig. 12. TPD experiments following UV irradiation of a pure $\mathrm{CH}_{3} \mathrm{OH}$ ice at $30 \mathrm{~K}$ (solid), $70 \mathrm{~K}$ (dotted), a $\mathrm{CH}_{3} \mathrm{OH}: \mathrm{CH}_{4}$ 1:2 ice mixture at $30 \mathrm{~K}$ (dashed) and a $\mathrm{CH}_{3} \mathrm{OH}: \mathrm{CO}$ 1:1 mixture at $30 \mathrm{~K}$ (dashed-dotted). $m / z=62$ can only contain contributions from $\left(\mathrm{CH}_{2} \mathrm{OH}\right)_{2}, m / z=60$ from $\left(\mathrm{CH}_{2} \mathrm{OH}\right)_{2}, \mathrm{HOCH}_{2} \mathrm{CHO}, \mathrm{CH}_{3} \mathrm{COOH}$ and $\mathrm{HCOOCH}_{3}, m / z=46$ from $\mathrm{HCOOH}, \mathrm{CH}_{3} \mathrm{CH}_{2} \mathrm{OH}$ and $\mathrm{CH}_{3} \mathrm{OCH}_{3}$, and $m / z=44$ from $\mathrm{CO}_{2}$, $\mathrm{CH}_{3} \mathrm{CHO}$ and all heavier complex organics. Finally $m / z=30$ can contain contributions from $\mathrm{C}_{2} \mathrm{H}_{6}, \mathrm{CH}_{3} \mathrm{OH}, \mathrm{H}_{2} \mathrm{CO}$ and several heavier organics compounds. All TPD series are scaled to the same initial $\mathrm{CH}_{3} \mathrm{OH}$ abundance to facilitate comparison.

to check that the expected shifts occur as discussed in Sect. 3.3.6;

5. the irradiated spectra are examined for band enhancements and suppressions in $\mathrm{CH}_{3} \mathrm{OH}$ mixtures with $\mathrm{CO}$ and $\mathrm{CH}_{4}$. In $\mathrm{CH}_{4}$ experiments, species containing $\mathrm{CH}_{3}$ groups are expected to be over-produced compared to pure $\mathrm{CH}_{3} \mathrm{OH}$ ice experiments. Similarly in CO containing experiments, HCOgroup containing species should have enhanced abundances;

6. irradiation experiments at different temperatures are compared to ensure consistency with the expected relative diffusion barriers of differently sized radicals (see also Sect. 3.3.4);

7. finally, the temperatures at which radicals disappear during warm-up are compared with the spectroscopic appearance or increase of the molecular band in question; where radicals are detected, the loss of radical bands during warm-up should correspond to the enhancement of molecular bands formed from recombination of these same radicals.

All observed bands and their inferred carrier properties are listed in Table 3, i.e. if a band is enhanced in the $\mathrm{CO}: \mathrm{CH}_{3} \mathrm{OH}$ mixture its main contributor contains a $\mathrm{CO}$ group, if it is enhanced in the 
$\mathrm{CH}_{4}: \mathrm{CH}_{3} \mathrm{OH}$ mixture the main contributor contains a $\mathrm{CH}_{3}$ group and if the band disappears in the $\mathrm{CH}_{3} \mathrm{OD}$ experiment the main contributor contains an $\mathrm{OH}$ group.

\subsubsection{Small molecules: $\mathrm{H}_{2}, \mathrm{H}_{2} \mathrm{O}, \mathrm{CH}_{4}, \mathrm{CO}, \mathrm{O}_{2}, \mathrm{H}_{2} \mathrm{CO}, \mathrm{H}_{2} \mathrm{O}_{2}$ and $\mathrm{CO}_{2}$}

$\mathrm{H}_{2}$ probably forms in the photolysis experiments, since $\mathrm{CH}_{2} \mathrm{OH}$ is observed and thus $\mathrm{H}$ atoms must be produced in the ice (see below). Two $\mathrm{H}$ atoms can subsequently recombine to form $\mathrm{H}_{2}$ as observed in $\mathrm{D}_{2} \mathrm{O}$ photodesorption experiments (Watanabe et al. 2000) and following irradiation of $\mathrm{H}_{2} \mathrm{O}: \mathrm{CH}_{3} \mathrm{OH}: \mathrm{NH}_{3}$ : $\mathrm{CO}$ experiments (Sandford \& Allamandola 1993). Detections or determinations of strict upper limits of $\mathrm{H}_{2}$ are however not possible because of a lack of strong infrared transitions together with the expected fast desorption of any $\mathrm{H}_{2}$ from ices above $20 \mathrm{~K}$.

$\mathrm{H}_{2} \mathrm{O}\left(\mathrm{D}_{2} \mathrm{O}\right)$ is visible during warm-up following the desorption of $\mathrm{CH}_{3} \mathrm{OH}\left(\mathrm{CH}_{3} \mathrm{OD}\right)$. However, its origin is unclear, since $\mathrm{H}_{2} \mathrm{O}$ is the main contaminant in the chamber. During irradiation, the $\mathrm{H}_{2} \mathrm{O}$ stretching and libration modes are hidden under strong $\mathrm{CH}_{3} \mathrm{OH}$ bands and thus cannot be used for identification. The $1670 \mathrm{~cm}^{-1}$ bending mode coincides with the broad wing of the $1727 \mathrm{~cm}^{-1}$ band found in most irradiated $\mathrm{CH}_{3} \mathrm{OH}$ spectra. The wing is probably reduced in the $\mathrm{CH}_{3} \mathrm{OD}$ ice, depending on the baseline determination, but it is also not visible in the $\mathrm{CD}_{3} \mathrm{OH}$ ice (Fig. 8). Thus, there is no clear evidence for the amount that $\mathrm{H}_{2} \mathrm{O}$ contributes to this feature. The best constraints on water formation come instead from the $\mathrm{CH}_{3} \mathrm{OD}$ experiments where $\sim 0.5 \mathrm{ML} \mathrm{D}_{2} \mathrm{O}$ is detected at the end of the experiment, corresponding to a few percent with respect to the initial $\mathrm{CH}_{3} \mathrm{OD}$ amount.

$\mathrm{CH}_{4}$ is formed in all experiments, identified by its relatively isolated $v_{4}$ band at $1301 \mathrm{~cm}^{-1}$ (D'Hendecourt \& Allamandola 1986). The $\mathrm{CH}_{4} v_{3}$ feature at $3008 \mathrm{~cm}^{-1}$ is also one of the few bands that are clearly visible on top of the $\mathrm{CH}_{3} \mathrm{OH}$ bands in that region.

CO has a single strong feature at $2139 \mathrm{~cm}^{-1}$ (Gerakines et al. 1995), which is shifted to $2135 \mathrm{~cm}^{-1}$ in the experiments here. The feature cannot be confused with those of any other species and the identification is thus clear. Of the observed $\mathrm{CO}$ ice amount $\sim 0.2 \mathrm{ML}$ originates outside of the $\mathrm{CH}_{3} \mathrm{OH}$ ice. This is however only significant for the thin $(\sim 6 \mathrm{ML}) 20 \mathrm{~K}$ ice experiments. At $30 \mathrm{~K}$ and above the $\mathrm{CO}$ sticking coefficient is low (Bisschop et al. 2007b).

$\mathrm{O}_{2}$ has no strong infrared bands. During warm-up of the 20 and $30 \mathrm{~K}$ experiment there is no $\mathrm{m} / \mathrm{z}=32$ detected at the expected $\mathrm{O}_{2}$ desorption temperature of $\sim 30 \mathrm{~K}$ (Acharyya et al. 2007). In contrast there is a clear $\mathrm{m} / z=28$ band from CO in this temperature region. If $\mathrm{CO}$ and $\mathrm{O}_{2}$ can be assumed to behave similarly this puts an upper limit on the $\mathrm{O}_{2}$ production to less than $5 \%$ of that of $\mathrm{CO}$ at $20 \mathrm{~K}$.

$\mathrm{H}_{2} \mathrm{CO}$ has three strong bands between 2000 and $800 \mathrm{~cm}^{-1}$ at 1723,1494 and $1244 \mathrm{~cm}^{-1}$. The $1723 \mathrm{~cm}^{-1}$ band overlaps with several complex spectral features, and the $1494 \mathrm{~cm}^{-1}$ band sits on the shoulder of a strong $\mathrm{CH}_{3} \mathrm{OH}$ band. The $1244 \mathrm{~cm}^{-1}$ band is relatively isolated and has been used previously to constrain the $\mathrm{H}_{2} \mathrm{CO}$ production (Bennett et al. 2007). All three bands are readily observed in the irradiated ices between 20 and $50 \mathrm{~K}$. The 1244 and $1494 \mathrm{~cm}^{-1}$ bands are strongly correlated and are most abundantly formed at low temperatures, while the $1723 \mathrm{~cm}^{-1}$ band is less dependent on temperature, as expected from its multiple carriers. All three bands are enhanced in all $\mathrm{CH}_{3} \mathrm{OH}: \mathrm{CO}$ ice-mixture experiments and these identifications are therefore considered secure.
All fundamental $\mathrm{H}_{2} \mathrm{O}_{2}$ infrared bands completely overlap with strong $\mathrm{CH}_{3} \mathrm{OH}$ bands in the investigated spectral region (e.g. Loeffler et al. 2006; Ioppolo et al. 2008). A small $\mathrm{m} / \mathrm{z}=$ 34 peak was observed during $\mathrm{CH}_{3} \mathrm{OH}$ desorption. Without comparison TPD this cannot be used quantitatively, however. Thus, while some $\mathrm{h}_{2} \mathrm{O}_{2}$ probably forms, its formation rate cannot be constrained experimentally.

$\mathrm{CO}_{2}$ has a strong band at $2340 \mathrm{~cm}^{-1}$, which is seen in all experiments at high fluences. Because of purge problems this spectral region is somewhat polluted with $\mathrm{CO}_{2}$ lines from gas outside of the vacuum chamber. This results in a larger uncertainty in the derived $\mathrm{CO}_{2}$ abundance than would have been the case otherwise.

\subsubsection{Radicals: $\mathrm{OH}, \mathrm{CH}_{3}, \mathrm{HCO}, \mathrm{CH}_{3} \mathrm{O}, \mathrm{CH}_{2} \mathrm{OH}$}

$\mathrm{OH}$ absorbs at 3423 and $3458 \mathrm{~cm}^{-1}$ from a study on pure $\mathrm{H}_{2} \mathrm{O}$ ice photolysis by Gerakines et al. (1996), using transmission spectroscopy. Bennett et al. (2007) calculated the band position to be at $3594 \mathrm{~cm}^{-1}$ using the hybrid density functional theory with the $6-311 \mathrm{G}(\mathrm{d}, \mathrm{p})$ basis set and refining the output with the coupled cluster CCSD(T) method - these calculations have typical gas-phase band-position uncertainties of $0.5-1 \%$ or $<50 \mathrm{~cm}^{-1}$ (Galabov et al. 2002). There are some shallow bands in the $3400-3600 \mathrm{~cm}^{-1}$ wavelength region in our $\mathrm{CH}_{3} \mathrm{OH}$ experiments, that disappear between 30 and $50 \mathrm{~K}$, and that are also present in the $\mathrm{CD}_{3} \mathrm{OH}$ ices but not in the $\mathrm{CH}_{3} \mathrm{OD}$ ones. The bands are however an order of magnitude broader than observed for $\mathrm{OH}$ radicals in matrix studies (Acquista et al. 1968). This may be due to their interactions with other H-bonding molecules, but with such a disagreement present, these bands cannot be assigned to $\mathrm{OH}$ radicals with any certainty. The presence of the broad features also prevents the determination of strict upper limits.

HCO can be identified from its $v_{2}$ band between 1840 and $1860 \mathrm{~cm}^{-1}$ (Gerakines et al. 1996; Bennett et al. 2007). No stable species considered in this study absorbs in this region. Bennett et al. (2007) calculated the band positions of a large number of unstable species that can theoretically form in an irradiated $\mathrm{CH}_{3} \mathrm{OH}$ ice and none of these have absorption features within $50 \mathrm{~cm}^{-1}$ of 1840 or $1860 \mathrm{~cm}^{-1}$. Furthermore the band enhancement in the $\mathrm{CO}$ ice mixture and the low temperature at which the bands disappear all point to HCO. The assignment of this band to $\mathrm{HCO}$ is thus considered secure.

Calculations predict that $\mathrm{CH}_{3}$ absorb at 1361 and $3009 \mathrm{~cm}^{-1}$ (Bennett et al. 2007). In the $30 \mathrm{~K} \mathrm{CH}_{4}$ ice mixture, two bands appear close to these wavelengths, at 1385 and $2965 \mathrm{~cm}^{-1}$. Using the band width from the $\mathrm{CH}_{4}$ ice mixture, this wavelength region could be used to constrain the $\mathrm{CH}_{3}$ production in all ices. Unfortunately, the band strength is not known well enough to derive useful upper limits.

Bennett et al. (2007) calculated that the CO stretching band around $1170 \mathrm{~cm}^{-1}$ is the strongest $\mathrm{CH}_{2} \mathrm{OH}$ band within our spectral range. From matrix isolation experiments $\mathrm{CH}_{2} \mathrm{OH}$ has been found to have one strong band at $1183 \mathrm{~cm}^{-1}$ in agreement with the calculations (Jacox \& Milligan 1973). Similarly to Gerakines et al. (1996) and Bennett et al. (2007), we detect a feature at $1195 \mathrm{~cm}^{-1}$, which appears at the onset of irradiation in all pure $\mathrm{CH}_{3} \mathrm{OH}$ experiments and is most abundant in the $20 \mathrm{~K}$ ice as would be expected for a radical (Fig. 6). The band is not enhanced in the $\mathrm{CO}$ - or $\mathrm{CH}_{4}$-containing ice mixtures, which confirms that the band forms from $\mathrm{CH}_{3} \mathrm{OH}$ alone. It is also not present in the $\mathrm{CH}_{3} \mathrm{OD}$ ice after irradiation. The band starts to disappear around $50 \mathrm{~K}$ during warm-up, at the same time other bands grow, which can be assigned to more complex $\mathrm{CH}_{2} \mathrm{OH}$ 


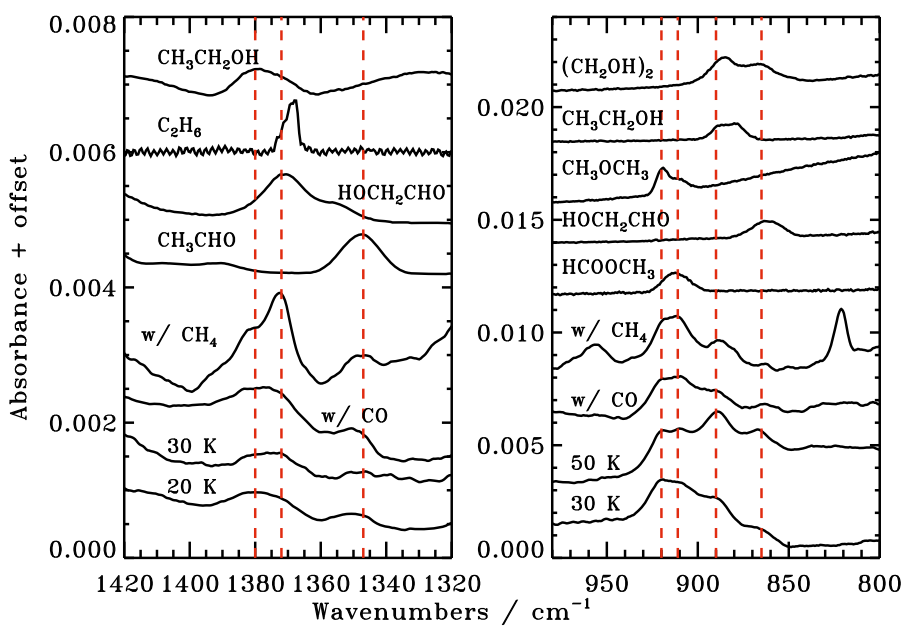

Fig. 13. The left panel shows spectra of UV-irradiated pure $\mathrm{CH}_{3} \mathrm{OH}$ ice at 20 and $30 \mathrm{~K}$, and $\mathrm{CH}_{3} \mathrm{OH}: \mathrm{CO}$ 1:1 and $\mathrm{CH}_{3} \mathrm{OH}: \mathrm{CH}_{4}$ 1:2 ice mixtures at $30 \mathrm{~K}$ after the same fluence of $2.4 \times 10^{17} \mathrm{~cm}^{-2}$, together with pure ice spectra of the complex species that absorb in this region. The right panel shows the complex absorption pattern between 980 and $820 \mathrm{~cm}^{-1}$ in pure ices at 30 and $50 \mathrm{~K}$ and mixed ices at $30 \mathrm{~K}$, together with the possible carriers of these bands. In both panels the $\mathrm{CH}_{3} \mathrm{OH}$ bands have been subtracted from the spectra for visibility and the features have been scaled to the initial $\mathrm{CH}_{3} \mathrm{OH}$ abundance in each experiment to facilitate comparison. The red dashed lines are present to guide the eye between band positions in the irradiated ices and in pure complex ice spectra.

bearing species. Thus we confirm the results of Gerakines et al. (1996) and Bennett et al. (2007) that the $1195 \mathrm{~cm}^{-1}$ band observed at low temperatures is due to $\mathrm{CH}_{2} \mathrm{OH}$. Above $50 \mathrm{~K}$, it is only possible to derive $\mathrm{CH}_{2} \mathrm{OH}$ upper limits, because of overlap with other absorption features.

$\mathrm{CH}_{3} \mathrm{O}$ is predicted to have two fundamental transitions, isolated from strong $\mathrm{CH}_{3} \mathrm{OH}$ bands, at 1319 and $1329 \mathrm{~cm}^{-1}$ (Bennett et al. 2007). The closest observed bands are the $\mathrm{CH}_{4}$ band at $1300 \mathrm{~cm}^{-1}$ and a weak band at $1350 \mathrm{~cm}^{-1}$. The $1350 \mathrm{~cm}^{-1}$ feature only starts to disappear at $70 \mathrm{~K}$, which is a higher temperature than expected for a radical. It is also somewhat enhanced in $\mathrm{CO}$ - and $\mathrm{CH}_{4}$-containing mixtures. Hence there is no evidence for abundant build-up of $\mathrm{CH}_{3} \mathrm{O}$ in any of the experiments. This is consistent with the comparatively small formation of $\mathrm{CH}_{3} \mathrm{O}$-containing molecules during warm-up of the irradiated ice as is reported in more detail below.

\subsection{3. $\mathrm{CH}_{3}$-bearing complex molecules: $\mathrm{C}_{2} \mathrm{H}_{6}, \mathrm{CH}_{3} \mathrm{CHO}$, $\mathrm{CH}_{3} \mathrm{CH}_{2} \mathrm{OH}$ and $\mathrm{CH}_{3} \mathrm{OCH}_{3}$}

$\mathrm{C}_{2} \mathrm{H}_{6}$ is only detected in the UV-irradiated $30 \mathrm{~K} \mathrm{CH}_{3} \mathrm{OH}: \mathrm{CH}_{4}$ ice mixture experiment (Fig. 7). This ice spectrum contains a clear feature at $822 \mathrm{~cm}^{-1}$ with the expected band width of $\mathrm{C}_{2} \mathrm{H}_{6}$. The band starts to disappear at $50 \mathrm{~K}$ during warm-up and it can thus be securely assigned to $\mathrm{C}_{2} \mathrm{H}_{6}$. The same spectral region is used in the other experiments to derive strict upper limits on the $\mathrm{C}_{2} \mathrm{H}_{6}$ production.

Figure 13 shows that there is a shallow band at the frequency of the $\mathrm{CH}_{3} \mathrm{CHO} 1350 \mathrm{~cm}^{-1}$ feature in most experiments and that $\mathrm{CH}_{3} \mathrm{CHO}$ is the only molecule with a directly overlapping band, though the wing of the $\mathrm{HOCH}_{2} \mathrm{CHO}$ band cannot be excluded as a carrier from spectral comparison alone. At $30 \mathrm{~K}$, the feature is somewhat enhanced in both the $\mathrm{CH}_{4}$ - and $\mathrm{CO}$-containing mixtures, when comparing ices at the same temperature. The temperature at which the feature starts to disappear $(100 \mathrm{~K})$ is close to

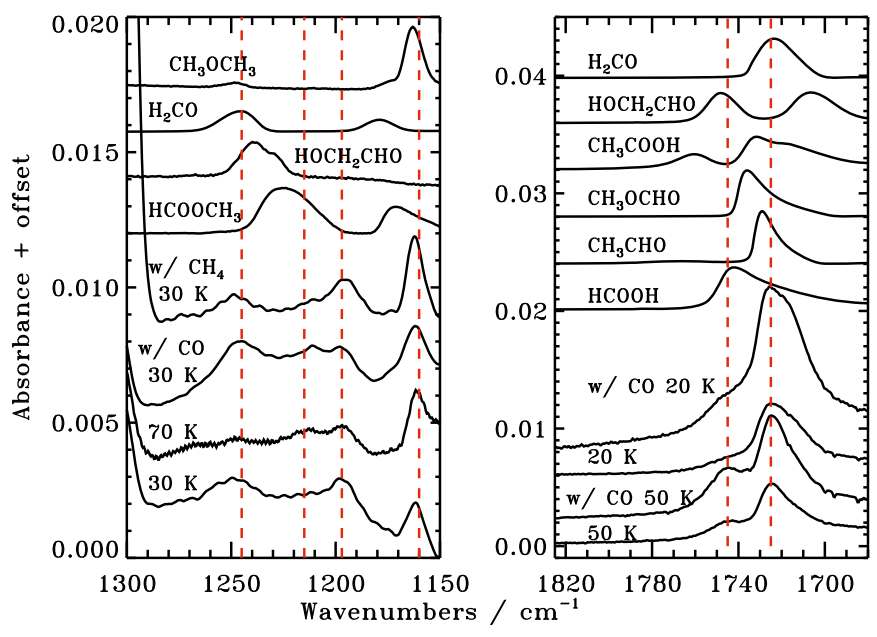

Fig. 14. The left panel panel shows the observed absorption bands between 1140 and $1290 \mathrm{~cm}^{-1}$ following UV irradiation of pure $\mathrm{CH}_{3} \mathrm{OH}$ ice, $\mathrm{CH}_{3} \mathrm{OH}: \mathrm{CO}$ 1:1 and $\mathrm{CH}_{3} \mathrm{OH}: \mathrm{CH}_{4}$ 1:2 ice mixtures, and the possible carriers of these features. The right panel shows the $1700-1770 \mathrm{~cm}^{-1}$ $\mathrm{HCO}$ feature in irradiated pure $\mathrm{CH}_{3} \mathrm{OH}$ ices at 20 and $50 \mathrm{~K}$ together with irradiated $\mathrm{CH}_{3} \mathrm{OH}: \mathrm{CO} \sim 1: 1$ mixtures, and the possible carriers. In both panels the red dashed lines indicate some of the complex band positions.

the expected desorption temperature for $\mathrm{CH}_{3} \mathrm{CHO}$ from the pure TPD experiments. The feature is completely gone before the onset of $\mathrm{CH}_{3} \mathrm{OH}$ desorption which excludes significant contributions from less volatile molecules, like $\mathrm{HOCH}_{2} \mathrm{CHO}$. Together these observations are only consistent with $\mathrm{CH}_{3} \mathrm{CHO}$ as the main carrier.

Figure 13 also shows that a band at $1380 \mathrm{~cm}^{-1}$ in the photolysis spectra correlates with the pure $\mathrm{CH}_{3} \mathrm{CH}_{2} \mathrm{OH}$ ice feature, but $\mathrm{HOCH}_{2} \mathrm{CHO}$ is also a potential carrier. The band is, however, enhanced in the $\mathrm{CH}_{4}$-mixture experiments. Simultaneously a band at $885 \mathrm{~cm}^{-1}$ is enhanced (Fig. 13), which can be attributed to $\mathrm{CH}_{3} \mathrm{CH}_{2} \mathrm{OH}$ as well. Furthermore, the $1380 \mathrm{~cm}^{-1}$ band starts to desorb at $120 \mathrm{~K}$, with $\mathrm{CH}_{3} \mathrm{OH}$, while the complex HCO-bearing species only experience significant desorption at $150 \mathrm{~K}$. This suggests that $\mathrm{CH}_{3} \mathrm{CH}_{2} \mathrm{OH}$ is the main carrier of the $1380 \mathrm{~cm}^{-1}$ feature. The assignment is confirmed by a $\mathrm{m} / \mathrm{z}=46$ detection at the desorption temperature of $\mathrm{CH}_{3} \mathrm{CH}_{2} \mathrm{OH}$; the QMS signal is enhanced by about a factor of three in the $\mathrm{CH}_{4}$ mixture experiment, which is of the same order as the RAIRS band enhancement. In the $\mathrm{CO}$ ice mixtures the contribution of $\mathrm{HOCH}_{2} \mathrm{CHO}$ may however be significant and in these ices the $1380 \mathrm{~cm}^{-1}$ feature is only used to provide upper limits on the $\mathrm{CH}_{3} \mathrm{CH}_{2} \mathrm{OH}$ production.

$\mathrm{CH}_{3} \mathrm{OCH}_{3}$ has not been generally considered as a photoproduct of $\mathrm{CH}_{3} \mathrm{OH}$ ice in previous experimental studies (Gerakines et al. 1996; Bennett et al. 2007). $\mathrm{CH}_{3} \mathrm{OCH}_{3}$ is however formed in the ice in our experiments; the feature at $1090 \mathrm{~cm}^{-1}$, which can contain contributions from $\mathrm{CH}_{3} \mathrm{OCH}_{3}$, $\mathrm{CH}_{3} \mathrm{CH}_{2} \mathrm{OH}$ and $\left(\mathrm{CH}_{2} \mathrm{OH}\right)_{2}$ loses intensity at $90 \mathrm{~K}$, before the onset of desorption of any of the other two species, which is only consistent with the presence of $\mathrm{CH}_{3} \mathrm{OCH}_{3}$ in the ice. Furthermore, Fig. 14 shows that the band seen around $1170 \mathrm{~cm}^{-1}$ agrees better with $\mathrm{CH}_{3} \mathrm{OCH}_{3}$ than any other complex molecule and that it has no similarity with the nearby $\mathrm{HCOOCH}_{3}$ band, with which it is usually identified (Gerakines et al. 1996; Bennett et al. 2007). The band is not significantly affected by the ice temperature during irradiation and during warm-up it starts to lose intensity around $90 \mathrm{~K}$, close to the $\mathrm{CH}_{3} \mathrm{OCH}_{3}$ desorption 


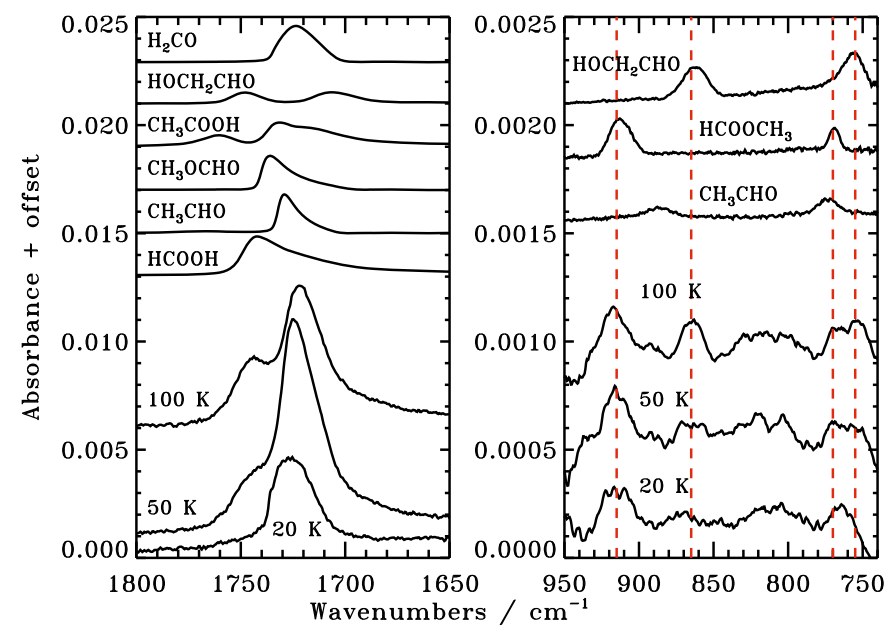

Fig. 15. The left panel shows the $1700 \mathrm{~cm}^{-1}$ feature during warm-up of a $\mathrm{CH}_{3} \mathrm{OH}$ :CO 1:10 ice from 20 to $100 \mathrm{~K}$, after irradiation at $20 \mathrm{~K}$, together with six possible carriers of these bands. The right panel shows the $950-750 \mathrm{~cm}^{-1}$ region in the same heated mixture together with possible carriers of the detected features. All spectra are scaled with the same fraction in both panels, so that the absorbance of each spectrum corresponds to $\sim 0.1 \mathrm{ML}$ of each of the complex species.

temperature (Fig. 11). At the same time a $\mathrm{m} / \mathrm{z}$ value of 46 , characteristic of $\mathrm{CH}_{3} \mathrm{OCH}_{3}$, is detected by the QMS (Fig. 12). The $1170 \mathrm{~cm}^{-1}$ band is enhanced in the $\mathrm{CH}_{4}$ mixture and so is a feature at $920 \mathrm{~cm}^{-1}$, which can also be attributed to $\mathrm{CH}_{3} \mathrm{OCH}_{3}$. Neither feature is enhanced in the $\mathrm{CO}$ ice mixture, which confirms the identification of the band carrier with $\mathrm{CH}_{3} \mathrm{OCH}_{3}$. The uncertainty of the integrated abundance of the $\mathrm{CH}_{3} \mathrm{OCH}_{3}$ feature is relatively large because of uncertainties in the baseline due to overlap with $\mathrm{HCOOCH}_{3}$ and $\mathrm{CH}_{3} \mathrm{OH}$ bands.

\subsection{4. $\mathrm{CHO}$-bearing complex molecules: $\mathrm{HCOOH}$, $\mathrm{HOCH}_{2} \mathrm{CHO}, \mathrm{HCOOCH}_{3}$ and $\mathrm{CH}_{3} \mathrm{COOH}$}

In the pure $\mathrm{CH}_{3} \mathrm{OH}$ ice experiments, none of the $\mathrm{CHO}$-bearing species, except $\mathrm{H}_{2} \mathrm{CO}$ and $\mathrm{CH}_{3} \mathrm{CHO}$, are uniquely identified. Similarly $\mathrm{HCOOH}$ and $\mathrm{CH}_{3} \mathrm{COOH}$ have no unique bands. A mixture of these compounds can, however, be identified from the growth of the $1700 \mathrm{~cm}^{-1}$ complex (Fig. 14). The relative importance of the different contributors in different mixtures and at different temperatures can also be assessed by spectral comparison. Figure 14 shows that the shape of the $1700 \mathrm{~cm}^{-1}$ band depends on the ice temperature during irradiation. At lower temperatures, a broad feature, peaking at $1725 \mathrm{~cm}^{-1}$ dominates, which can be identified with $\mathrm{H}_{2} \mathrm{CO}$. At higher temperatures the band is more similar in width to $\mathrm{CH}_{3} \mathrm{CHO}$ and $\mathrm{HCOOCH}_{3}$. This is true both when the ice is irradiated at higher temperatures and when an ice irradiated at $20 \mathrm{~K}$ is warmed up to $>50 \mathrm{~K}$. Simultaneously, the high frequency wing becomes more pronounced, suggesting an increasing importance of $\mathrm{HOCH}_{2} \mathrm{CHO}$, compared to $\mathrm{HCOOH}$. This is the case in both pure and $\mathrm{CH}_{3} \mathrm{OH}: \mathrm{CO}$ ice mixtures.

In the $\mathrm{CO}$-dominated $\mathrm{CH}_{3} \mathrm{OH}: \mathrm{CO}$ 1:10 mixtures, where the formation of many of the complex molecules is quenched, some of the weaker features of molecules like $\mathrm{HOCH}_{2} \mathrm{CHO}$ and $\mathrm{HCOOCH}_{3}$ are visible during warm-up of an ice irradiated at $20 \mathrm{~K}$ (Fig. 15). The final abundance ratio of $\mathrm{HOCH}_{2} \mathrm{CHO} / \mathrm{HCOOCH}_{3}$ is approximately $1 / 2$ at $100 \mathrm{~K}$. However, $\mathrm{HCOOCH}_{3}$ starts to form at a lower temperature; thus the ratio of the two species changes with temperature. The similar $1700 \mathrm{~cm}^{-1}$ feature in this experiment and in the pure $\mathrm{CH}_{3} \mathrm{OH}$ ice experiments suggests that these two molecules contribute the same fractions to the $1700 \mathrm{~cm}^{-1}$ band in all mixtures, depending only on the temperatures at which they are irradiated, or the temperature to which they are subsequently heated.

\subsection{5. $\left(\mathrm{CH}_{2} \mathrm{OH}\right)_{2}$}

$\left(\mathrm{CH}_{2} \mathrm{OH}\right)_{2}$ is the main carrier of the $866 \mathrm{~cm}^{-1}$ feature in Fig. 13. This is inferred from the ice warm-up, where the band does not decrease by more than 10-20\% around the desorption temperature of $\mathrm{HOCH}_{2} \mathrm{CHO}$ - the only other possible carrier. The remainder of the band disappears around $180 \mathrm{~K}$, the desorption temperature of $\left(\mathrm{CH}_{2} \mathrm{OH}\right)_{2}$. The QMS simultaneously detects a strong $\mathrm{m} / z=62$ signal. The assignment of this band to mainly $\left(\mathrm{CH}_{2} \mathrm{OH}\right)_{2}$ is thus secure, but the uncertainty in the abundance is higher than for some other species because of a small contribution of a $\mathrm{HOCH}_{2} \mathrm{CHO}$ feature to the band. In the $\mathrm{CO}$ ice mixtures the $\left(\mathrm{CH}_{2} \mathrm{OH}\right)_{2}$ abundance is instead calculated from the $890 \mathrm{~cm}^{-1}$ band, which partially overlaps with a $\mathrm{CH}_{3} \mathrm{CH}_{2} \mathrm{OH}$ ice feature.

\subsection{Abundance determinations of photoproducts}

Table 4 lists the possible photoproducts considered in the previous section that have strong infrared transitions, together with the bands used for quantification, the fitting regions, the band strengths and the estimated uncertainties of the integrated absorbance. The integrated absorbance of each molecular band is determined by first automatically scaling the previously acquired complex molecule spectra to the band over a defined fitting region, using a personal IDL routine. The scaled band in the complex molecule spectrum is then integrated to determine the molecular abundance rather than directly integrating the band in the irradiated $\mathrm{CH}_{3} \mathrm{OH}$ spectra. The complex ice spectra used of comparison are pure ice spectra. Mixing these complex ices with $\mathrm{CH}_{3} \mathrm{OH}$ may cause some changes in the band shape, position and strength of the complex features. The change in band shapes for some key species, such as $\mathrm{CH}_{3} \mathrm{OCH}_{3}$, between pure ice and ice mixtures with $\mathrm{CH}_{3} \mathrm{OH}$ have therefore been investigated to ensure that they are not substantial enough to affect band assignments. The changes in band strengths remains unknown but are unlikely to exceed $20 \%$ from previous studies on organic species in pure ices and in hydrogen-bonding ices (Boogert et al. 1997). The fitting regions are chosen for each species to ensure that the template spectra are fitted to the part of the band that has no other possible contributors than the species in question. This is especially important in spectrally crowded regions, where the absorption features of different potential photoproducts partially overlap. For example, the $\mathrm{CH}_{3} \mathrm{CH}_{2} \mathrm{OH}$ spectrum is only fitted to the high frequency half of the $1360 \mathrm{~cm}^{-1}$ band when determining the $\mathrm{CH}_{3} \mathrm{CH}_{2} \mathrm{OH}$ abundance to avoid contributions to the band intensity from $\mathrm{HOCH}_{2} \mathrm{CHO}$. The integrated absorbance uncertainty varies by an order of magnitude between the different species, mainly dependent on how crowded the region is, since a major source of error is the choice of the local baseline.

The integrated absorbance of each species is converted to an abundance using literature band strengths for pure ices, with a $\sim 20 \%$ uncertainty. Calculated band strengths are less well defined for solid-state features, resulting in at least a factor of five uncertainty for the affected species (when comparing calculated values to experimental ones). All abundances are reported with respect to the initial $\mathrm{CH}_{3} \mathrm{OH}$ abundance in each experiment to 
Table 4. Potential photoproducts with infrared transitions.

\begin{tabular}{|c|c|c|c|c|c|}
\hline Species & $\overline{\text { Band }}$ & $\begin{array}{l}\text { Band position } \\
\left(\mathrm{cm}^{-1}\right)\end{array}$ & $\begin{array}{l}\text { Fitting region } \\
\left(\mathrm{cm}^{-1}\right)\end{array}$ & $\begin{array}{c}\sigma \text { band area } \\
\left(\mathrm{cm}^{-1}\right)\end{array}$ & $\begin{array}{c}\text { Band strength }^{a} \\
\left(\mathrm{~cm}^{-1}\right)\end{array}$ \\
\hline $\mathrm{H}_{2} \mathrm{O}$ & $v_{2}$ & 1670 & $1600-1670$ & $\mathrm{ul}^{b}$ & $1.2 \times 10^{-17}(1)$ \\
\hline $\mathrm{CH}_{3}$ & $v_{2}$ & 1385 & $1380-1390$ & ul & $6.9 \times 10^{-19}(2)$ \\
\hline $\mathrm{CH}_{4}$ & $v_{4}$ & 1301 & $1290-1310$ & 0.002 & $1.2 \times 10^{-17}$ \\
\hline $\mathrm{CO}$ & $v_{1}$ & 2135 & $2125-2145$ & 0.001 & $1.1 \times 10^{-17}(1)$ \\
\hline $\mathrm{HCO}$ & $v_{1}$ & 1850 & $1840-1860$ & 0.0005 & $2.1 \times 10^{-17}(2)$ \\
\hline $\mathrm{H}_{2} \mathrm{CO}$ & $v_{2}$ & 1245 & $1228-1265$ & 0.01 & $1.0 \times 10^{-18}(4)$ \\
\hline $\mathrm{CH}_{2} \mathrm{OH}$ & $v_{4}$ & 1195 & $1185-1195$ & 0.01 & $1.6 \times 10^{-17}(2)$ \\
\hline $\mathrm{C}_{2} \mathrm{H}_{6}$ & $v_{12}$ & 822 & 809-832 & 0.001 & $1.6 \times 10^{-17}(5)$ \\
\hline $\mathrm{CO}_{2}$ & $v_{1}$ & 2340 & $2330-2350$ & 0.005 & $1.2 \times 10^{-17}(1)$ \\
\hline $\mathrm{CH}_{3} \mathrm{CHO}$ & $v_{7}$ & 1350 & $1337-1350$ & 0.003 & $6.1 \times 10^{-18}(5)$ \\
\hline $\mathrm{CH}_{3} \mathrm{CH}_{2} \mathrm{OH}$ & $v_{12}$ & 1380 & $1380-1395$ & 0.002 & $1.9 \times 10^{-18}(5)$ \\
\hline $\mathrm{HCOOH}$ & $v_{3}$ & 1740 & $1739-1773$ & ul & $6.7 \times 10^{-17}(6)$ \\
\hline $\mathrm{CH}_{3} \mathrm{OCH}_{3}$ & $v_{10}$ & 1161 & $1151-1171$ & 0.003 & $1.2 \times 10^{-17}(7)$ \\
\hline $\mathrm{HCOOCH}_{3}$ & $v_{9}$ & 1214 & $1216-1233$ & ul & $2.1 \times 10^{-17}(2)$ \\
\hline $\mathrm{HOCH}_{2} \mathrm{CHO}$ & $v_{6}$ & 861 & $851-871$ & ul & $3.4 \times 10^{-18}(8)$ \\
\hline $\mathrm{CH}_{3} \mathrm{COOH}$ & $v_{14}$ & $1746 / 1770$ & $1760-1772$ & $\mathrm{ul}$ & $1.1 \times 10^{-16}(9)$ \\
\hline$\left(\mathrm{CH}_{2} \mathrm{OH}\right)_{2}$ & $v_{14}$ & $866 / 890$ & $851-876$ & 0.006 & $3.4 \times 10^{-18}(8)$ \\
\hline $\mathrm{X}-\mathrm{CHO} / \mathrm{X}-\mathrm{COOH}^{c}$ & $\mathrm{CO}$ stretch & $1680-1780$ & - & 0.01 & $5.4 \times 10^{-17}(2,6,8)$ \\
\hline
\end{tabular}

${ }^{a}$ The listed values are transmission band strengths, for our RAIRS experiments they are scaled by a factor of 5.5, determined empirically.

${ }^{b}$ Only an upper limit could be determined.

${ }^{c}$ An average of the $\mathrm{HCOOH}, \mathrm{HCOOCH}_{3}$ and $\mathrm{HOCH}_{2} \mathrm{CHO}$ band strengths of $6.7,4.8$ and $4.6 \times 10^{-17} \mathrm{~cm}^{-1}$ is used.

(1) Gerakines et al. (1995), (2) calculated band strengths from Bennett et al. (2007), (3) D'Hendecourt \& Allamandola (1986), (4) Schutte et al. (1993), (5) Moore \& Hudson (1998), (6) Hudson \& Moore (1999), (7) from $\mathrm{CH}_{3} \mathrm{OH}: \mathrm{CH}_{3} \mathrm{OCH}_{3}$ ice mixture spectroscopy, (8) Hudson et al. (2005), (9) Maréchal (1987).

remove the uncertainty in the band strength conversion factor between transmission and reflection-absorption spectroscopy as well as to cancel the variations in the initial ice thickness between the different experiments. Section 3.3.3 showed that the ice chemistry does not depend significantly on ice thickness or irradiation flux and therefore only the results from the $\sim 20 \mathrm{ML}$ thick ices with the low irradiation flux are shown explicitly.

The sum of all $\mathrm{CHO}$ - and $\mathrm{COOH}$-containing complex species, except for $\mathrm{H}_{2} \mathrm{CO}$ and $\mathrm{CH}_{3} \mathrm{CHO}$, are also reported since these species have no uniquely detected features in most experiments. This sum is calculated by subtracting the $\mathrm{H}_{2} \mathrm{CO}$ and $\mathrm{CH}_{3} \mathrm{CHO}$ contributions from the $1700 \mathrm{~cm}^{-1}$ feature and calculating the remaining integrating absorbance. The integrated absorbance is converted into a molecular abundance by using an averaged band strength, which is within $20 \%$ of the reported band strengths of the three suspected main contributors, $\mathrm{HCOOCH}_{3}, \mathrm{HOCH}_{2} \mathrm{CHO}$ and $\mathrm{HCOOH}$. The fourth potential major contributor $\mathrm{CH}_{3} \mathrm{COOH}$ has a factor of two larger band strength, but as shown below the $\mathrm{CH}_{3} \mathrm{COOH}$ upper limits are strict in most experiments and thus it contributes at most $10 \%$ to the $1700 \mathrm{~cm}^{-1}$ feature.

Figures 16 and 17 show the photoproduct abundances with respect to the initial $\mathrm{CH}_{3} \mathrm{OH}$ abundance as a function of $\mathrm{UV}$ fluence in 20 and $70 \mathrm{~K}$ ices (growth curves for the other experiments are shown in the Appendices (A1-3). The abundances of all fragments and molecules that can form directly from $\mathrm{CH}_{3} \mathrm{OH}$ photodissociation or from hydrogenation of a dissociation fragment have a clear inverse dependence on ice temperature, i.e., the abundances of $\mathrm{CO}, \mathrm{CH}_{4}, \mathrm{HCO}$ and $\mathrm{H}_{2} \mathrm{CO}$ are significantly higher at low temperatures than at high temperatures, where recombination of large radicals dominates the chemistry. For the more complex products the temperature dependence varies. Abundances of molecules that contain an HCO- or a $\mathrm{CH}_{3}$ group do not depend on temperature within the experimental
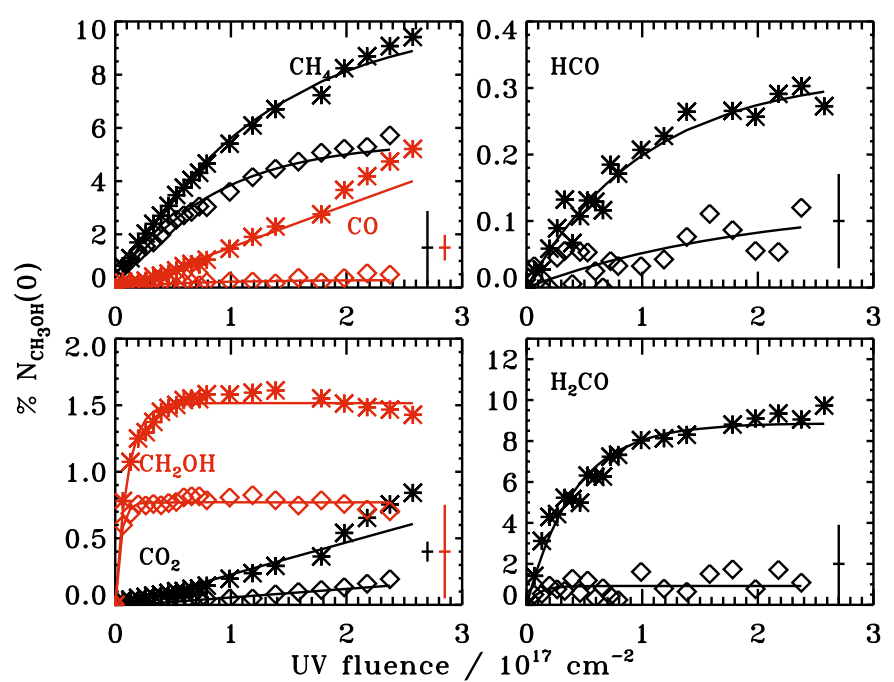

Fig. 16. The evolution of small $\mathrm{CH}_{3} \mathrm{OH}$ photo-products with respect to UV fluence in $\%$ of the initial $\mathrm{CH}_{3} \mathrm{OH}$ ice abundance $\left(\mathrm{CH}_{3} \mathrm{OH}(0)\right)$ in each experiment during six hours of irradiation at $20 \mathrm{~K}$ (stars) and at $70 \mathrm{~K}$ (diamonds). The average abundance uncertainties are indicated in the bottom right corner of each panel. The lines are exponential fits to the abundance growths.

uncertainties, while the $\left(\mathrm{CH}_{2} \mathrm{OH}\right)_{2}$ abundance is strongly temperature dependent.

Initial formation cross sections can be derived for the photochemistry products using

$$
\frac{\mathrm{d} n}{\mathrm{~d} \phi}=\sigma
$$

where $n$ is the fractional abundance of the product with respect to $\mathrm{CH}_{3} \mathrm{OH}, \phi$ the fluence in $\mathrm{cm}^{-2}$ and $\sigma$ the formation cross 


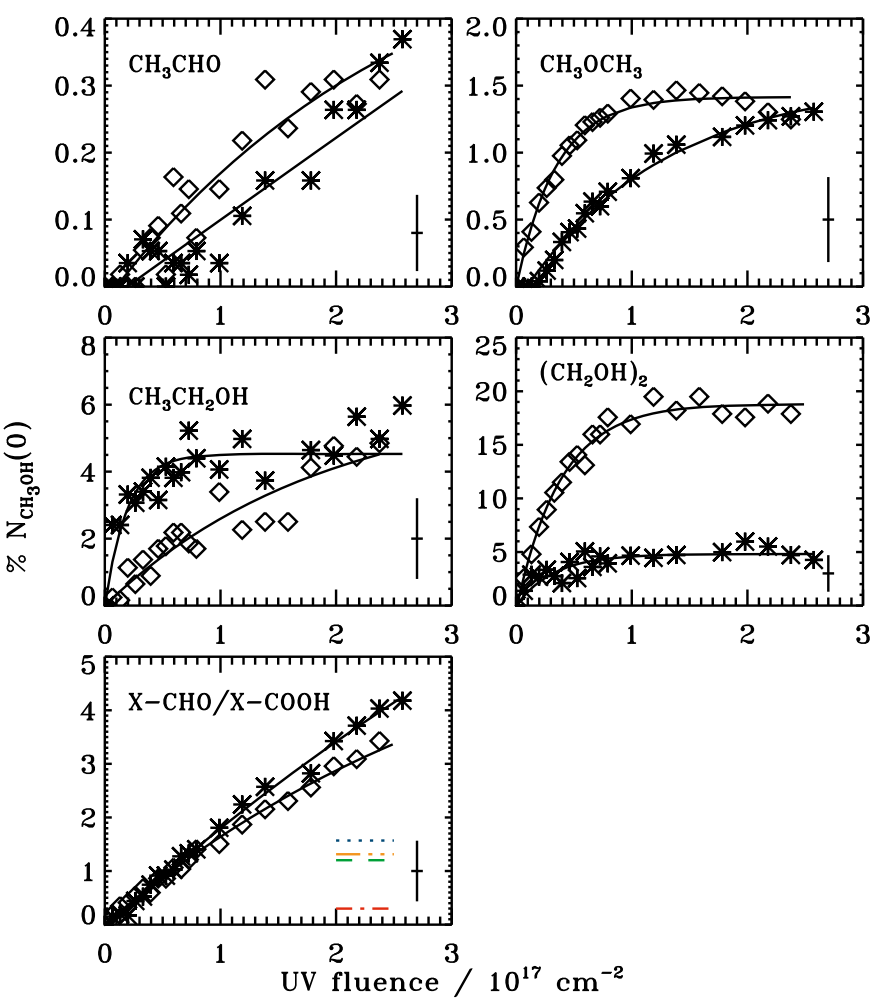

Fig. 17. The evolution of complex $\mathrm{CH}_{3} \mathrm{OH}$ photo-products with respect to UV fluence in $\%$ of the initial $\mathrm{CH}_{3} \mathrm{OH}$ ice abundance in each experiment during six hours of irradiation at $20 \mathrm{~K}$ (stars) and $70 \mathrm{~K}$ (diamonds). In the bottom panel the final upper limit abundances in the $20 \mathrm{~K}$ ice of $\mathrm{HCOOH}$ (blue dotted), $\mathrm{HCOOCH}_{3}$ (green dashed), $\mathrm{CH}_{3} \mathrm{COOH}$ (red dashed-dotted) and $\mathrm{HOCH}_{2} \mathrm{CHO}$ (yellow dashed-triple-dotted) are also shown. The average uncertainty in each abundance is indicated in the bottom right corner. The lines are exponential fits to the abundance growths.

section. A formation cross section only makes strict physical sense for fragments that form directly from $\mathrm{CH}_{3} \mathrm{OH}$ photodissociation; however, it is also a relevant number whenever photodissociation is the formation-limiting step. Therefore, formation cross sections for all simple and complex products forming in the pure $\mathrm{CH}_{3} \mathrm{OH}$ ice experiments between $20 \mathrm{~K}$ and $70 \mathrm{~K}$ are presented in Table 5. The cross sections are calculated from the first $5 \times 10^{16} \mathrm{UV}$-photons $\mathrm{cm}^{-2}$, which is within the linear growth regime for most molecules.

The complete shapes of the ice growth curves belonging to the small products, $\mathrm{CH}_{4}, \mathrm{CH}_{2} \mathrm{OH}, \mathrm{HCO}$ and $\mathrm{H}_{2} \mathrm{CO}$, are proportional to $A_{1}\left(1-\mathrm{e}^{-A_{2} \phi}\right)$, where $\phi$ is the fluence, $A_{1}$ the steady-state abundance, and $A_{2}$ combines information about the formation and destruction of the molecules in question in $\mathrm{cm}^{2}$. At 50 and $70 \mathrm{~K}$, this type of equation also fits the growth in abundances of complex species. Several complex production curves are however better fitted with $A_{1}\left(1-\mathrm{e}^{-A_{2}\left(\phi-A_{3}\right)}\right)$ at $20-30 \mathrm{~K}$, where $A_{3}$ is a delay, in fluence units, before the production of the species in question starts. In other words, at low temperatures a certain build-up of radicals is required before the production of complex molecules becomes efficient (see also Fig. 3) and therefore a more general equation $A_{1}\left(1-\mathrm{e}^{-A_{2}\left(\phi-A_{3}\right)}\right)$, is used to fit their abundances curves. The measured delay is typically $(1-2) \times 10^{16}$ photons $\mathrm{cm}^{-2}$ : significant for $\mathrm{CH}_{3} \mathrm{CHO}$ and $\mathrm{CH}_{3} \mathrm{OCH}_{3}$ abundances and for the upper limits of $\mathrm{HCOOCH}_{3}$ and $\mathrm{HCOOH}$, but not for the $\mathrm{CH}_{2} \mathrm{OH}$ containing molecules. $\mathrm{CO}$ and $\mathrm{CO}_{2}$ cannot be fitted with either equation; the $\mathrm{CO}_{2}$ growth rate even increases with
Table 5. Formation cross sections in $10^{-19} \mathrm{~cm}^{2}$ during pure $\mathrm{CH}_{3} \mathrm{OH}$ ice photolysis.

\begin{tabular}{lcccc}
\hline \hline Species & $20 \mathrm{~K}$ & $30 \mathrm{~K}$ & $50 \mathrm{~K}$ & $70 \mathrm{~K}$ \\
\hline $\mathrm{CH}_{4}$ & $7.0[1.2]$ & $7.1[1.3]$ & $5.8[1.3]$ & $4.9[1.2]$ \\
$\mathrm{CO}$ & $1.0[0.5]$ & $1.0[0.6]$ & $0.5[0.5]$ & $0.6[0.5]$ \\
$\mathrm{HCO}^{a}$ & $0.4[0.2]$ & $0.3[0.2]$ & $0.3[0.2]$ & $<0.2$ \\
$\mathrm{H}_{2} \mathrm{CO}$ & $15.7[3.4]$ & $15.4[3.8]$ & $7.4[3.6]$ & $<3.3$ \\
$\mathrm{CH}_{2} \mathrm{OH}^{a}$ & $3.7[1.0]$ & $2.9[1.1]$ & $2.8[1.1]$ & $1.9[1.0]$ \\
$\mathrm{CO}_{2}$ & $0.2[0.2]$ & $<0.2$ & $<0.2]$ & $<0.2$ \\
$\mathrm{CH}_{3} \mathrm{CHO}$ & $<0.1$ & $<0.1$ & $<0.1$ & $0.2[0.1]$ \\
$\mathrm{CH}_{3} \mathrm{OCH}$ & $0.6[0.7]$ & $1.1[0.8]$ & $2.2[0.7]$ & $2.4[0.7]$ \\
$\mathrm{CH}_{3} \mathrm{CH}_{2} \mathrm{OH}$ & $8.6[3.4]$ & $8.8[3.8]$ & $2.3[3.6]$ & $3.9[3.3]$ \\
$\left(\mathrm{CH}_{2} \mathrm{OH}\right)_{2}$ & $8.4[5.1]$ & $10.4[5.7]$ & $21.8[5.4]$ & $32.2[5.0]$ \\
$\mathrm{X}-\mathrm{CHO} / \mathrm{X}-\mathrm{COOH}$ & $1.5[1.8]$ & $1.7[1.9]$ & $2.3[1.8]$ & $2.0[1.7]$ \\
\hline
\end{tabular}

${ }^{a}$ The absolute uncertainty is a factor of 5 for $\mathrm{HCO}$ and $\mathrm{CH}_{2} \mathrm{OH}$.

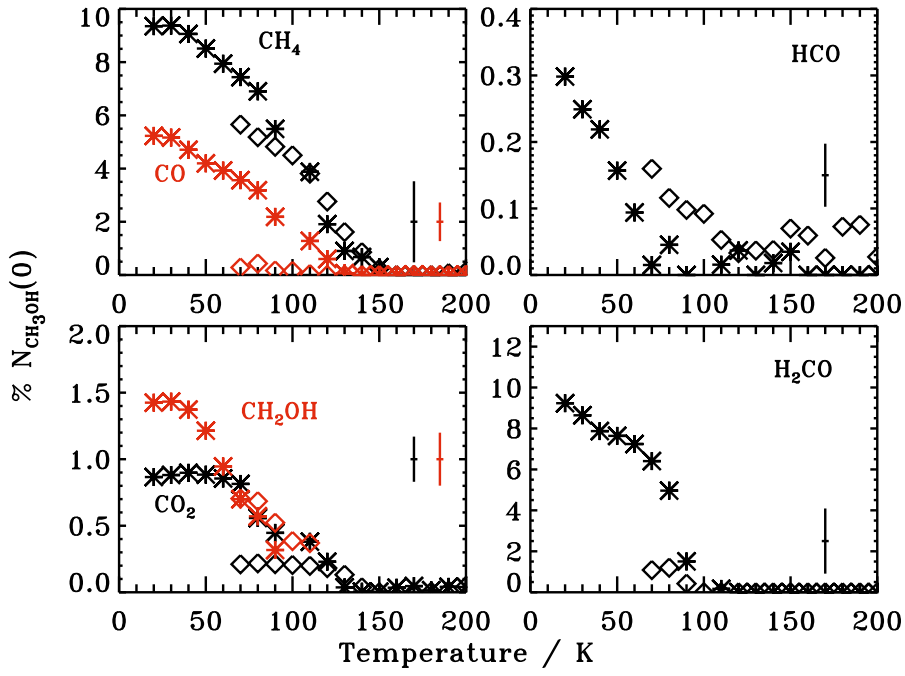

Fig. 18. The evolution of small $\mathrm{CH}_{3} \mathrm{OH}$ photo-products, in $\%$ of the initial $\mathrm{CH}_{3} \mathrm{OH}$ ice abundance in each experiment, during $1 \mathrm{~K} \mathrm{~min}^{-1}$ warmup following UV irradiation at $20 \mathrm{~K}$ (stars) and $70 \mathrm{~K}$ (diamonds). The average uncertainty in each abundance is indicated to the right in each panel.

fluence. This behavior is explained below when the complete reaction scheme for the ice is discussed in detail.

The exponential fits for all experiments are tabulated in the Appendices (C). It should be noted however, that while this is a convenient way of describing the experimental outcomes, these equations cannot be directly translated to an astrophysical setting without intermediate modeling as will be discussed in Sect. 5.

\subsection{Ice formation and destruction during warm-up following irradiation}

During warm-up after the completion of the UV-irradiation experiment, the ice composition changes due to recombination of diffusing radicals and sequential thermal desorption. This results in the depletion of volatile molecules and radicals from the ice as the temperature increases, while more complex molecules increase in abundance before they also start to desorb. The temperature at which a species displays a maximum abundance depends both on the diffusion barriers of the radicals it forms from and the desorption temperature of the complex molecule in question. Figure 18 shows that the small molecules and radicals follow the expected behavior. HCO disappears the fastest, though it is not 


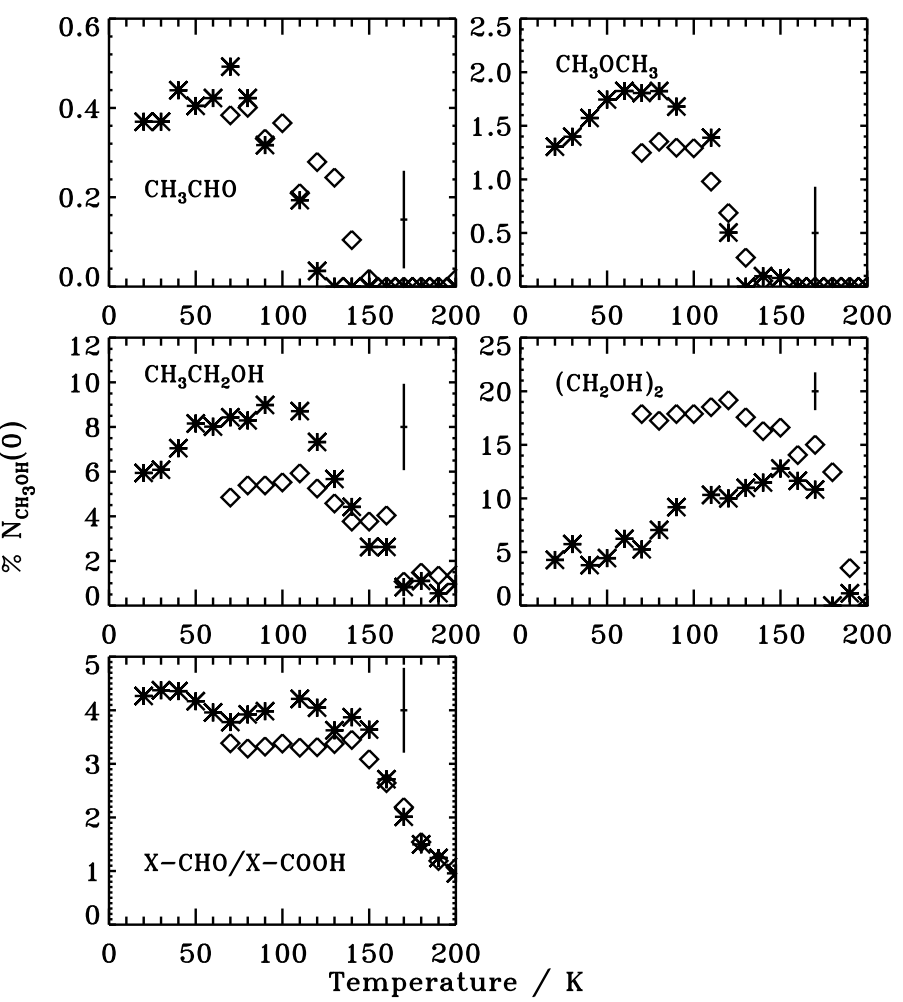

Fig. 19. The evolution of complex $\mathrm{CH}_{3} \mathrm{OH}$ photo-products, in $\%$ of the initial $\mathrm{CH}_{3} \mathrm{OH}$ ice abundance in each experiment, during $1 \mathrm{~K} \mathrm{~min}^{-1}$ warm-up following UV irradiation at $20 \mathrm{~K}$ (stars) and $70 \mathrm{~K}$ (diamonds). The average uncertainty in each abundance is indicated to the right in each panel.

below the noise level until $90 \mathrm{~K}$. The other small molecules all desorb slowly, and only completely disappear at $120 \mathrm{~K}$, the temperature at which $\mathrm{CH}_{3} \mathrm{OH}$ starts to desorb. This is indicative of significant trapping of volatiles inside the $\mathrm{CH}_{3} \mathrm{OH}$ ice.

The more complex molecules also behave as expected following the assumption that they form from recombining radicals; all complex ice abundances initially increase before desorption sets in (Fig. 19). The temperature at which a maximum abundance is reached during warm-up varies with molecular species and also somewhat with the ice temperature during irradiation; for example, it appears that $\mathrm{CH}_{3} \mathrm{CH}_{2} \mathrm{OH}$ formed in the warmer ices experiences somewhat less co-desorption with $\mathrm{CH}_{3} \mathrm{OH}$, and thus it desorbs mainly at its pure-ice desorption temperature. This can be understood from recent experiments that show that segregation is a general feature of mixed ices when kept at elevated temperatures; the ice irradiated at 50 and $70 \mathrm{~K}$ may thus be partially segregated before the onset of $\mathrm{CH}_{3} \mathrm{OH}$ desorption, while the ices irradiated at 20-30 K do not have time to segregate before reaching the $\mathrm{CH}_{3} \mathrm{OH}$ desorption temperature, at which they co-desorb. Co-desorption with $\mathrm{CH}_{3} \mathrm{OH}$ around $120 \mathrm{~K}$ is especially important for $\mathrm{CH}_{3} \mathrm{CH}_{2} \mathrm{OH}$ and $\mathrm{CH}_{3} \mathrm{OCH}_{3} . \mathrm{CH}_{3} \mathrm{CHO}, \mathrm{CH}_{3} \mathrm{OCH}_{3}$ and $\mathrm{CH}_{3} \mathrm{CH}_{2} \mathrm{OH}$ reach maximum abundances at $\sim 70,80$ and $\sim 110 \mathrm{~K}$, respectively. $\left(\mathrm{CH}_{2} \mathrm{OH}\right)_{2}$ only reaches a maximum at $120-150 \mathrm{~K}$ (Fig. 19). The formation and desorption pattern of $\mathrm{X}-\mathrm{CHO}$ and $\mathrm{X}-\mathrm{COOH}$ is, as expected, complicated with several peaks, corresponding to formation maxima of the different contributors to the band. The initial decrease suggests that the subtraction of $\mathrm{H}_{2} \mathrm{CO}$ is imperfect and that up to $20 \%$ of the $\mathrm{X}-\mathrm{CHO} / \mathrm{X}-\mathrm{COOH}$ abundance at low temperatures is due to $\mathrm{H}_{2} \mathrm{CO}$.

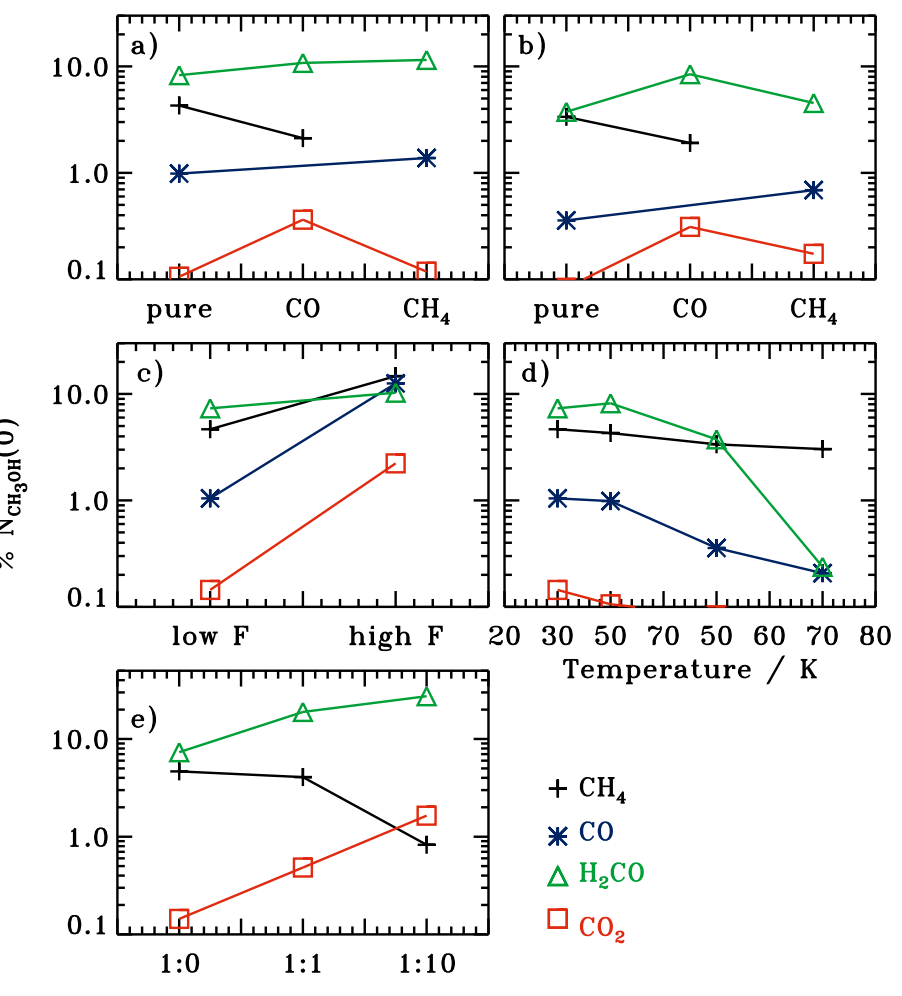

Fig. 20. The final simple ice abundances, with respect to initial $\mathrm{CH}_{3} \mathrm{OH}$ abundance, after the completion of irradiation, plotted as functions of: a) and b) composition (pure $\mathrm{CH}_{3} \mathrm{OH}$ vs. $\mathrm{CH}_{3} \mathrm{OH}: \mathrm{CH}_{4} 1: 2$ and $\mathrm{CH}_{3} \mathrm{OH}: \mathrm{CO} 1: 1$ ice mixtures) at 30 and $50 \mathrm{~K}$, respectively; c) fluence; d) ice temperature; e) amount of $\mathrm{CO}$ mixed into the ice. All ices were irradiated with $2.4 \times 10^{17}$ photons $\mathrm{cm}^{-2}$, except for the the high flux/fluence case in c), in which a final UV fluence four-times greater was attained. In d) and e) the ice temperature is $20 \mathrm{~K}$. The uncertainties are as in Fig. 16.

\subsection{Dependence of ice products on physical conditions}

The previous two sections quantified the growth of complex ices in detail as a function of fluence and temperature under specific conditions. In this section, the focus is on the final complex ice abundances in each experiment after completion of irradiation at a low temperature and the maximum abundance reached during warm-up. This is used to determine trends in the final complex abundances as a function of the experimental conditions. Figures 20 and 21 show how the final irradiated ice composition changes with ice composition (pure vs. 1(2):1 mixtures with $\mathrm{CO}$ and $\mathrm{CH}_{4}$ ), fluence, ice temperature during irradiation and the amount of $\mathrm{CO}$ mixed in at $20 \mathrm{~K}$. The small photoproducts in Fig. 20 are all affected by temperature, though the COcontaining ones, much more severly than $\mathrm{CH}_{4}$. Both $\mathrm{CO}_{2}$ and $\mathrm{H}_{2} \mathrm{CO}$ are enhanced in the CO-containing mixtures, while $\mathrm{CO}_{2}$ and $\mathrm{CO}$ are the species most affected by increases in fluence.

Among the complex products in Fig. $21 \mathrm{CHO}-$ and $\mathrm{COOH}-$ containing species are enhanced in the $\mathrm{CO}$ ice mixtures regardless of temperature, though $\mathrm{CH}_{3} \mathrm{CHO}$, is enhanced in the $\mathrm{CH}_{4}$-containing ices as well. The $\mathrm{CHO}$-containing molecules, except for $\mathrm{CH}_{3} \mathrm{CHO}$, thus trace $\mathrm{CO}$-rich $\mathrm{CH}_{3} \mathrm{OH}$ ices. In the $\mathrm{CH}_{3} \mathrm{OH}: \mathrm{CO}$ 1:10 mixture this enhancement of CHOand $\mathrm{COOH}$-bearing species is more extreme; only $\mathrm{CHO}-$ and $\mathrm{COOH}$-bearing complex species are detected and these have a total abundance of maximum $\sim 20 \%$ during warm-up. $\mathrm{CH}_{3} \mathrm{OCH}_{3}, \mathrm{CH}_{3} \mathrm{CH}_{2} \mathrm{OH}$ and $\mathrm{CH}_{3} \mathrm{CHO}$ are enhanced in the 


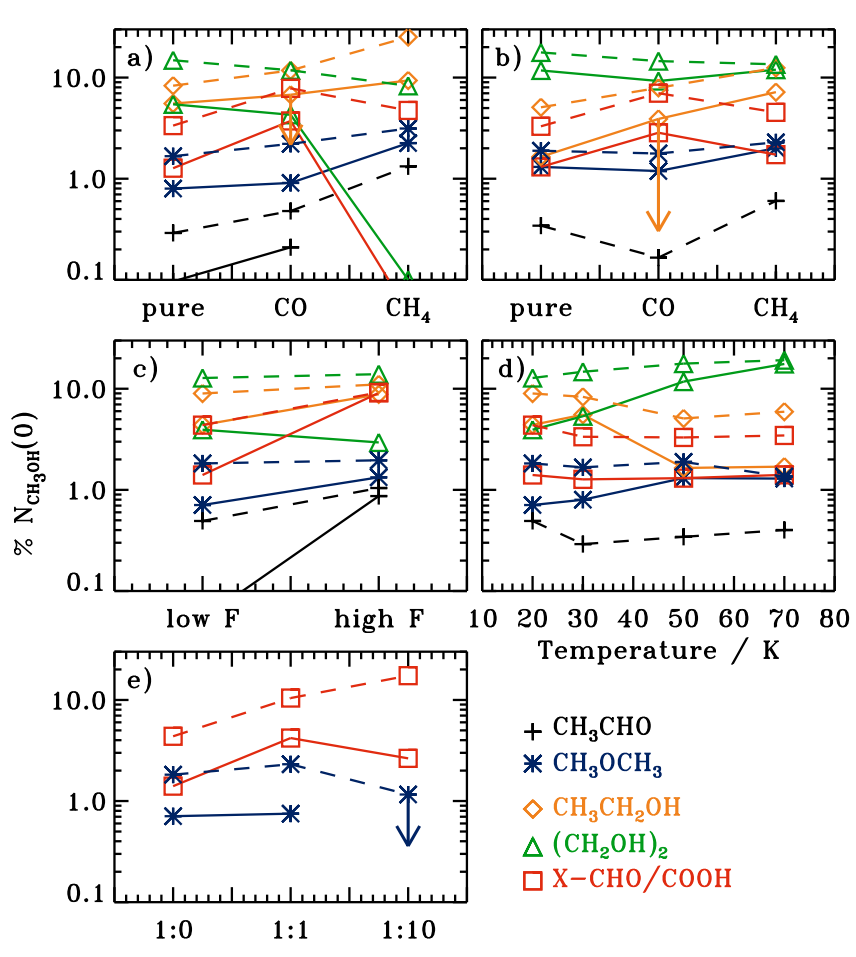

Fig. 21. The equivalent of Fig. 20 for the complex ice products, with the addition that the product abundances are shown both at the completion of irradiation (solid lines) and the maximum abundance reached during warm-up (dashed lines). The uncertainties are as in Fig. 17.

$\mathrm{CH}_{4}$ ice mixture at $30 \mathrm{~K}$, but this enhancement almost disappears at $50 \mathrm{~K}$, except for the case of $\mathrm{CH}_{3} \mathrm{CH}_{2} \mathrm{OH}$. Thus, $\mathrm{CH}_{3} \mathrm{CH}_{2} \mathrm{OH}$ is the most sensitive tracer of the addition of $\mathrm{CH}_{4}$ to the ice. Overall, the complex-product abundances do not change by more than a factor of $2-3$ in 1(2): 1 mixtures compared to pure $\mathrm{CH}_{3} \mathrm{OH}$ ice, nor between ices at different temperatures. However, the $\mathrm{X}-\mathrm{CHO}$ abundance increases by more than a factor of five in the $\mathrm{CH}_{3} \mathrm{OH}: \mathrm{CO}$ 1:10 mixture.

Of all detected complex molecules, $\left(\mathrm{CH}_{2} \mathrm{OH}\right)_{2}$ depends most steeply on ice temperature, especially in the ice mixtures; its abundance varies by almost an order of magnitude between experiments of different temperatures after UV irradiation of the ice is completed. The dependence is, however, significantly weakened by the time of desorption. Increasing the UV fluence increases the importance of $\mathrm{CH}_{3} \mathrm{CHO}$ and the other $\mathrm{CHO}$ and $\mathrm{COOH}$-bearing species. In contrast, the $\mathrm{CH}_{3}$-containing species are not affected by fluence, while the $\left(\mathrm{CH}_{2} \mathrm{OH}\right)_{2}$ abundance decreases somewhat, for a fluence increased from 2.4 to $9.6 \times 10^{17} \mathrm{~cm}^{-2}$.

Different molecular production rates are thus affected differently by changes in ice composition, temperature and UV fluence. These varied responses of molecular production rates to changes in the experimental conditions can be used both to derive chemical properties and to make astrophysical predictions on complex molecule production. This is one of the topics in Sects. 4 and 5 below.

\section{Discussion}

\subsection{Comparison with previous experiments}

The simple ice products found in this study at $20 \mathrm{~K}$ are qualitatively comparable to those found previously in UV irradiated pure $\mathrm{CH}_{3} \mathrm{OH}$ ices at $10-15 \mathrm{~K}$. Quantitatively, the relative amount of formed $\mathrm{CH}_{4}$ and $\mathrm{H}_{2} \mathrm{CO}$ are the same compared to Baratta et al. (2002), while an order of magnitude more $\mathrm{CO}$ and $\mathrm{CO}_{2}$ is reported by the end of their experiment. The $\mathrm{CO}$ and $\mathrm{CO}_{2}$ abundances are enhanced by a similar factor in Gerakines et al. (1996) compared to the the experiments presented here. The enhancement may be due to the higher UV fluence used in the previous studies, since the relative $\mathrm{CO}$ content increases in our ices with fluence. The high $\mathrm{CO}$ abundance may also be partly a result of investigating thick ices $(\sim 0.1-1 \mu \mathrm{m})$ in high vacuum chambers $\left(\sim 10^{-7} \mathrm{mbar}\right)$; the ice thickness reduces the escape probability of $\mathrm{CO}$ through photodesorption and the high vacuum (as opposed to ultra-high vacuum) increases the chance of contaminations, which may change the final ice composition. The formation cross sections of $\mathrm{CH}_{4}$ and $\mathrm{H}_{2} \mathrm{CO}$ presented in Sect. 3.6 agree with those reported by Gerakines et al. (1996) within the experimental uncertainties of $50 \%$. Thus, the overall agreement is good, between previous studies and the pure $\mathrm{CH}_{3} \mathrm{OH}$ photochemistry experiment at $20 \mathrm{~K}$ presented here.

Complex products are difficult to identify in both UV irradiated and ion-bombarded $\mathrm{CH}_{3} \mathrm{OH}$-rich ices, which has resulted in different assignments in the literature to the same bands, or simply no presentation of absolute complex product abundances. As discussed in the band-assignment section, more stringent criteria for band identification allow for both more secure and more numerous band identifications. The most important disagreements between this and previous studies are the assignments of $\mathrm{HCOOCH}_{3}$ and $\mathrm{CH}_{3} \mathrm{OCH}_{3}$ bands (Gerakines et al. 1996; Bennett et al. 2007). We agree with Bennett et al. (2007) on the assignments of bands to $\left(\mathrm{CH}_{2} \mathrm{OH}\right)_{2}$, but are hesitant with $\mathrm{HOCH}_{2} \mathrm{CHO}$ assignments in the $\mathrm{CH}_{3} \mathrm{OH}$-dominated ices, because of overlap with features from e.g. $\mathrm{HCOOH}$. However, $\mathrm{HOCH}_{2} \mathrm{CHO}$ may be produced more efficiently during ion bombardment than during UV irradiation, facilitating band identification; we do not find so sharp a band at the position of one of the $\mathrm{HOCH}_{2} \mathrm{CHO}$ bands as observed by Bennett et al. (2007) in their ion-bombardment study. No other complex molecules were identified in either study. Hudson \& Moore (2000) also tentatively detected $\left(\mathrm{CH}_{2} \mathrm{OH}\right)_{2}$ following proton bombardment of a $\mathrm{CH}_{3} \mathrm{OH}: \mathrm{H}_{2} \mathrm{O}$ mixture. Its formation appears prominent under a range of conditions.

Similarly to Bennett \& Kaiser (2007), we do observe bands of $\mathrm{HCOOCH}_{3}$ and $\mathrm{HOCH}_{2} \mathrm{CHO}$ in a $\mathrm{CO}$ dominated $\mathrm{CH}_{3} \mathrm{OH}$ ice mixture, indicating that overall the chemistry induced by UV radiation and ion bombardment is similar. $\mathrm{HOCH}_{2} \mathrm{CHO}$ was also tentatively detected by (Hudson et al. 2005) following UV irradiation of a CO: $\mathrm{CH}_{2} \mathrm{OH} \mathrm{100:1} \mathrm{ice} \mathrm{mixture,} \mathrm{though} \mathrm{more} \mathrm{work} \mathrm{is}$ required to confirm its formation under those conditions.

\subsection{Dependence of complex chemistry on experimental variables}

Section 3 showed that the final results of $\mathrm{CH}_{3} \mathrm{OH}$ photochemistry depend on the initial ice composition and the ice temperature during irradiation, but not on UV flux or ice thickness. The independence of ice thickness for the final abundances of complex species between 6 and 20 ML puts an upper limit on the efficiency of surface photochemistry versus bulk photochemistry. Employing a typical relative product abundance uncertainty of $10 \%$, the upper limit on a relative enhancement in the $6 \mathrm{ML}$ ice compared to the $20 \mathrm{ML}$ one is $\sqrt{2 \times 10^{2}} \sim 14 \%$. This puts an upper limit on excess production in the 6 top ML combined, while the upper limit on excess production in the very 
top layer is $6 \times 14 \sim 84 \%$. Surface reactions are therefore at most twice as efficient as bulk reactions in producing complex molecules. This does not directly limit surface diffusion, since photodesorption is efficient enough that many of the radicals and recombined products in the surface layers may escape, thus lowering the efficient surface yield. In fact the initial rates in the $6 \mathrm{ML}$ ices seem somewhat higher, though this difference is barely significant (Appendix C).

The independence of the ice chemistry on UV flux, i.e. the ice composition depends only on the total UV fluence at any time, suggests that the experiments operate in a regime where photodissociation is the rate-limiting step for production of complex organics. If the opposite were true, more complex molecules should form at the lower flux level after the same fluence, when radicals have had more time to diffuse and recombine. This may be counter-intuitive since diffusion is expected to be slow at $20 \mathrm{~K}$. It suggests that the chemistry, at least at low temperatures, is dominated by fast non-thermalized diffusion following photodissociation. This is consistent with the small differences in formation rates between 20 and $70 \mathrm{~K}-$ in cross-section terms, the formation rate increases by a factor of four or less for all complex organics. In contrast, formation rates dependent on thermal diffusion should change dramatically within this temperature regime since quantified segregation studies show that the thermal diffusion rate of molecules, such as $\mathrm{CO}_{2}$, changes by an order of magnitude between only 50 and $60 \mathrm{~K}$ (Öberg et al., submitted). The low production rate of complex organics during irradiation at $20 \mathrm{~K}$ in the $\mathrm{CH}_{3} \mathrm{OH}: \mathrm{CO}$ $1: 10$ ice mixture is also consistent with the expected fast thermalization, and thus short diffusion range, of photo-fragments with excess energy (Andersson \& van Dishoeck 2008). In this experiment it is instead thermal diffusion during warm-up that dominate the complex organic production.

Whether thermalized or non-thermalized diffusion drives the chemistry thus depends on a number of factors, including the concentration of radicals in the ice and the temperature during irradiation. To quantify the relative importance of thermalized and non-thermalized diffusion for specific radicals at different temperatures requires quantitative modeling of the complex molecule production during both the irradiation and the warm-up phases. Qualitatively, an increase in thermal diffusion with temperature is required to understand the observed four times higher $\left(\mathrm{CH}_{2} \mathrm{OH}\right)_{2}$ abundance and formation rate during irradiation at $70 \mathrm{~K}$ compared to $20 \mathrm{~K}$. Faster diffusion is also required to explain the immediate onset in formation of most molecules at high temperatures, compared to the short delay at $20 \mathrm{~K}$. Some molecular abundances, such as $\mathrm{CH}_{3} \mathrm{CH}_{2} \mathrm{OH}$, seem hardly affected by a change in ice temperature. Still it must form at least partly through diffusion of radicals since there is an abundance increase during warm-up. The insensitivity to ice temperature during irradiation may instead be due to increased competition between other reaction pathways once the $\mathrm{CH}_{2} \mathrm{OH}$ radical becomes mobile, especially to form $\left(\mathrm{CH}_{2} \mathrm{OH}\right)_{2}$, as is discussed further below. The complexity of these interactions makes it impossible to better quantify the dependence on ice temperature for ice photochemistry until a complete grid of models has been run, which is the topic of Paper II.

$\mathrm{CH}_{4}$ and $\mathrm{CO}$ are small molecules with a simple photodissociation chemistry: $\mathrm{CH}_{4}$ mainly loses an $\mathrm{H}$ to form $\mathrm{CH}_{3}$, though direct dissociation to $\mathrm{CH}_{2}$ is also possible (Romanzin et al. 2008), while CO does not photodissociate measurably with the UV lamp in this experiment (Öberg et al. 2007). Previous experiments show that $\mathrm{CO}$ can react with hydrogen to form $\mathrm{HCO}$, and with $\mathrm{OH}$ to form $\mathrm{CO}_{2}$ (Watanabe et al. 2003;
Hudson \& Moore 1999). Thus adding $\mathrm{CO}$ or $\mathrm{CH}_{4}$ to $\mathrm{CH}_{3} \mathrm{OH}$ ice should as a first approximation not add any reaction pathways, but only provide excess functional group radicals. Figure 21 shows that enriching the ice with these molecules also increases the importance of ice temperature on the final ice composition. $\left(\mathrm{CH}_{2} \mathrm{OH}\right)_{2}$ displays the most dramatic change; in the pure ice the final abundance changes by a factor of two between 30 and $50 \mathrm{~K}$, in the $\mathrm{CH}_{4}$ mixture the final abundance is an order of magnitude different at the two temperatures. This effect is mainly because less $\mathrm{CH}_{4}$ is retained in the $2: 1$ ice mixture at $50 \mathrm{~K}$ compared to $30 \mathrm{~K}$ even though the same mixtures were deposited. The same is true for $\mathrm{CO}$, where less than half of the originally deposited $\mathrm{CO}$ was trapped in the $50 \mathrm{~K}$ ice, resulting in less building material for HCO-containing species. This will be true in astrophysical ices as well and is therefore important to keep in mind, i.e. the building material of complex molecules will change with ice temperature also when the starting point is a typical interstellar ice mixture.

\section{3. $\mathrm{CH}_{3} \mathrm{OH}$ photochemistry reaction scheme}

When considering the possible chemistry induced in the $\mathrm{CH}_{3} \mathrm{OH}$ ice through UV irradiation it is necessary to chose a level of complexity to investigate, since theoretically the products can continue to dissociate and recombine into ever more complex species. In this qualitative analysis we choose to only consider the dissociation and recombination of first generation radicals from $\mathrm{CH}_{3} \mathrm{OH}$ dissociation, with one exception - the dissociation of $\mathrm{H}_{2} \mathrm{CO}$ into $\mathrm{HCO}$ and $\mathrm{CO}$ and its reaction to $\mathrm{CO}_{2}$. This path was included because it only results in smaller molecules that are easily detected and thus the kinetics can be modeled. In fact, the photodissociation track from $\mathrm{CH}_{2} \mathrm{OH} / \mathrm{CH}_{3} \mathrm{O}$ to $\mathrm{H}_{2} \mathrm{CO}$ and further to $\mathrm{HCO}$ and $\mathrm{CO}$ is an important strand of reactions to understand, since these are the only reactions that do not depend on diffusion and thus their production yields provide a clean measure of radical production due to photodissociation of small molecules and radicals. Qualitatively, the relative production rates of $\mathrm{CH}_{2} \mathrm{OH}, \mathrm{H}_{2} \mathrm{CO}, \mathrm{HCO}, \mathrm{CO}$ and $\mathrm{CO}_{2}$ agree well with the prediction of the reaction scheme that the observed normalized formation rates should decrease from one generation of species to the next (Fig. 16.)

Within this framework it is assumed that the vast majority of reactions consists of radical recombination without breaking of bonds i.e. no abstraction. This needs to be further tested through experiments and modeling, but so far there has been no reported evidence for abstraction in ice chemistry experiments.

Taking all this into account, Fig. 22 shows the proposed reaction scheme describing the formation of the observed species from photoproduced radicals. The scheme shares many features with previous ones considered by e.g. Garrod \& Herbst (2006). It starts with four possible photodissociation products of $\mathrm{CH}_{3} \mathrm{OH}$ that form from breaking one bond i.e. $\mathrm{CH}_{2} \mathrm{OH}, \mathrm{OCH}_{3}, \mathrm{CH}_{3}, \mathrm{OH}$ and $\mathrm{H}$ (the evidence for no direct dissociation to $\mathrm{H}_{2} \mathrm{CO}$ is discussed in Sect. 4.4). The formed radicals are then allowed to recombine into stable species or photo-dissociate further. This scheme should reproduce the chemistry in the ice at low fluences well. As the chemistry proceeds the destruction of complex molecules becomes important to obtain the observed equilibrium conditions and then a more elaborate reaction scheme is required to analyze the outcome.

Within the framework of Fig. 22, the final irradiated ice composition depends on both the production rate of each radical and the probability of two specific radicals finding each other and recombining in the ice. The radical production rate depends on 


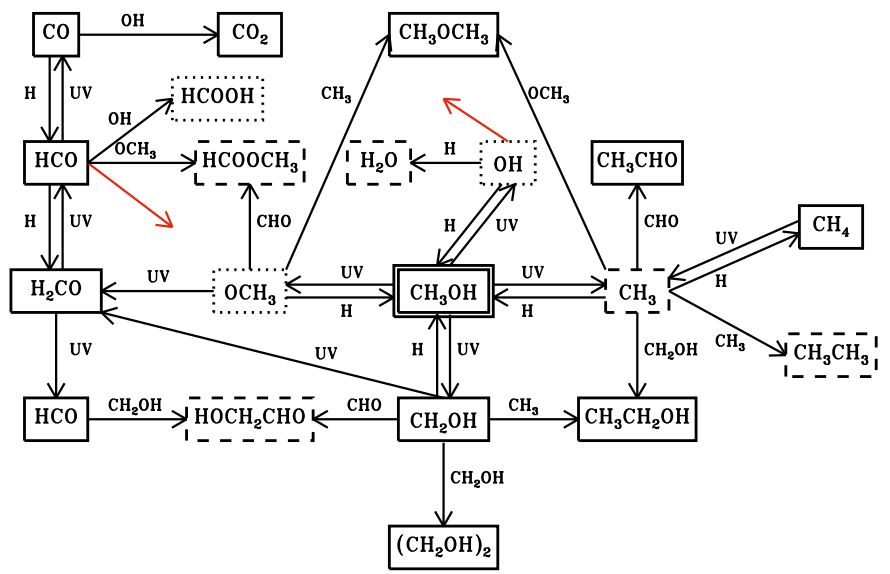

Fig. 22. The proposed reaction scheme to form the observed products following UV-irradiation of pure $\mathrm{CH}_{3} \mathrm{OH}$ ice (solid boxes), of $\mathrm{CO}$ or $\mathrm{CH}_{4}: \mathrm{CH}_{3} \mathrm{OH}$ ice mixtures (dashed boxes) and products whose production could only be constrained with upper limits (dotted boxes). Though not shown for clarity, all reactions can be reversed. The two red arrows indicate that the radicals in question take part in more reactions in other parts of the reaction scheme.

the UV flux, the photodissociation branching ratio and photodissociation cross section of $\mathrm{CH}_{3} \mathrm{OH}$, and the relative photodissociation rates of $\mathrm{CH}_{2} \mathrm{OH}, \mathrm{H}_{2} \mathrm{CO}$ and $\mathrm{HCO}$ into smaller species. Once produced, the radicals diffuse through the ice. The scheme shows that all complex molecules are formed in competition with several others that are formed from the same radicals. The recombination branching ratio of any one radical therefore depends both on the amount of other radicals and on their relative diffusion rates. As an example $\mathrm{CH}_{2} \mathrm{OH}$ can react with $\mathrm{H}, \mathrm{CH}_{3}$, $\mathrm{HCO}, \mathrm{OCH}_{3}$ and $\mathrm{CH}_{2} \mathrm{OH}$ as well as further dissociate to $\mathrm{H}_{2} \mathrm{CO}$. Whether dissociation or recombination occurs depends on both the UV flux and the diffusion rates of $\mathrm{CH}_{2} \mathrm{OH}$ and other radicals, and the amount of other radicals in the ice. At high UV fluxes and low temperatures further dissociation to $\mathrm{H}_{2} \mathrm{CO}$ and recombination with the volatile $\mathrm{H}$ to reform $\mathrm{CH}_{3} \mathrm{OH}$ should dominate. At slightly higher ice temperatures recombination with less volatile radicals will become competitive and finally, once $\mathrm{CH}_{2} \mathrm{OH}$ can diffuse through the ice, the $\mathrm{CH}_{2} \mathrm{OH}+\mathrm{CH}_{2} \mathrm{OH}$ pathway will dominate, since $\mathrm{CH}_{3} \mathrm{OH}$ ice photodissociation favors $\mathrm{CH}_{2} \mathrm{OH}$ production as shown in Sect. 4.4.

To quantify which reaction pathway dominates at which temperature and flux, requires a large self-consistent model (see Paper II). Already this simplified analysis shows that all observed molecules can be formed straightforwardly with a simple reaction scheme involving recombination of small radicals. This is promising for quantification of complex ice chemistry, both in the laboratory and in space.

\section{4. $\mathrm{CH}_{3} \mathrm{OH}$ photo-dissociation branching ratios}

UV photodissociation of $\mathrm{CH}_{3} \mathrm{OH}$ ice can theoretically result in several different products. Experiments and calculations have shown that $\mathrm{CH}_{3} \mathrm{OH}$ has multiple absorption bands in the range of our UV lamp, which are associated with fission of different bonds, producing the different radicals shown in Fig. 22 (e.g. Nee et al. 1985; Cheng et al. 2002). With a broadband UV lamp it is thus difficult to predict which dissociation fragments are formed and their relative importance.
While it is therefore not possible a priori to exclude any photodissociation pathways, the direct dissociation to form $\mathrm{H}_{2} \mathrm{CO}$ is however eliminated as an important dissociation pathway by the experiments. $\mathrm{H}_{2} \mathrm{CO}$ production depends dramatically on ice temperature, such that an order of magnitude less $\mathrm{H}_{2} \mathrm{CO}$ forms at $70 \mathrm{~K}$ compared to $20 \mathrm{~K}$. This is consistent with a two-step process where $\mathrm{CH}_{3} \mathrm{OH}$ is first photodissociated into $\mathrm{CH}_{3} \mathrm{O}$ or $\mathrm{CH}_{2} \mathrm{OH}$ followed by further photodissociation into $\mathrm{H}_{2} \mathrm{CO}$ dependent on the relative time scales of diffusion and UV absorption at a certain temperature. The strong temperature dependence is inconsistent with $\mathrm{H}_{2} \mathrm{CO}$ forming directly from $\mathrm{CH}_{3} \mathrm{OH}$ since then a large amount of $\mathrm{H}_{2} \mathrm{CO}$ should form at higher temperatures, similarly to $\mathrm{CH}_{4}$, which only requires a single photodissociation event followed by diffusion of $\mathrm{H}$ to form. The considered photodissociation channels for this discussion are then $\mathrm{CH}_{2} \mathrm{OH}+\mathrm{H}, \mathrm{OCH}_{3}+\mathrm{H}$ and $\mathrm{CH}_{3}+\mathrm{OH}$.

Without a complete model, the branching ratios cannot be calculated accurately, but inspection of the experimental results allows for some conclusions. Under the assumption that both the photodissociation cross sections of the formed $\mathrm{CH}_{3} \mathrm{OH}$ fragments and the rate at which they recombine with hydrogen are approximately the same, the amount of formed complex molecules can be used to assess the importance of different photodissociation pathways. First $\mathrm{CH}_{3} \mathrm{CH}_{2} \mathrm{OH}$ and $\mathrm{CH}_{3} \mathrm{OCH}_{3}$ both form through recombination of $\mathrm{CH}_{3}$ with $\mathrm{OCH}_{3}$ and $\mathrm{CH}_{2} \mathrm{OH}$, respectively. $\mathrm{CH}_{3}$ is predicted to be most mobile of the three radicals and thus its diffusion should determine the recombination rates of both complex molecules. The relative production rates of $\mathrm{CH}_{3} \mathrm{CH}_{2} \mathrm{OH}$ and $\mathrm{CH}_{3} \mathrm{OCH}_{3}$ should then to a first approximation only depend on the $\mathrm{OCH}_{3}: \mathrm{CH}_{2} \mathrm{OH}$ branching ratio during $\mathrm{CH}_{3} \mathrm{OH}$ photodissociation. The $\mathrm{CH}_{3} \mathrm{CH}_{2} \mathrm{OH} / \mathrm{CH}_{3} \mathrm{OCH}_{3}$ abundance ratio is consistently $4 \pm 2$ at all fluences, temperatures and ice compositions. The value derived from the $\mathrm{CH}_{4}$ ice mixture experiment at $30 \mathrm{~K}$ should describe the photodissociation branching ratio most accurate, since the enhancement of $\mathrm{CH}_{3}$ radicals minimizes the effect of different diffusion properties of $\mathrm{OCH}_{3}$ and $\mathrm{CH}_{2} \mathrm{OH}$. There the ratio is $5 \pm 1$.

The importance of the $\mathrm{CH}_{3}+\mathrm{OH}$ dissociation pathway is more difficult to asses. An upper limit can be estimated by comparing the detected $\left(\mathrm{CH}_{2} \mathrm{OH}\right)_{2}$ abundances and the upper limits on $\mathrm{C}_{2} \mathrm{H}_{6}$ at $30 \mathrm{~K}$ following irradiation of pure $\mathrm{CH}_{3} \mathrm{OH}$ ice. Since $\mathrm{CH}_{3}$ is more volatile than $\mathrm{CH}_{2} \mathrm{OH}$ and thus diffuses faster, more $\mathrm{C}_{2} \mathrm{H}_{6}$ will form per produced $\mathrm{CH}_{3}$ radical in the ice than $\left(\mathrm{CH}_{2} \mathrm{OH}\right)_{2}$ per produced $\mathrm{CH}_{2} \mathrm{OH}$ and thus the estimated upper limit will not be very strict. The observed $\left(\mathrm{CH}_{2} \mathrm{OH}\right)_{2}$ abundance to $\mathrm{C}_{2} \mathrm{H}_{6}$ upper limit is $\sim 40$ in this experiment. The abundance of each complex molecule depends on the radical abundance squared, which results in a total branching ratio of $\mathrm{CH}_{2} \mathrm{OH}: \mathrm{OCH}_{3}: \mathrm{CH}_{3}$ of $5 \pm 1: 1:<1$.

This effective photodissociation branching ratio of $\mathrm{CH}_{3} \mathrm{OH}$ ice is not necessarily equal to the branching ratio of gas phase $\mathrm{CH}_{3} \mathrm{OH}$ molecules. The effective branching ratio may favor the $\mathrm{CH}_{3}$ radical since hydrogenation of $\mathrm{CH}_{2} \mathrm{OH}$ and $\mathrm{OCH}_{3}$ results in $\mathrm{CH}_{3} \mathrm{OH}$, while $\mathrm{CH}_{3}$ hydrogenation produces $\mathrm{CH}_{4}$ that mainly photodissociates back into $\mathrm{CH}_{3}$. This may however be compensated for by a higher recombination rate of $\mathrm{CH}_{3}$ and $\mathrm{OH}$ than between the larger fragments and $\mathrm{H}$, since $\mathrm{H}$ will diffuse away from its dissociation partner faster. It is interesting to note that the calculated branching ratio is consistent with a purely statistical one, i.e. three different bond breaks result in $\mathrm{CH}_{2} \mathrm{OH}$ and one each in $\mathrm{CH}_{3}$ and $\mathrm{OCH}_{3}$. The model in Part II will further demonstrate whether this simple treatment of the branching ratio is valid. 


\subsection{Diffusion of radicals}

The diffusion barriers of all radicals involved in complex molecule formation can only be properly quantified by modeling the entire chemical network self-consistenly under different irradiation and warm-up conditions. The relative heights of diffusion barriers can however be estimated from the decrease of radical abundances and the increase of molecular abundances during warm-up of irradiated ices. Inspection of the warm-up plots in Fig. 19 together with the reaction scheme in Fig. 22 qualitatively shows that the products of the radicals in question, $\mathrm{H}, \mathrm{OH}, \mathrm{HCO}, \mathrm{CH}_{3}, \mathrm{OCH}_{3}$ and $\mathrm{CH}_{3} \mathrm{OH}$, depend differently on temperature.

The only radicals that are detected are $\mathrm{HCO}$ and $\mathrm{CH}_{2} \mathrm{OH}$. $\mathrm{HCO}$ clearly disappears faster of the two and thus has a lower diffusion barrier than $\mathrm{CH}_{2} \mathrm{OH}$. This is also evident when comparing $\left(\mathrm{CH}_{2} \mathrm{OH}\right)_{2}$ and $\mathrm{X}-\mathrm{CHO}$ production during warmup; the $\mathrm{X}-\mathrm{CHO}$ abundance does not increase beyond $80 \mathrm{~K}$, while $\left(\mathrm{CH}_{2} \mathrm{OH}\right)_{2}$ is produced up to at least $110 \mathrm{~K}$. $\mathrm{CH}_{3} \mathrm{OCH}_{3}$ and $\mathrm{CH}_{3} \mathrm{CH}_{2} \mathrm{OH}$ behave similarly during warm-up, though $\mathrm{CH}_{3} \mathrm{CH}_{2} \mathrm{OH}$ grows to slightly higher temperatures, suggesting that $\mathrm{CH}_{3}$ diffusion is the most important limiting step, but that $\mathrm{OCH}_{3}$ and $\mathrm{CH}_{2} \mathrm{OH}$ mobility matters as well. The $\mathrm{OCH}_{3}$ and $\mathrm{CH}_{2} \mathrm{OH}$ diffusion is even more important in reactions with $\mathrm{HCO}$; during warm-up of the $\mathrm{CH}_{3} \mathrm{OH}$ :CO 10:1 ice, $\mathrm{HCOOCH}_{3}$ forms at lower temperatures, and thus consumes most of the HCO, compared to $\mathrm{HOCH}_{2} \mathrm{CHO}$. The increased importance of the diffusion capabilities of the heavier radicals in reactions with $\mathrm{HCO}$ compared to $\mathrm{CH}_{3}$ suggest that the diffusion barrier for $\mathrm{HCO}$ is higher than for $\mathrm{CH}_{3}$. This is confirmed by the slightly lower formation temperature of $\mathrm{CH}_{3} \mathrm{OCH}_{3}$ and $\mathrm{CH}_{3} \mathrm{CH}_{2} \mathrm{OH}$ compared to $\mathrm{X}-\mathrm{CHO}$. The $\mathrm{OH}$ barrier is the only one that cannot be assessed since it is only involved in $\mathrm{CO}_{2}$ and $\mathrm{HCOOH}$ production. $\mathrm{HCOOH}$ is not uniquely identified and $\mathrm{CO}_{2}$ production may instead be limited by $\mathrm{CO}$ diffusion. Combining the above results the relative diffusion barriers increases as $\mathrm{H}<\mathrm{CH}_{3}<\mathrm{HCO}<\mathrm{OCH}_{3}<\mathrm{CH}_{2} \mathrm{OH}$. This is in qualitative agreement with the assumptions by Garrod et al. (2008).

These relative diffusion barriers, together with the dissociation branching ratios and the observed dependences on ice composition are used below to test a possibility of an ice origin of observed complex molecules in different astrophysical environments.

\section{Astrophysical implications}

\subsection{Potential importance of photochemistry around protostars}

$\mathrm{CH}_{3} \mathrm{OH}$ ice probably forms in dense cloud cores; it is absent from the cloud edges, but often abundant towards protostars. This is in contrast to for example $\mathrm{CO}_{2}$ and $\mathrm{H}_{2} \mathrm{O}$ ice, which are present already at a few $A_{\mathrm{V}}$ in dark clouds. Because of its formation deep into the cloud, the $\mathrm{CH}_{3} \mathrm{OH}$ ice is shielded from external UV irradiation during most of its lifetime. A conservative test of whether enough radicals can be produced from irradiated $\mathrm{CH}_{3} \mathrm{OH}$ ice to account for observations of complex molecules should then only include the locally produced UV field inside the cloud core from cosmic ray interactions with $\mathrm{H}_{2}$. This cosmic-ray induced UV field results in an approximate flux of $10^{4} \mathrm{~cm}^{-2} \mathrm{~s}^{-1}$ (Shen et al. 2004). During a million years in the cloud core $\mathrm{CH}_{3} \mathrm{OH}$ ice is thus exposed to a fluence of $3 \times 10^{17} \mathrm{~cm}^{-2}$, which is the same as the final fluence in most of the experiments here, where more than $50 \%$ of the $\mathrm{CH}_{3} \mathrm{OH}$ is destroyed. Previous experiments at $10 \mathrm{~K}$ and the irradiated ice experiments at $20 \mathrm{~K}$ here show that of the radicals formed from photodissociation, a large fraction is either further dissociated or hydrogenated to form simpler species than $\mathrm{CH}_{3} \mathrm{OH}$. In this study $\sim 25 \%$ of the destroyed $\mathrm{CH}_{3} \mathrm{OH}$ is converted into simpler molecules at $20 \mathrm{~K}$, but up to $50 \%$ in previous studies (Gerakines et al. 1996). The amount of "frozen in" radicals may be further reduced in astrophysical environments, where hydrogen atoms accrete onto the ice surface and re-hydrogenate radicals. Hydrogenation studies of $\mathrm{O}_{2}$ and $\mathrm{CO}$ have revealed that the hydrogen penetration depth at $10-15 \mathrm{~K}$ is limited to the top few monolayers (Ioppolo et al. 2008, Fuchs et al. A\&A in press) and re-hydrogenation will therefore mainly affect predictions of the complex chemistry on the ice surface. The radical formation rates in $\mathrm{CH}_{3} \mathrm{OH}$ ices thicker than a few monolayers and in $\mathrm{CH}_{3} \mathrm{OH}$ ices covered by $\mathrm{CO}$ ice should not be significantly perturbed by this effect.

More than $50 \%$ of the photodissociated $\mathrm{CH}_{3} \mathrm{OH}$ ice may thus result in "frozen in" radicals or complex molecule formation at the dark cloud stage. Once the radicals become mobile following cloud core collapse and the turn-on of the protostar, the approximate complex molecule to $\mathrm{CH}_{3} \mathrm{OH}$ ice abundance ratio is $25 \%$, since each complex molecule forms from two $\mathrm{CH}_{3} \mathrm{OH}$ fragments. This is assuming $\mathrm{CH}_{3} \mathrm{OH}$ is the precursor of all complex O-bearing organics. The fraction of complex molecules in the ice will increase if $\mathrm{CH}_{4}, \mathrm{H}_{2} \mathrm{O}, \mathrm{CO}$ and $\mathrm{CO}_{2}$ ice take part in the photochemistry, which will depend on the structure of the ice. The ratio will also increase in protostellar envelopes if the effects of the enhanced UV-radiation field from the star are included for ices in the inner parts.

Laboratory data on ice photochemistry thus predict that a large fraction of $\mathrm{CH}_{3} \mathrm{OH}$ will be converted into more complex molecules during the pre- and proto-stellar stages. This can be compared with observations. The sum of detected oxygen-rich complex molecule abundances is approximately 50\% with respect to the $\mathrm{CH}_{3} \mathrm{OH}$ abundances in hot cores (Bisschop et al. 2007b) and closer to $10-20 \%$ in other sources rich in complex molecules. Photochemistry in ices thus provide the right order of magnitude of complex ice species compared to what is observed in regions where ice desorption has occurred. This does not prove that the observed complex molecules have an ice origin, but quantified experimental results do provide a way to test this.

\subsection{Abundance ratios as formation condition diagnostics}

The analysis of the complex ice composition following irradiation in the laboratory can be used to test an ice formation scenario for complex species in star-forming regions. The first piece of information from the warm-up plots is that the ice temperature during irradiation only has a limited effect on most complex ice abundances at the time of desorption. Thus in protostellar envelopes with large $\mathrm{CH}_{3} \mathrm{OH}$ ice fractions, where the complex ice chemistry is dominated by pure $\mathrm{CH}_{3} \mathrm{OH}$ chemistry, similar relative fractions of complex ices would be expected in the gas phase over a large range of objects if only thermal desorption is assumed. If on the other hand the entire lifetime of the ice can be sampled by non-thermal desorption, temperature effects on the ice composition may be observed. This temperature effect will be especially clear if the coldest parts are still dominated by a CO-rich $\mathrm{CH}_{3} \mathrm{OH}$ ice, which is predicted to favor an $\mathrm{HCO}$ rich complex chemistry. However, parts of the complex ice product composition seem robust to a range of physical conditions and can therefore be used to test formation scenarios without 
Table 6. Abundances of complex molecules relative to $\mathrm{CH}_{3} \mathrm{OH}$.

\begin{tabular}{lccccccc}
\hline \hline & IRAS 16293-2422/A $\mathrm{A}^{a, b}$ & Hot cores $^{c}$ & L1157 $^{d}$ & MC G-0.02 & Hale-Bopp & CH $_{3} \mathrm{OH}^{g}$ & $\mathrm{CH}_{3} \mathrm{OH}^{e} \mathrm{CO}^{g}$ \\
\hline $\mathrm{CH}_{3} \mathrm{OH}$ & $1 / 1$ & 1 & 1 & 1 & 1 & 1 & 1 \\
$\mathrm{CH}_{3} \mathrm{CHO}$ & $0.038 /<0.0016$ & $2.9[3.1] \times 10^{-5}$ & - & 0.033 & 0.010 & 0.01 & $<0.04$ \\
$\mathrm{CH}_{3} \mathrm{CH}_{2} \mathrm{OH}$ & $-/ 0.031$ & $0.019[0.012]$ & 0.007 & 0.040 & $<0.042$ & 0.1 & $<0.01$ \\
$\mathrm{CH}_{3} \mathrm{OCH}_{3}$ & $0.20 / 0.013$ & $0.41[0.51]$ & - & 0.050 & - & 0.04 & $<0.01$ \\
$\mathrm{HCOOCH}_{3}$ & $0.30 / 0.0084$ & $0.089[0.084]$ & 0.019 & 0.037 & 0.033 & $<0.03$ & $>0.08$ \\
$\mathrm{HOCH}_{2} \mathrm{CHO}$ & $-/-$ & - & - & 0.01 & $<0.017$ & $<0.04$ & $>0.04$ \\
$\left(\mathrm{CH}_{2} \mathrm{OH}\right)_{2}$ & $-/-$ & - & - & 0.01 & 0.10 & 0.4 & $<0.01$ \\
\hline
\end{tabular}

${ }^{a}$ The first value is from single dish data, the second from interferometric studies of the A core. ${ }^{b}$ Cazaux et al. (2003); Huang et al. (2005); Bisschop et al. (2008) and van Dishoeck \& Herbst (2009). ${ }^{c}$ Average data and standard deviations towards a sample of seven high-mass hot cores (Bisschop et al. 2008). ${ }^{d}$ Arce et al. (2008). ${ }^{e}$ Requena-Torres et al. $(2006,2008) .{ }^{f}$ Crovisier et al. (2004). ${ }^{g}$ The relative abundance with respect to $\mathrm{CH}_{3} \mathrm{OH}$ during warm-up of an irradiated $20 \mathrm{~K}$ pure $\mathrm{CH}_{3} \mathrm{OH}$ ice and a $\mathrm{CH}_{3} \mathrm{OH}: \mathrm{CO}$ 1:10 ice mixture.

making assumptions about the original ice composition or the ice-desorption mechanism.

Regardless of mixture composition and ice temperature, the $\mathrm{CH}_{3} \mathrm{CH}_{2} \mathrm{OH}$ and $\mathrm{CH}_{3} \mathrm{OCH}_{3}$ ratio is constant in the experiments and it is thus expected to be constant in astrophysical environments as well, even though the ratio of 5 to 1 may not be reproduced in interstellar regions because of different time scales, desorption temperatures and gas phase destruction rates. The ratio may also be affected by hot gas-phase chemistry around high mass protostars. Indeed, the detected abundances of $\mathrm{CH}_{3} \mathrm{OCH}_{3}$ may be strongly affected by gas-phase processes; Garrod et al. (2008) found that gas-phase formation of this molecule, following the evaporation of methanol, is efficient, even with conservative rate estimates. Thus the $\mathrm{CH}_{3} \mathrm{CH}_{2} \mathrm{OH}$ and $\mathrm{CH}_{3} \mathrm{OCH}_{3}$ ratio can only be used directly as an ice chemistry test where the gas phase processing is negligible.

Similarly, the $\mathrm{HCOOCH}_{3}$ and $\mathrm{HOCH}_{2} \mathrm{CHO}$ ratio changes little with ice composition, though it does depend on ice temperature. Thus, while detailed modeling of absolute ratios of this pair of molecules is saved for Paper II, strong correlations between such pairs of molecules towards different astrophysical objects would support the idea that ice photochemistry followed by desorption is responsible for gas phase organics.

In contrast, the $\mathrm{CH}_{3} \mathrm{CH}_{2} \mathrm{OH}, \mathrm{HOCH}_{2} \mathrm{CHO}$ and $\left(\mathrm{CH}_{2} \mathrm{OH}\right)_{2}$ relative abundances at the time of ice desorption vary with ice temperature during irradiation and composition even on laboratory time scales. They range between $1:<1: 1\left(\mathrm{CH}_{3} \mathrm{OH}: \mathrm{CO} 1: 1\right.$, $30 \mathrm{~K}$ ), $2:<1: 10$ (pure $\mathrm{CH}_{3} \mathrm{OH} 70 \mathrm{~K}$ ), 10: $<1: 4\left(\mathrm{CH}_{3} \mathrm{OH}: \mathrm{CH}_{4}\right.$ $1: 2,30 \mathrm{~K})$ and $<1: 8:<1\left(\mathrm{CH}_{3} \mathrm{OH}: \mathrm{CO} 1: 1020 \mathrm{~K}\right)$ (Fig. 21). Of these product compositions, the pure $\mathrm{CH}_{3} \mathrm{OH}$ and the different $\mathrm{CO}$ mixtures are perfectly plausible astrophysical compositions since $\mathrm{CH}_{3} \mathrm{OH}$ is proposed to form from $\mathrm{CO}$ ice. The relative abundances of these three complex molecules can thus potentially be used to investigate when and under which conditions complex molecules form in different astrophysical objects, when an ice formation route has been established. This is pursued qualitatively below though there is a general lack of statistical samples that contain the diagnostically most valuable abundances.

The experiments did not consider the photochemistry of $\mathrm{H}_{2} \mathrm{O}: \mathrm{CH}_{3} \mathrm{OH}$ ice mixtures because the expected formation path of $\mathrm{CH}_{3} \mathrm{OH}$ from $\mathrm{CO}$ in astrophysical environments. Once the original ice heats up, mixing between the $\mathrm{H}_{2} \mathrm{O}$ and $\mathrm{CO}$-rich ice phase may however occur at a similar time scale as radical diffusion within the $\mathrm{CO}: \mathrm{CH}_{3} \mathrm{OH}$ ice, resulting in a different complex product composition than expected from radical reactions within the $\mathrm{CO}: \mathrm{CH}_{3} \mathrm{OH}$ phase. In a $\mathrm{H}_{2} \mathrm{O}$-rich environment, some of the $\mathrm{CH}_{3} \mathrm{OH}$ photodissociation fragments should react with
$\mathrm{OH}$ rather than other $\mathrm{CH}_{3} \mathrm{OH}$ fragments, forming species such as $\mathrm{HOCH}_{2} \mathrm{OH}$. Observations of $\mathrm{OH}$-rich complex species together with a quantification of the mixed $\mathrm{H}_{2} \mathrm{O}: \mathrm{CH}_{3} \mathrm{OH}$ and the layered $\mathrm{CH}_{3} \mathrm{OH} / \mathrm{H}_{2} \mathrm{O}$ chemistry may therefore provide constraints both on the initial ice composition and the efficiency of ice mixing in the protostellar stage.

\subsection{Comparison with astrophysical sources}

Complex molecules have been detected in the gas phase towards a variety of astrophysical environments. Table 6 lists the detected abundances towards a low-mass protostar IRAS 16293-2422, a sample of high-mass protostars, a low-mass outflow L1157, a galactic-center cloud MC G-0.02 and the comet Hale-Bopp. Typical uncertainties are factors of a few, but can be larger along some lines of sight.

Overall, complex-molecule abundances vary by less than an order of magnitude, with respect to $\mathrm{CH}_{3} \mathrm{OH}$, within these dramatically different astrophysical environments. For example the $\mathrm{CH}_{3} \mathrm{CH}_{2} \mathrm{OH} / \mathrm{CH}_{3} \mathrm{OH}$ ratio varies between 0.02 and 0.04 (Table 6). This suggests a formation scenario where reaction barriers are not rate determining, in agreement with an ice photochemistry scenario.

Focusing on specific ratios, the $\mathrm{HOCH}_{2} \mathrm{CHO}$ to $\mathrm{HCOOCH}_{3}$ ratio is only available in one of these environments and therefore not possible to use as a test. The $\mathrm{CH}_{3} \mathrm{CH}_{2} \mathrm{OH}$ to $\mathrm{CH}_{3} \mathrm{OCH}_{3}$ ratio is unity within the observational uncertainties towards the IRAS 16293-2422 core and the galactic center sources, but it is an order of magnitude lower in the high-mass hot core sample. This may be due to a more extended temperature gradient in the hot core objects, which would increase the importance of $\mathrm{CH}_{3} \mathrm{OCH}_{3}$ release into the gas phase at lower temperatures and thus over a larger volume. It may also be the result of gas phase chemistry modifying the released ice abundances. The physics of these objects thus needs to be addressed and more molecules observed, to confirm an ice origin of these complex molecules.

Another interesting ratio is the $\mathrm{CH}_{3} \mathrm{CHO}$ to $\mathrm{CH}_{3} \mathrm{CH}_{2} \mathrm{OH}$ one, which varies by two orders of magnitude between the different objects (Table 6). In addition, an interferometric study has revealed spatial separations between these two species around the protostar IRAS 16293-2422 (Bisschop et al. 2008). Part of this may be due to different destruction efficiencies of $\mathrm{CH}_{3} \mathrm{CHO}$ towards different objects. It is however difficult to explain such a lack of correlation with a more traditional ice formation scenario of complex molecules, through successive hydrogenation and oxygenation of small carbon chains. In such a reaction network $\mathrm{CH}_{3} \mathrm{CHO}$ and $\mathrm{CH}_{3} \mathrm{CH}_{2} \mathrm{OH}$ are formed under the same conditions. In contrast, photochemistry of ices does not predict a 
correlation between $\mathrm{CH}_{3} \mathrm{CH}_{2} \mathrm{OH}$ and $\mathrm{CH}_{3} \mathrm{CHO}$ since $\mathrm{CH}_{3} \mathrm{CHO}$ formation may not even require $\mathrm{CH}_{3} \mathrm{OH}$ as a starting point (Moore et al. 2003), while $\mathrm{CH}_{3} \mathrm{CH}_{2} \mathrm{OH}$ does.

The abundances of $\mathrm{CHO}$-containing species are in general expected to vary between different astrophysical objects in the ice-photochemistry scenario because of their large enhancements in CO-rich and thus colder ices. Comparing the different types of sources in Table 6, only the single dish observations towards IRAS 16293 contain more $\mathrm{HCOOCH}_{3}$ than $\mathrm{CH}_{3} \mathrm{OCH}_{3}$ or $\mathrm{CH}_{3} \mathrm{CH}_{2} \mathrm{OH}$. This suggests that the complex molecules in the colder areas of IRAS 16293 are formed in a more CO-rich ice matrix than towards the warmer sources, which is consistent with the high volatility of $\mathrm{CO}$. The uncertainties are yet too high for any conclusive comparison, however.

Quantitatively, the pure $\mathrm{CH}_{3} \mathrm{OH}$ experimental results are in closest agreement with the ice desorption found in Hale-Bopp. This may not be too surprising, since these observations are less affected by gas-phase reactions that can both form and destroy complex molecules. It may also be a sign of a warmer formation path compared to most larger-scale astrophysical objects, and thus an insignificant $\mathrm{CO}$ ice content. The almost one-toone correlation is tentative evidence that cometary ices have reached their current composition through ice photochemistry, though both more cometary observations and actual modeling of their chemical evolution are necessary to evaluate whether this holds in general. The formation and destruction mechanisms around massive protostars are clearly too complicated to evaluate the origins of complex molecules there directly, without a more complete gas-grain model. In addition, time-scale effects may be significant for all astrophysical abundances compared to those found in the laboratory. It is, however, reassuring that the interferometric study towards the low mass protostar IRAS 16293, where high-temperature gas-phase reactions should be of less importance, agrees reasonably well with our experiments. Observations of $\mathrm{HOCH}_{2} \mathrm{CHO}$ and $\left(\mathrm{CH}_{2} \mathrm{OH}\right)_{2}$ towards IRAS 16293 and other low-mass protostars would probably provide the strongest constraints available on the prevalence of UV-ice photochemistry in star-forming regions.

\section{Conclusions}

The major experimental and analytical results of this study are summarized below:

1. The $\mathrm{CH}_{3} \mathrm{OH}$ ice photodissociation cross section increases from 2.6[0.9] to $3.9[1.3] \times 10^{-18} \mathrm{~cm}^{2}$ between 20 and $70 \mathrm{~K}$ suggesting that a significant amount of the dissociated fragments recombines immediately to form $\mathrm{CH}_{3} \mathrm{OH}$ at $20 \mathrm{~K}$ when radical diffusion in ices is slower.

2. $\mathrm{CH}_{3} \mathrm{OH}$ ice photodesorbs with a yield of $2.1[1.0] \times 10^{-3}$ per incident UV photon at $20 \mathrm{~K}$. The yield is independent of temperature and of the same order as the yields found previously for $\mathrm{CO}-, \mathrm{CO}_{2}$ - and $\mathrm{H}_{2} \mathrm{O}$-ice photodesorption.

3. UV photolysis of 6-21 ML pure $\mathrm{CH}_{3} \mathrm{OH}$ ice at $20-70 \mathrm{~K}$ results in a product mixture of simple and complex molecules, whose abundances have been quantified. The identified species are $\mathrm{CO}, \mathrm{CO}_{2}, \mathrm{CH}_{4}, \mathrm{HCO}, \mathrm{H}_{2} \mathrm{CO}, \mathrm{CH}_{2} \mathrm{OH}$, $\mathrm{CH}_{3} \mathrm{CHO}, \mathrm{CH}_{3} \mathrm{OCH}_{3}, \mathrm{CH}_{3} \mathrm{CH}_{2} \mathrm{OH},\left(\mathrm{CH}_{2} \mathrm{OH}\right)_{2}$ and a mixture of complex $\mathrm{CHO}-$ and $\mathrm{COOH}-$ containing molecules. The small temperature dependence may be explained by fast diffusion and recombination of non-thermalized radicals following $\mathrm{CH}_{3} \mathrm{OH}$ photo-dissociation.

4. The final product composition following $\mathrm{CH}_{3} \mathrm{OH}$ photolysis depends on UV fluence and temperature, but not on the UV flux level or the ice thickness when both are varied by a factor 3-4.

5. In $\mathrm{CH}_{3} \mathrm{OH}: \mathrm{CO}$ and $\mathrm{CH}_{3} \mathrm{OH}: \mathrm{CH}_{4}$ 1:1(2) mixtures the complex molecules containing $\mathrm{HCO}-$ and $\mathrm{CH}_{3}$ groups are moderately enhanced following UV irradiation compared to pure $\mathrm{CH}_{3} \mathrm{OH}$ ice photolysis. In an irradiated $\mathrm{CO}: \mathrm{CH}_{3} \mathrm{OH}$ 10:1 ice mixture, the $\mathrm{HCO}$-containing products dominate and both $\mathrm{HCOOCH}_{3}$ and $\mathrm{HOCH}_{2} \mathrm{CHO}$ are detected as the originally $20 \mathrm{~K}$ ice is warmed up. With the exception of this ice the final complex product mixture is robust within a factor of few in all different experiments.

6. Additional formation of complex molecules occurs following irradiation at 20-70 K, when all ices are slowly heated with the UV lamp turned off; some abundances increase by up to a factor of ten between 20 and $100 \mathrm{~K}$. Diffusion of thermalized radicals through the ice is thus important for complex molecule formation.

7. From abundance ratios of related products, formed during UV-irradiation of $\mathrm{CH}_{3} \mathrm{OH}$-rich ices, we infer an approximate $\mathrm{CH}_{3} \mathrm{OH}$ photodissociation branching ratio into $\mathrm{CH}_{2} \mathrm{OH}+\mathrm{H}: \mathrm{OCH}_{3}+\mathrm{H}: \mathrm{CH}_{3}+\mathrm{OH}$ of $5: 1:<1$

8. From the peak formation temperature of related molecules during warm-up, we find that the relative radical diffusion barriers increase as $\mathrm{H}<\mathrm{CH}_{3}<\mathrm{HCO}<\mathrm{OCH}_{3}<\mathrm{CH}_{2} \mathrm{OH}$. While the mobility of the radical with the lowest barrier is most important in determining the formation temperature of the product, the diffusion barrier of the heavier radical matters as well. For example $\mathrm{HCOOCH}_{3}$ forms at a lower temperature (from $\mathrm{HCO}$ and $\mathrm{OCH}_{3}$ ) than $\mathrm{HOCH}_{2} \mathrm{CHO}$ (from $\mathrm{HCO}$ and $\mathrm{CH}_{2} \mathrm{OH}$ ).

9. The predicted sum of oxygen-rich complex molecules compared to $\mathrm{CH}_{3} \mathrm{OH}$ in ices is $>25 \%$ after a UV fluence corresponding to 6 million years in a cloud core, followed by moderate ice heating to $30-50 \mathrm{~K}$ during the protostellar stage, though quantitative modeling is required to test the competition between radical diffusion, desorption, dissociation and recombination on astrophysical time scales.

10. Some complex molecular ratios, especially $\mathrm{CH}_{3} \mathrm{CH}_{2} \mathrm{OH}$ to $\mathrm{CH}_{3} \mathrm{OCH}_{3}$, do not depend significantly on experimental conditions and may thus to be constant in space as well, if gas-phase effects do not dominate. If quantitative modeling confirm this prediction, these ratios can be used to test the UV-induced ice formation scenario of complex molecules in astrophysical regions. Other ratios, such as $\left(\mathrm{CH}_{2} \mathrm{OH}\right)_{2} / \mathrm{CH}_{3} \mathrm{CH}_{2} \mathrm{OH}$ and $\mathrm{HCOOCH}_{3} / \mathrm{CH}_{3} \mathrm{CH}_{2} \mathrm{OH}$, depend both on the irradiated ice composition and the ice temperature and can therefore be used to investigate the formation conditions of observed complex molecules.

11. Comparison with astrophysical objects shows that the composition of complex ices in the Comet Hale-Bopp is readily explained by $\mathrm{UV}$ photolysis of of pure $\mathrm{CH}_{3} \mathrm{OH}$ ice, while $\mathrm{CH}_{3} \mathrm{OH}$ in a $\mathrm{CO}$-dominated ice can explain the variations in the $\mathrm{HCOOCH}_{3}$ and $\mathrm{CH}_{3} \mathrm{CHO}$ abundances between cold and warmer regions of protostars.

This study shows that complex ice chemistry can be quantified, though the process of doing so is more arduous than qualitative work. The discussed dependencies of molecule formation on different ice conditions show the impossibility of perfectly simulating the astrophysical ice evolution in the laboratory, especially since physical conditions vary in space as well. It is, however, possible to study ice processes under specific laboratory conditions, which through careful modeling (Paper II) can provide the energy barriers that govern these reactions both in the laboratory 
and in star forming regions. These can then be used to model ice chemistry in all possible astrophysical environments.

Acknowledgements. The authors wish to thank Herma Cuppen for stimulating discussions and Lou Allamandola, Ted Bergin and Eric Herbst for valuable comments on the manuscript. Funding is provided by NOVA, the Netherlands Research School for Astronomy, a grant from the European Early Stage Training Network ("EARA" MEST-CT-2004-504604) and a Netherlands Organisation for Scientific Research (NWO) Spinoza grant.

\section{References}

Acharyya, K., Fuchs, G. W., Fraser, H. J., van Dishoeck, E. F., \& Linnartz, H. 2007, A\&A, 466, 1005

Acquista, N., Schoen, L. J., \& David, R. Lide, J. 1968, J. Chem. Phys., 48, 1534

Allamandola, L. J., Sandford, S. A., \& Valero, G. J. 1988, Icarus, 76, 225

Andersson, S., \& van Dishoeck, E. F. 2008, A\&A, 491, 907

Arce, H. G., Santiago-García, J., Jørgensen, J. K., Tafalla, M., \& Bachiller, R. 2008, ApJ, 681, L21

Baratta, G. A., Leto, G., \& Palumbo, M. E. 2002, A\&A, 384, 343

Belloche, A., Garrod, R. T., Mueller, H. S. P., et al. 2009, ArXiv e-prints

Bennett, C. J., \& Kaiser, R. I. 2007, ApJ, 661, 899

Bennett, C. J., Chen, S.-H., Sun, B.-J., Chang, A. H. H., \& Kaiser, R. I. 2007, ApJ, 660, 1588

Bergin, E. A., Melnick, G. J., Gerakines, P. A., Neufeld, D. A., \& Whittet, D. C. B. 2005, ApJ, 627, L33

Bisschop, S. E., Fuchs, G. W., van Dishoeck, E. F., \& Linnartz, H. 2007a, A\&A, 474, 1061

Bisschop, S. E., Jørgensen, J. K., van Dishoeck, E. F., \& de Wachter, E. B. M. 2007b, A\&A, 465, 913

Bisschop, S. E., Jørgensen, J. K., Bourke, T. L., Bottinelli, S., \& van Dishoeck, E. F. 2008, A\&A, 488, 959

Blake, G. A., Sutton, E. C., Masson, C. R., \& Phillips, T. G. 1987, ApJ, 315, 621

Boogert, A. C. A., Schutte, W. A., Helmich, F. P., Tielens, A. G. G. M., \& Wooden, D. H. 1997, A\&A, 317, 929

Bottinelli, S., Ceccarelli, C., Lefloch, B., et al. 2004, ApJ, 615, 354

Bottinelli, S., Ceccarelli, C., Williams, J. P., \& Lefloch, B. 2007, A\&A, 463, 601

Cazaux, S., Tielens, A. G. G. M., Ceccarelli, C., et al. 2003, ApJ, 593, L51

Charnley, S. B. 2004, Adv. Space Res., 33, 23

Charnley, S. B., Tielens, A. G. G. M., \& Millar, T. J. 1992, ApJ, 399, L71

Cheng, B.-M., Bahou, M., Chen, W.-C., et al. 2002, J. Chem. Phys., 117, 1633

Collings, M. P., Anderson, M. A., Chen, R., et al. 2004, MNRAS, 354, 1133

Cottin, H., Moore, M. H., \& Bénilan, Y. 2003, ApJ, 590, 874

Crovisier, J., Bockelée-Morvan, D., Biver, N., et al. 2004, A\&A, 418, L35

D'Hendecourt, L. B., \& Allamandola, L. J. 1986, A\&AS, 64, 453

D'Hendecourt, L. B., Allamandola, L. J., Baas, F., \& Greenberg, J. M. 1982, A\&A, 109, L12

Fuchs, G. W., Acharyya, K., Bisschop, S. E., et al. 2006, Faraday Discussions, 133,331

Galabov, B., Yamaguchi, Y., Remington, R. B., \& Schaefer, H. F. 2002, J. Phys. Chem. A, 106, 819

Garrod, R. T., \& Herbst, E. 2006, A\&A, 457, 927

Garrod, R. T., Wakelam, V., \& Herbst, E. 2007, A\&A, 467, 1103

Garrod, R. T., Weaver, S. L. W., \& Herbst, E. 2008, ApJ, 682, 283

Gerakines, P. A., Schutte, W. A., Greenberg, J. M., \& van Dishoeck, E. F. 1995 A\&A, 296, 810
Gerakines, P. A., Schutte, W. A., \& Ehrenfreund, P. 1996, A\&A, 312, 289

Gibb, E. L., Whittet, D. C. B., Boogert, A. C. A., \& Tielens, A. G. G. M. 2004, ApJS, 151, 35

Hagen, W., Allamandola, L. J., \& Greenberg, J. M. 1979, Ap\&SS, 65, 215

Herbst, E., \& van Dishoeck, E. F. 2009, ARA\&A, 47, 427

Horn, A., Møllendal, H., Sekiguchi, O., et al. 2004, ApJ, 611, 605

Huang, H.-C., Kuan, Y.-J., Charnley, S. B., et al. 2005, Adv. Space Res., 36, 146

Hudson, R. L., \& Moore, M. H. 1999, Icarus, 140, 451

Hudson, R. L., \& Moore, M. H. 2000, Icarus, 145, 661

Hudson, R. L., Moore, M. H., \& Cook, A. M. 2005, Adv. Space Res., 36, 184

Ioppolo, S., Cuppen, H. M., Romanzin, C., van Dishoeck, E. F., \& Linnartz, H. 2008, ApJ, 686, 1474

Jacox, M. E., \& Milligan, D. E. 1973, J. Molec. Spectrosc., 47, 148

Jones, A. P., Tielens, A. G. G. M., \& Hollenbach, D. J. 1996, ApJ, 469, 740

Knez, C., Boogert, A. C. A., Pontoppidan, K. M., et al. 2005, ApJ, 635, L145

Loeffler, M. J., Teolis, B. D., \& Baragiola, R. A. 2006, J. Chem. Phys., 124, 104702

Maréchal, Y. 1987, J. Chem. Phys., 87, 6344

Mathis, J. S., Mezger, P. G., \& Panagia, N. 1983, A\&A, 128, 212

Moore, M. H., \& Hudson, R. L. 1998, Icarus, 135, 518

Moore, M. H., \& Hudson, R. L. 2005, IAU Symp., 231, Astrochemistry: Recent Successes and Current Challenges, ed. D. C. Lis, G. A. Blake, \& E. Herbst, 247

Moore, M. H., Hudson, R. L., \& Ferrante, R. F. 2003, Earth Moon and Planets, 92, 291

Muñoz Caro, G. M., \& Schutte, W. A. 2003, A\&A, 412, 121

Nee, J. B., Suto, M., \& Lee, L. C. 1985, Chem. Phys., 98, 147

Nomura, H., \& Millar, T. J. 2004, A\&A, 414, 409

Nummelin, A., Bergman, P., Hjalmarson, Å., et al. 2000, ApJS, 128, 213

Öberg, K. I., Fuchs, G. W., Awad, Z., et al. 2007, ApJ, 662, L23

Öberg, K. I., Linnartz, H., Visser, R., \& van Dishoeck, E. F. 2009a, ApJ, 693, 1209

Öberg, K. I., van Dishoeck, E. F., \& Linnartz, H. 2009b, A\&A, 496, 281

Pontoppidan, K. M. 2006, A\&A, 453, L47

Requena-Torres, M. A., Martín-Pintado, J., Rodríguez-Franco, A., et al. 2006, A\&A, 455, 971

Requena-Torres, M. A., Martín-Pintado, J., Martín, S., \& Morris, M. R. 2008, ApJ, 672, 352

Romanzin, C., Bénilan, Y., Jolly, A., \& Gazeau, M.-C. 2008, Adv. Space Res., 42, 2036

Sandford, S. A., \& Allamandola, L. J. 1993, ApJ, 409, L65

Schutte, W. A., Allamandola, L. J., \& Sandford, S. A. 1993, Icarus, 104, 118

Schutte, W. A., Boogert, A. C. A., Tielens, A. G. G. M., et al. 1999, A\&A, 343, 966

Shen, C. J., Greenberg, J. M., Schutte, W. A., \& van Dishoeck, E. F. 2004, A\&A, 415,203

Sternberg, A., Dalgarno, A., \& Lepp, S. 1987, ApJ, 320, 676

Stief, L. J., Decarlo, V. J., \& Hillman, J. J. 1965, Canadian Journal of Chemistry, 43, 2490

Teolis, B. D., Loeffler, M. J., Raut, U., Famá, M., \& Baragiola, R. A. 2007, Icarus, 190, 274

van Dishoeck, E. F., Blake, G. A., Jansen, D. J., \& Groesbeck, T. D. 1995, ApJ, 447, 760

Watanabe, N., Horii, T., \& Kouchi, A. 2000, ApJ, 541, 772

Watanabe, N., Shiraki, T., \& Kouchi, A. 2003, ApJ, 588, L121

Westley, M. S., Baragiola, R. A., Johnson, R. E., \& Baratta, G. A. 1995, Nature, 373,405

Williams, D. A. 1968, ApJ, 151, 935 


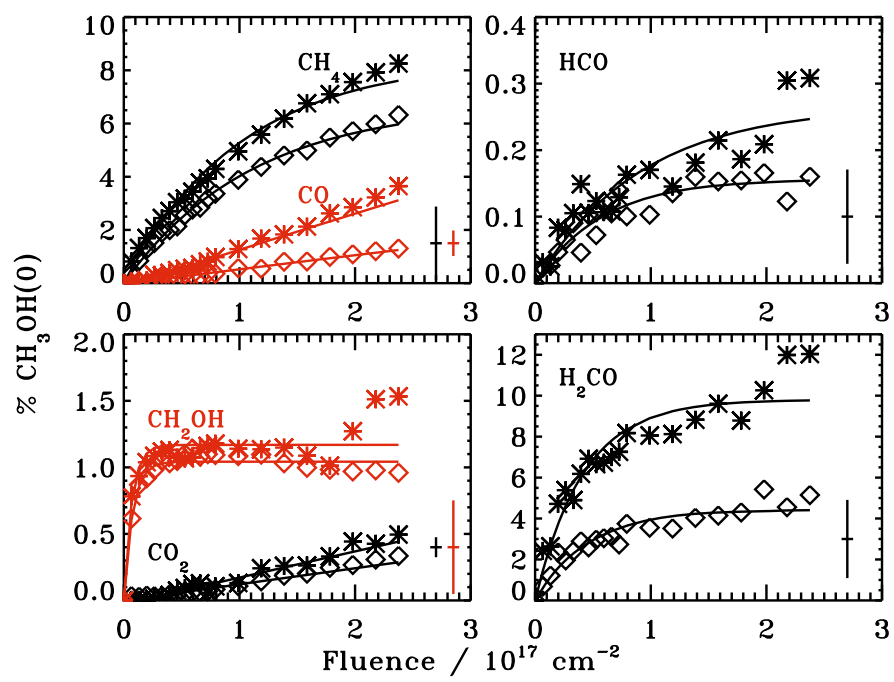

Fig. A.1. The evolution of small $\mathrm{CH}_{3} \mathrm{OH}$ photo-products with respect to UV fluence in $\%$ of the initial $\mathrm{CH}_{3} \mathrm{OH}$ ice abundance, $\mathrm{CH}_{3} \mathrm{OH}(0)$, in each experiment at $30 \mathrm{~K}$ (stars) and $50 \mathrm{~K}$ (diamonds). The relative uncertainty for each abundance is indicated in the bottom right corner. The lines are exponential fits to the abundance growths.

\section{Appendix A: Photoproduct growth curves during UV-irradiation}

\section{A.1. Pure $\mathrm{CH}_{3} \mathrm{OH}$ ice at different temperatures}

Figures A.1 and A.2 show the increasing abundances of photoproducts during irradiation of pure $\mathrm{CH}_{3} \mathrm{OH}$ ices at 30 and $50 \mathrm{~K}$ (experiments 2 and 3 ). The abundances are fitted as a function of UV fluence as described fully in Sect. 3.6 for $20 \mathrm{~K}$ and $70 \mathrm{~K}$ ices. The abundances follow the temperature trends suggested by the $20 \mathrm{~K}$ and $70 \mathrm{~K}$ ices (experiments 1 and 4), except possibly for $\mathrm{CH}_{3} \mathrm{CH}_{2} \mathrm{OH}$, which seems to be enhanced at $30 \mathrm{~K}$ compared to the other ices. This enhancement is barely significant however. The fit coefficients and uncertainties for all irradiated $\sim 20 \mathrm{~L}$, pure $\mathrm{CH}_{3} \mathrm{OH}$ ices are reported in Table C.1.

\section{A.2. High fluence experiments}

Figures A.3 and A.4 show the increasing abundances of photoproducts during irradiation at $20 \mathrm{~K}$ and $50 \mathrm{~K}$ with a high flux (experiments 5 and 6), together with the fitted growth curves. The first $2.5 \times 10^{17}$ photons $\mathrm{cm}^{-2}$ are consistent with the low flux experiments within the experimental uncertainties. For molecules such as $\mathrm{CH}_{3} \mathrm{CHO}$ that forms slowly, these experiments provide better constraints on the production rates than the low flux experiments. In contrast, molecules and fragments with high production rates are better constrained by the lower flux experiments, since they have a abundance determinations at a higher fluence resolution. The production rates of molecules that are destroyed/photodesorbed faster than they are produced at high fluences cannot be fit in these experiments. The fit coefficients of these experiments are reported in Table C.1.

\section{A.3. $\mathrm{CH}_{4}$ and $\mathrm{CO}$ mixtures}

Figures A.5-A.8 show the increasing abundances of photoproducts during irradiation of $\mathrm{CH}_{3} \mathrm{OH}: \mathrm{CH}_{4}$ 1:2 and $\mathrm{CH}_{3} \mathrm{OH}: \mathrm{CO}$ $1: 1$ mixtures at $30 \mathrm{~K}$ and $50 \mathrm{~K}$ together with fitted growth curves. The temperature trends are similar to what is seen for

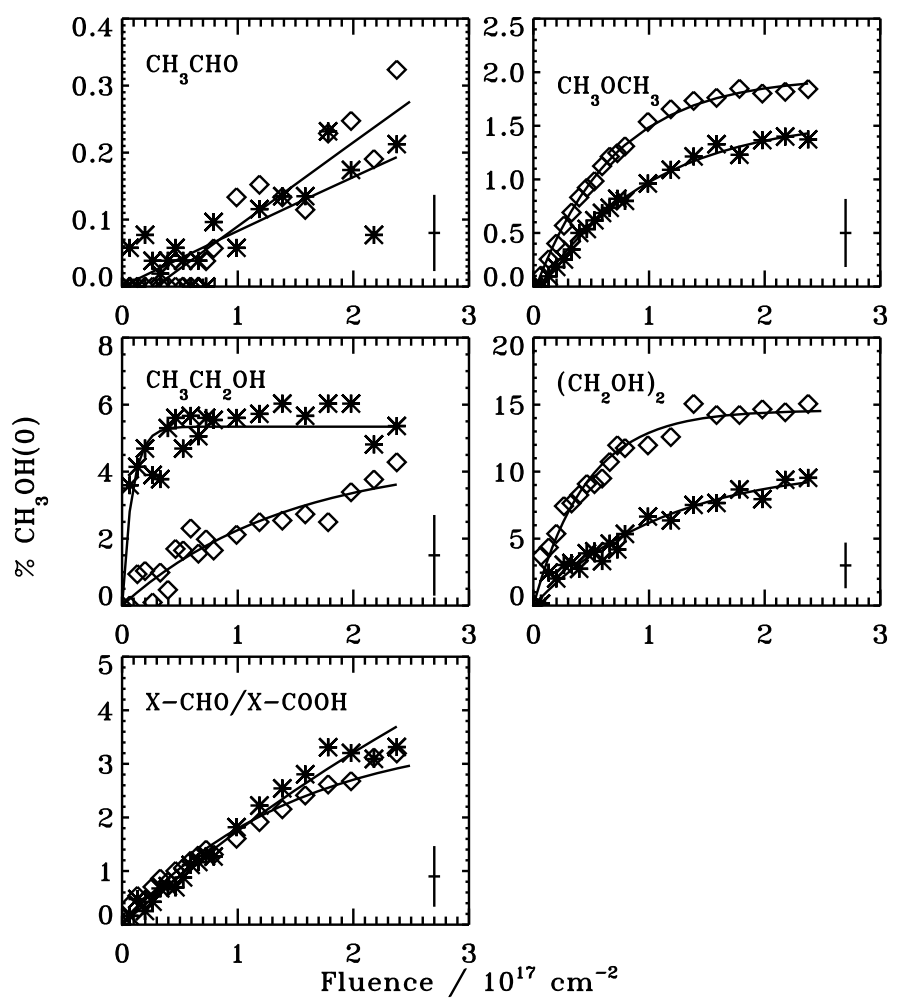

Fig. A.2. The evolution of complex $\mathrm{CH}_{3} \mathrm{OH}$ photo-products with respect to UV fluence in $\%$ of the initial $\mathrm{CH}_{3} \mathrm{OH}$ ice abundance. Otherwise as Fig. A.1.

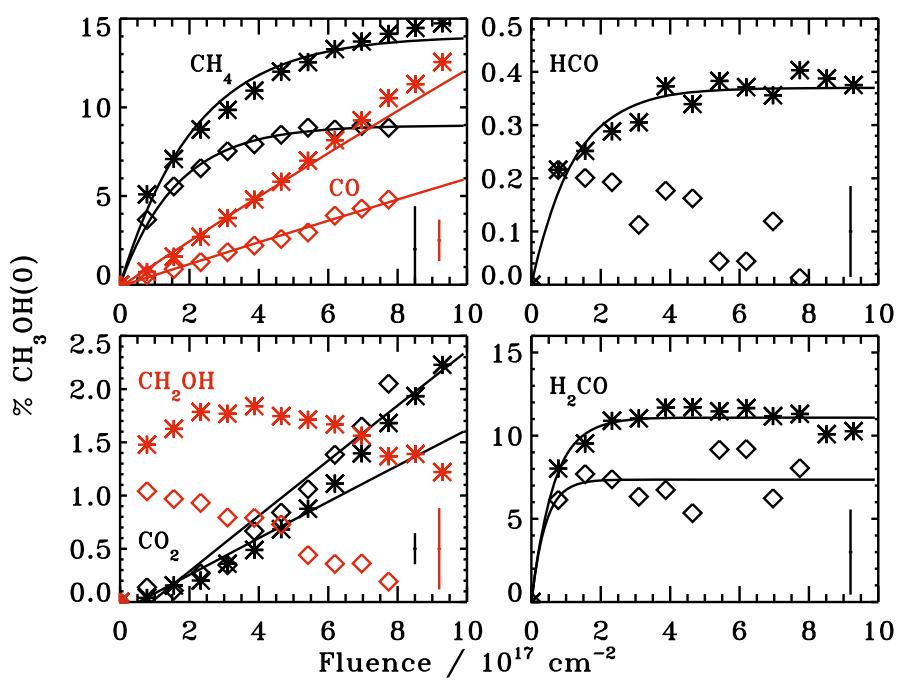

Fig. A.3. The evolution of small $\mathrm{CH}_{3} \mathrm{OH}$ photo-products with respect to UV fluence in \% of the initial $\mathrm{CH}_{3} \mathrm{OH}$ ice abundance $\left(\mathrm{CH}_{3} \mathrm{OH}(0)\right)$ in the two high flux/fluence experiments at $20 \mathrm{~K}$ (stars) and $50 \mathrm{~K}$ (diamonds). The relative uncertainty for each abundance is indicated in the bottom right corner. The lines are exponential fits to the abundance growths.

pure $\mathrm{CH}_{3} \mathrm{OH}$ ice. As suggested from the spectra in Sect. 3.3.5, all $\mathrm{HCO}$ containing species are increased in abundance in the $\mathrm{CO}$ mixtures, with the exception of $\mathrm{CH}_{3} \mathrm{CHO}$, which is mainly enhanced in the $\mathrm{CH}_{4}$ ice mixture. The other two $\mathrm{CH}_{3}$ containing species, $\mathrm{CH}_{3} \mathrm{CH}_{2} \mathrm{OH}$ and $\mathrm{CH}_{3} \mathrm{OCH}_{3}$, are also enhanced in the $\mathrm{CH}_{4}$ mixture compared both to pure $\mathrm{CH}_{3} \mathrm{OH}$ and the $\mathrm{CO}$ ice mixture - in the $\mathrm{CO}$ mixtures the abundance points represent upper limits. In contrast the $\left(\mathrm{CH}_{2} \mathrm{OH}\right)_{2}$ production is suppressed 

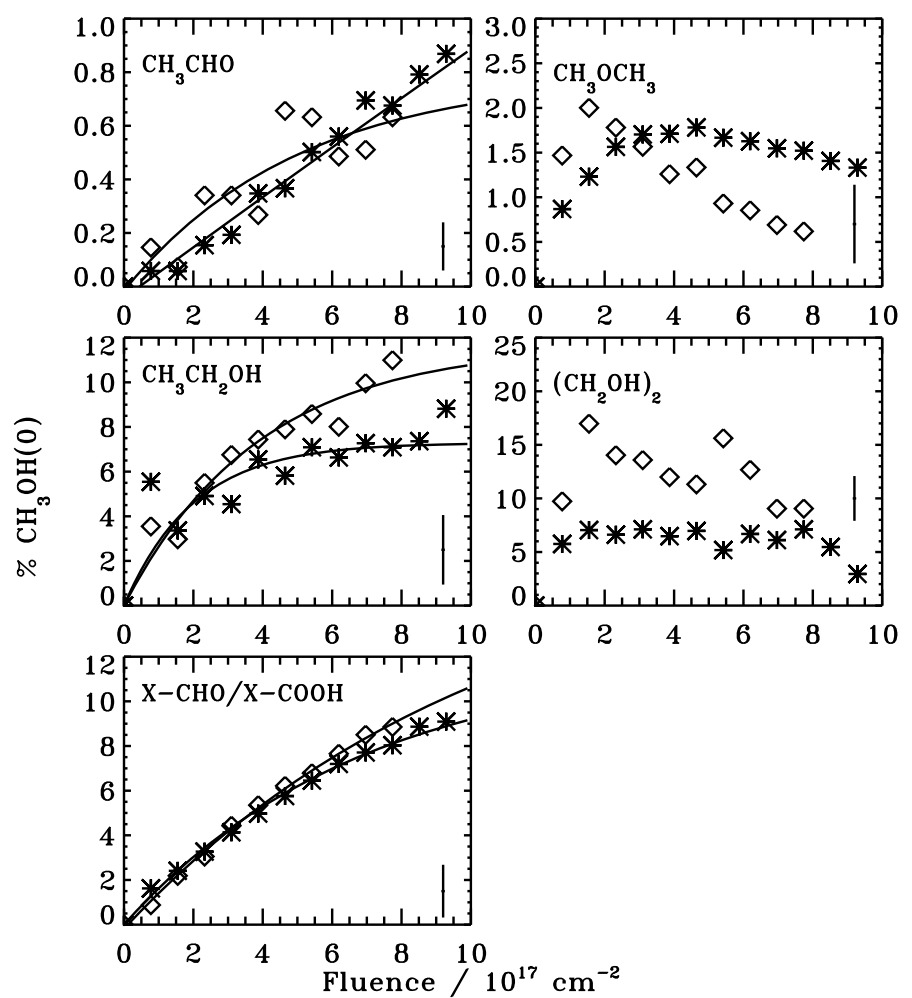

Fig. A.4. The evolution of complex $\mathrm{CH}_{3} \mathrm{OH}$ photo-products with respect to UV fluence in $\%$ of the initial $\mathrm{CH}_{3} \mathrm{OH}$ ice abundance. Otherwise as Fig. A.3.

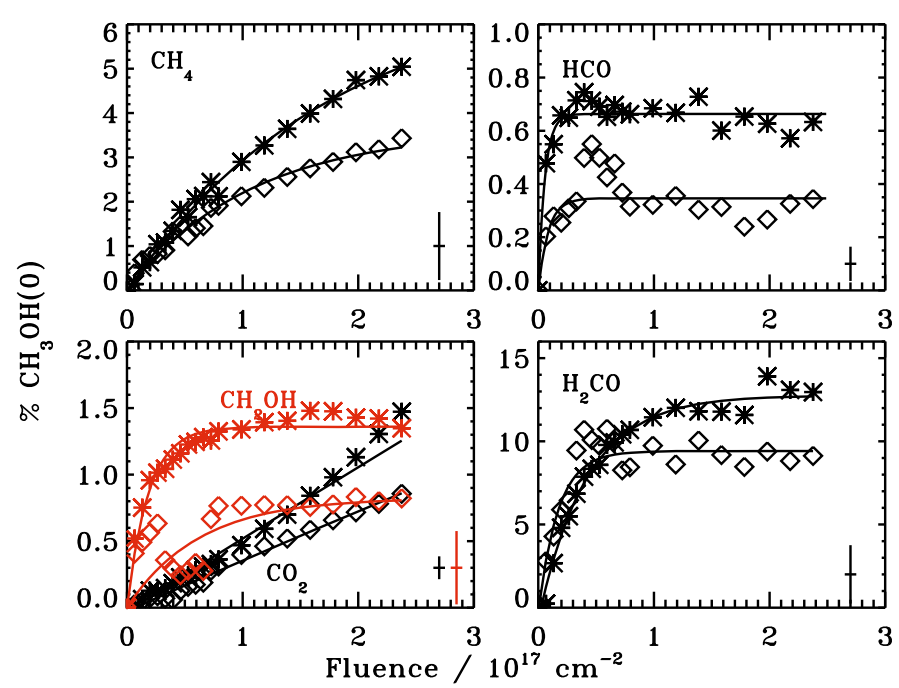

Fig. A.5. The evolution of small photo-products with respect to UV fluence in $\%$ of the initial $\mathrm{CH}_{3} \mathrm{OH}$ ice abundance in $\mathrm{CH}_{3} \mathrm{OH}: \mathrm{CO} 1: 1$ ice mixture experiments at $30 \mathrm{~K}$ (stars) and $50 \mathrm{~K}$ (diamonds).

in both ice mixtures at $30 \mathrm{~K}$. The fit coefficients of these experiments and $\mathrm{CO}: \mathrm{CH}_{3} \mathrm{OH}$ 1:1 mixture irradiated at $20 \mathrm{~K}$ are reported in Table C.2.
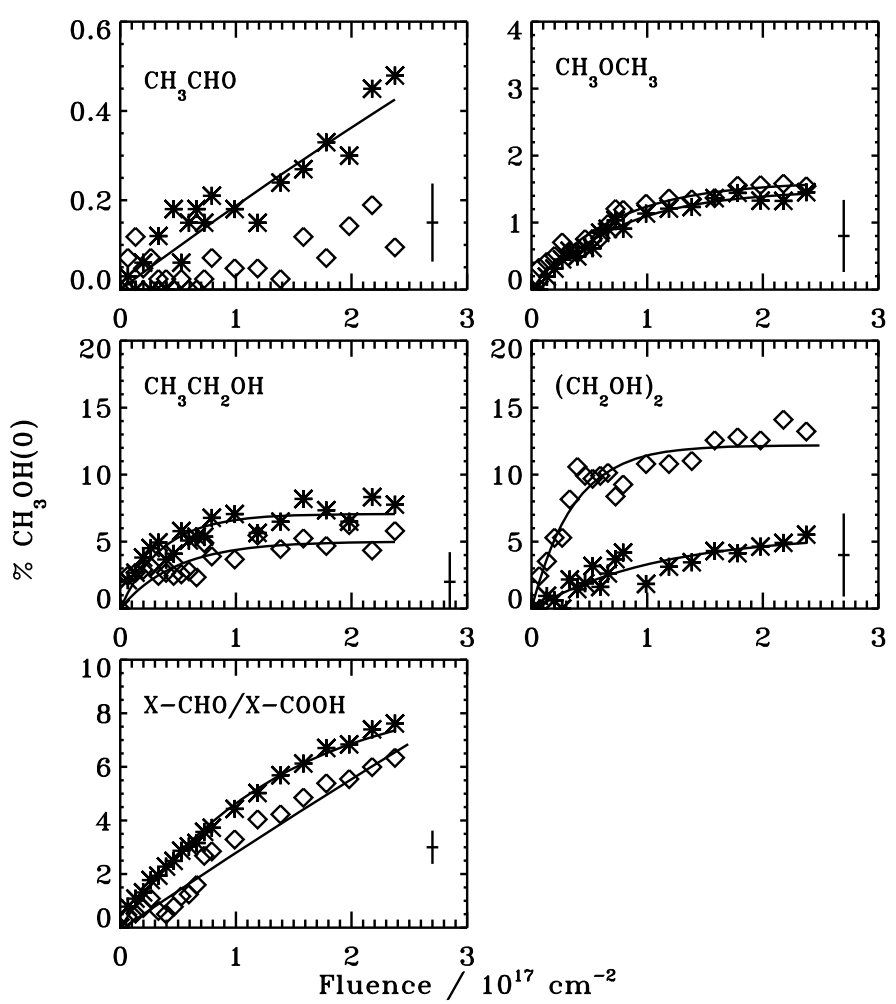

Fig. A.6. The evolution of complex photo-products with respect to UV fluence in $\%$ of the initial $\mathrm{CH}_{3} \mathrm{OH}$ ice abundance in $\mathrm{CH}_{3} \mathrm{OH}: \mathrm{CO}$ $1: 1$ ice mixture experiments at $30 \mathrm{~K}$ (stars) and $50 \mathrm{~K}$ (diamonds).

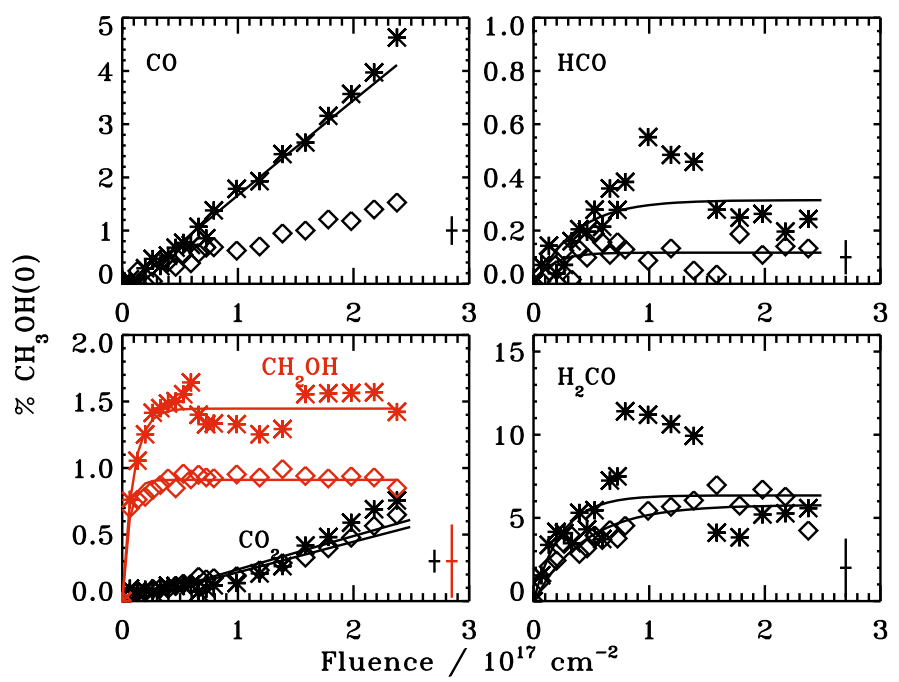

Fig. A.7. The evolution of small photo-products with respect to UV fluence in $\%$ of the initial $\mathrm{CH}_{3} \mathrm{OH}$ ice abundance in $\mathrm{CH}_{3} \mathrm{OH}: \mathrm{CH}_{4}$ 1:2 ice mixture experiments at $30 \mathrm{~K}$ (stars) and $50 \mathrm{~K}$ (diamonds).

\section{Appendix B: Formation and destruction curves during warm-up}

\section{B.1. Pure $\mathrm{CH}_{3} \mathrm{OH}$ at different irradiation temperatures}

Figures B.1 and B.2 show the evolution of photoproduct abundances during warm-up following irradiation of pure $\mathrm{CH}_{3} \mathrm{OH}$ ices at 30 and $50 \mathrm{~K}$ (experiments 2 and 3). The abundances follow the warm-up trends suggested by the 20 and $70 \mathrm{~K}$ ices (experiments 1 and 4). The $\mathrm{CH}_{3} \mathrm{CH}_{2} \mathrm{OH}$ desorption starts at a lower 


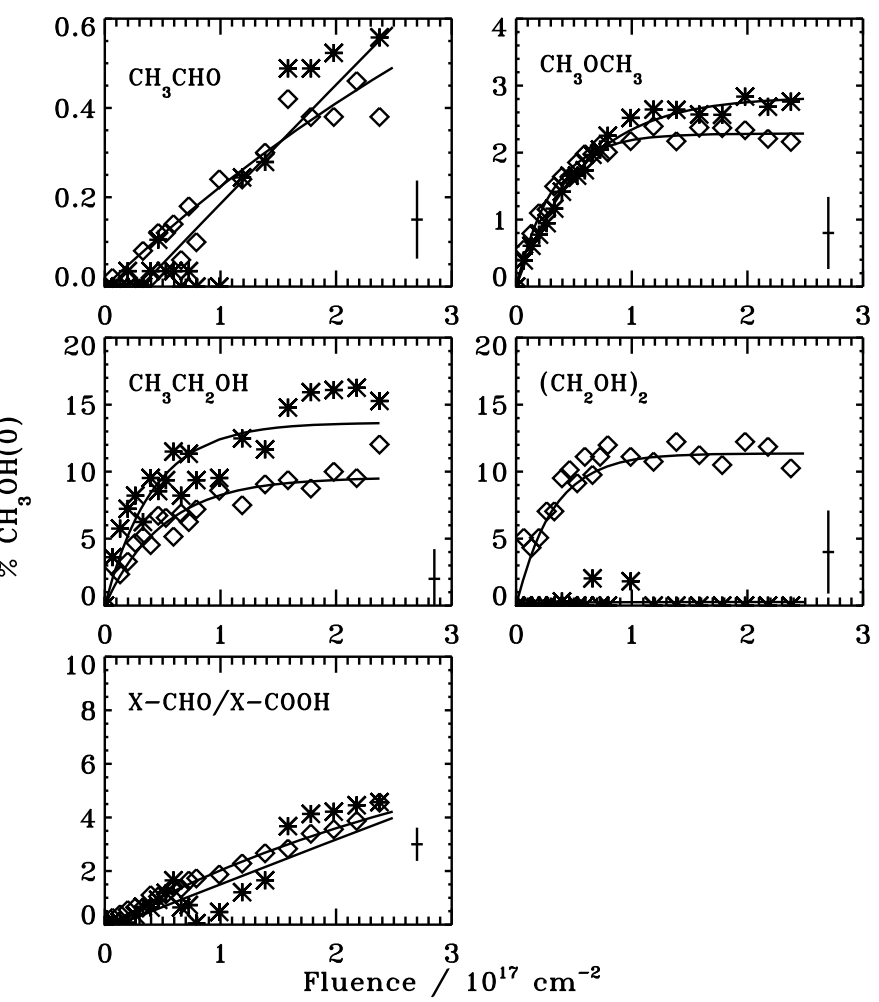

Fig. A.8. The evolution of small photo-products with respect to UV fluence in $\%$ of the initial $\mathrm{CH}_{3} \mathrm{OH}$ ice abundance in $\mathrm{CH}_{3} \mathrm{OH}: \mathrm{CH}_{4} 1: 2$ ice mixture experiments at $30 \mathrm{~K}$ (stars) and $50 \mathrm{~K}$ (diamonds).

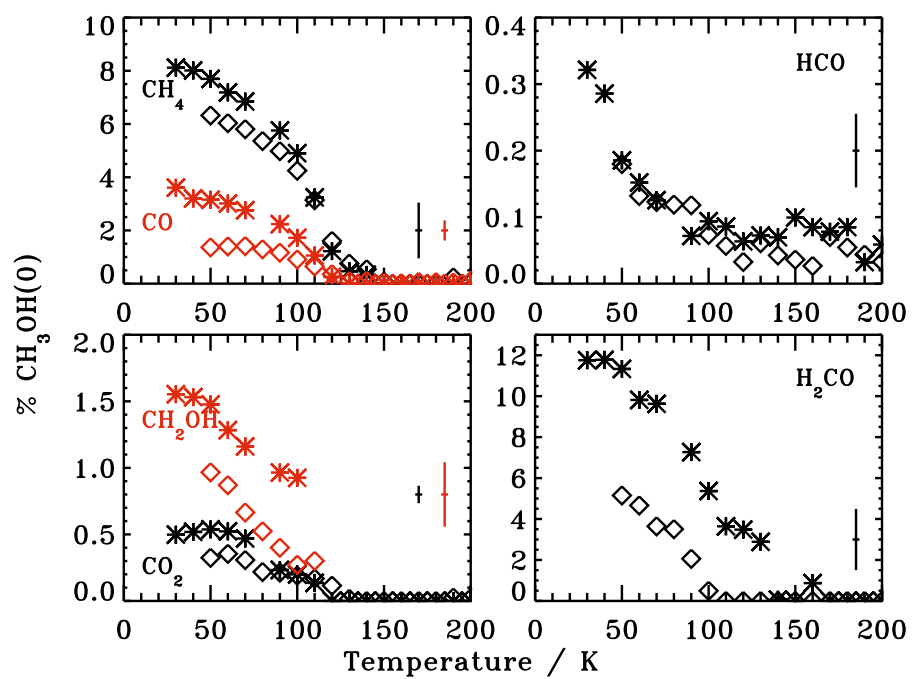

Fig. B.1. The evolution of small $\mathrm{CH}_{3} \mathrm{OH}$ photo-products with respect to UV fluence in $\%$ of the initial $\mathrm{CH}_{3} \mathrm{OH}$ ice abundance in pure $\mathrm{CH}_{3} \mathrm{OH}$ irradiation experiments at $30 \mathrm{~K}$ (stars) and $50 \mathrm{~K}$ (diamonds). The average uncertainties are indicated by the error bar to the right in each panel.

temperature than in pure $\mathrm{CH}_{3} \mathrm{CH}_{2} \mathrm{OH}$, suggesting that similarly to the $20 \mathrm{~K}$ experiment, a substantial part of the $\mathrm{CH}_{3} \mathrm{CH}_{2} \mathrm{OH}$ desorbs together with $\mathrm{CH}_{3} \mathrm{OH}$.

\section{B.2. $\mathrm{CH}_{4}$ and $\mathrm{CO}$ mixtures}

The warm-up trends are similar in the experiments where $\mathrm{CH}_{4}$ and $\mathrm{CO}$ are mixed with the $\mathrm{CH}_{3} \mathrm{OH}$ ice, at a $1(2): 1$ ratio, compared to the pure $\mathrm{CH}_{3} \mathrm{OH}$ experiments (Figs. B.3-B.6). The
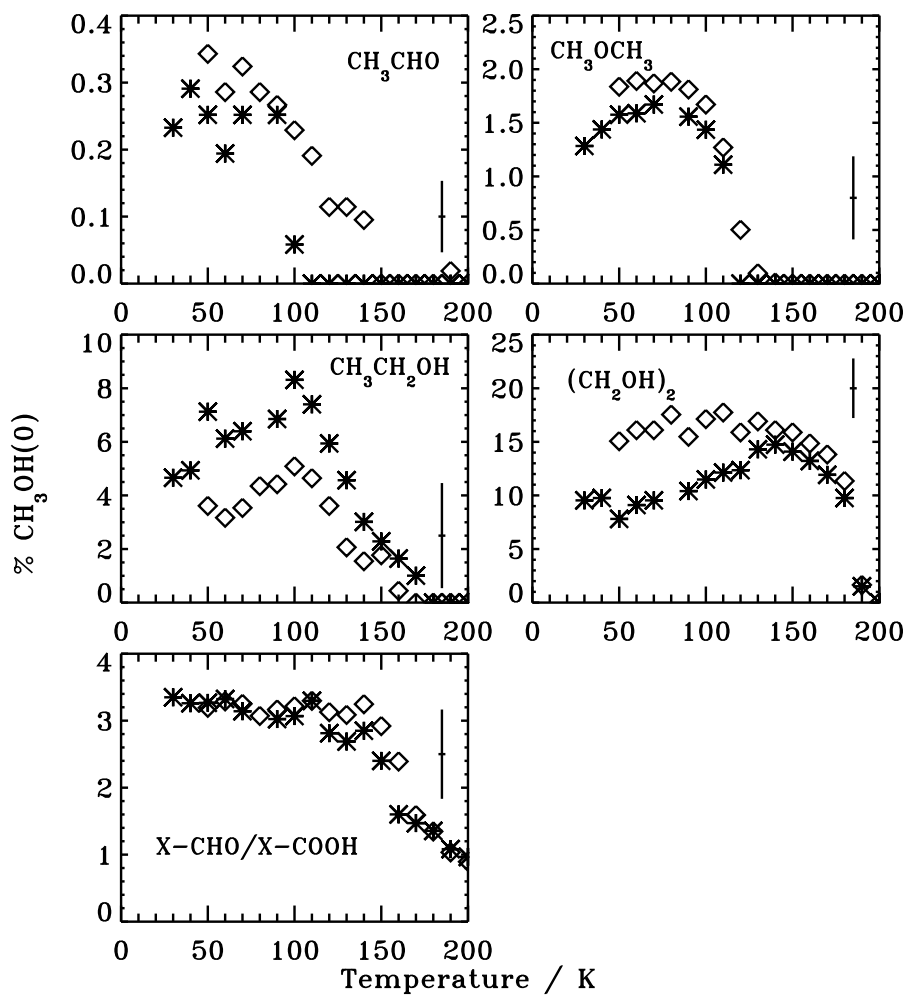

Fig. B.2. The evolution of complex $\mathrm{CH}_{3} \mathrm{OH}$ photo-products with respect to UV fluence in $\%$ of the initial $\mathrm{CH}_{3} \mathrm{OH}$ ice abundance in pure $\mathrm{CH}_{3} \mathrm{OH}$ irradiation experiments at $30 \mathrm{~K}$ (stars) and $50 \mathrm{~K}$ (diamonds). The average uncertainties are indicated by the error bar to the right in each panel.

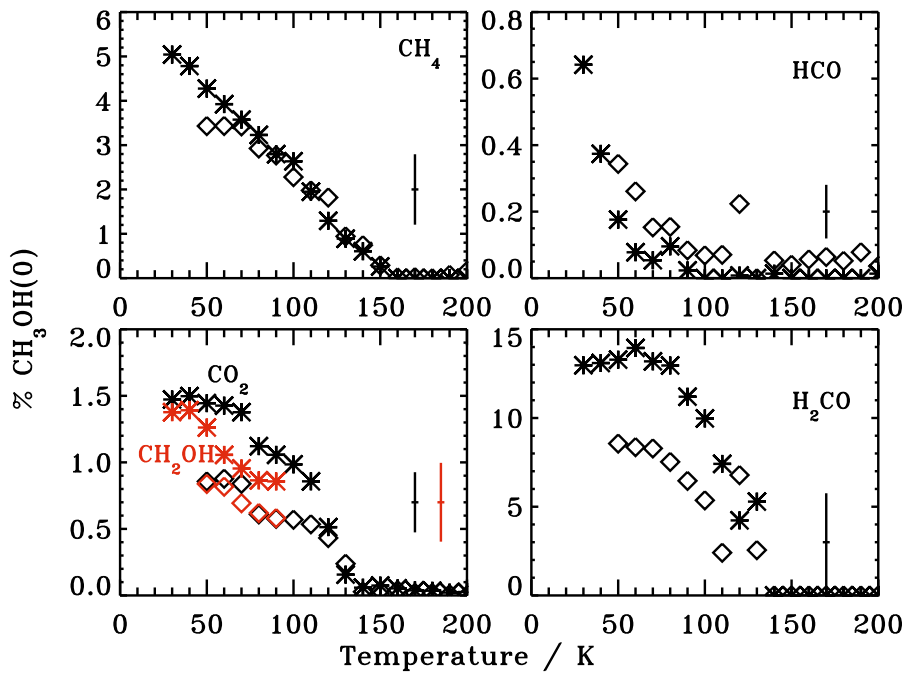

Fig. B.3. The evolution of small photo-products, in $\%$ of the initial $\mathrm{CH}_{3} \mathrm{OH}$ ice abundance, with respect to temperature following irradiation of $\mathrm{CH}_{3} \mathrm{OH}: \mathrm{CO}$ 1:1 ice mixtures at 30 (stars) and $50 \mathrm{~K}$ (diamonds). The average uncertainties are indicated by the error bar to the right in each panel.

$\mathrm{CH}_{3}$-containing molecules $\mathrm{CH}_{3} \mathrm{CHO}$ and $\mathrm{CH}_{3} \mathrm{CH}_{2} \mathrm{OH}$ show a remarkable growth between 30 and $50 \mathrm{~K}$, which is only hinted at in the pure $\mathrm{CH}_{3} \mathrm{OH}$ experiments, suggesting a significant buildup of $\mathrm{CH}_{3}$ radicals in these ice mixture experiments. In contrast the $\left(\mathrm{CH}_{2} \mathrm{OH}\right)_{2}$ formation rate is low during warm-up of the $30 \mathrm{~K}$ experiments. 


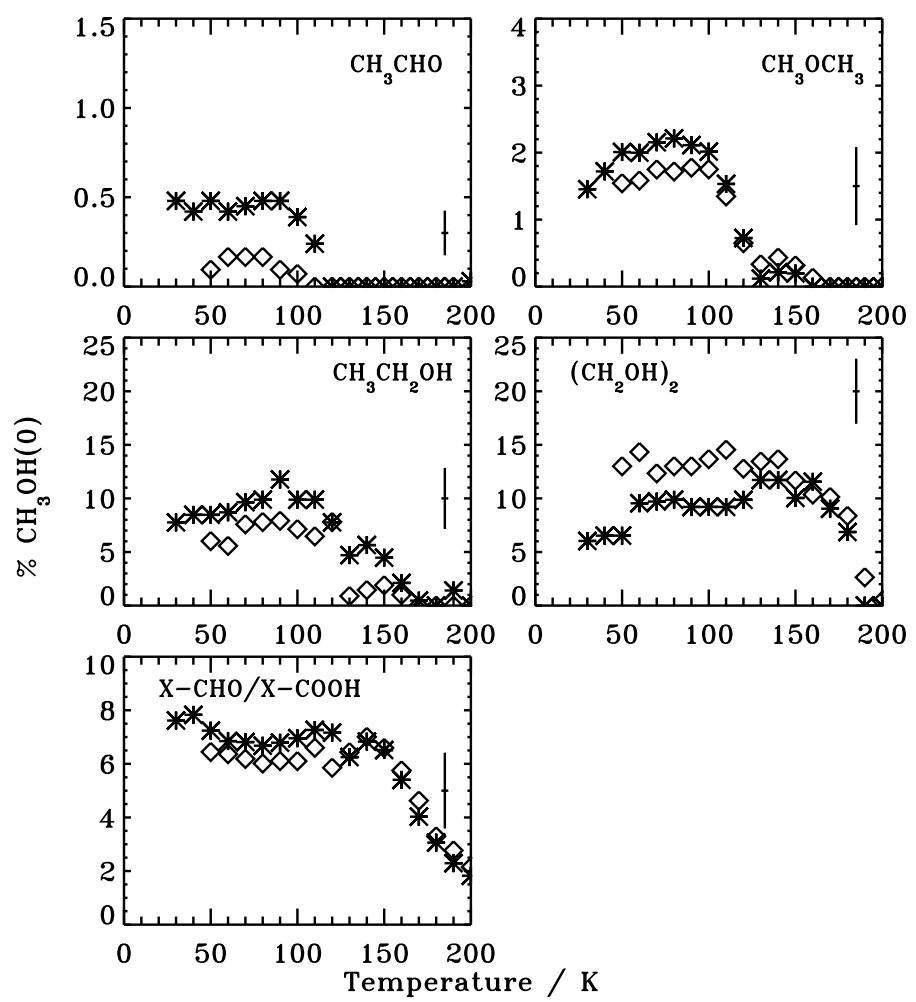

Fig. B.4. The evolution of small photo-products, in $\%$ of the initial $\mathrm{CH}_{3} \mathrm{OH}$ ice abundance, with respect to temperature following irradiation of $\mathrm{CH}_{3} \mathrm{OH}: \mathrm{CH}_{4} 1: 2$ ice mixtures at 30 (stars) and $50 \mathrm{~K}$ (diamonds). The average uncertainties are indicated by the error bar to the right in each panel.

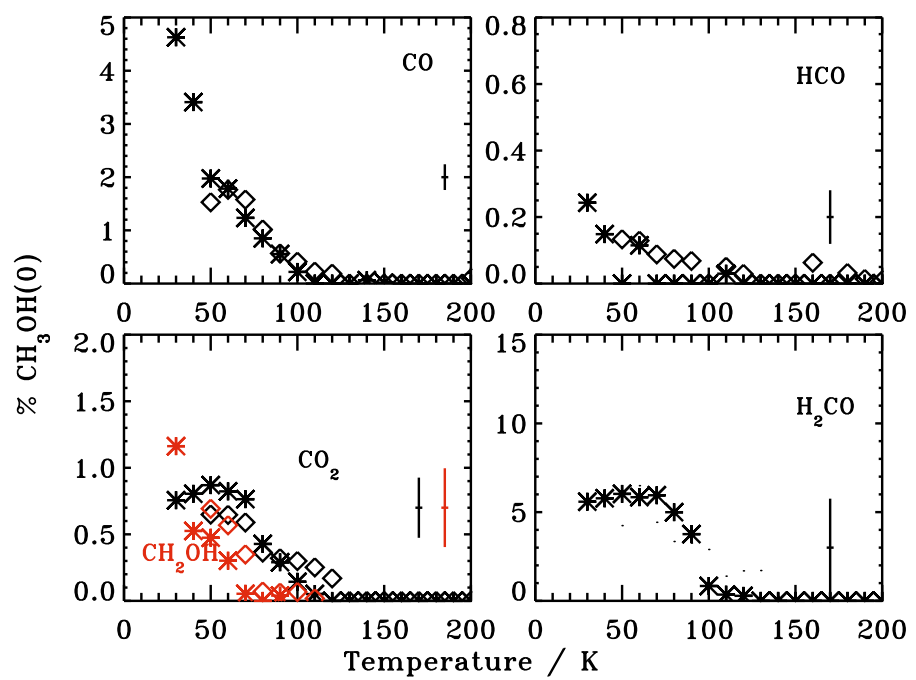

Fig. B.5. The evolution of small photo-products, in $\%$ of the initial $\mathrm{CH}_{3} \mathrm{OH}$ ice abundance, with respect to temperature following irradiation of $\mathrm{CH}_{3} \mathrm{OH}: \mathrm{CO}$ 1:1 ice mixtures at 30 (stars) and $50 \mathrm{~K}$ (diamonds). The average uncertainties are indicated by the error bar to the right in each panel.

\section{Appendix C: Formation rate parameters}

The production of simple and complex molecules during UV irradiation is parameterized with $A_{1}\left(1-\mathrm{e}^{-A_{2} \times\left(\phi-A_{3}\right)}\right)$ for 13 of the experiments, where $A_{1}$ correspond to the equilibrium abundance in $\%$ of the initial $\mathrm{CH}_{3} \mathrm{OH}$ abundance, $A_{2}$ is the fluence offset in $10^{17} \mathrm{~cm}^{-2}$ before production starts and $A_{3}$ de-
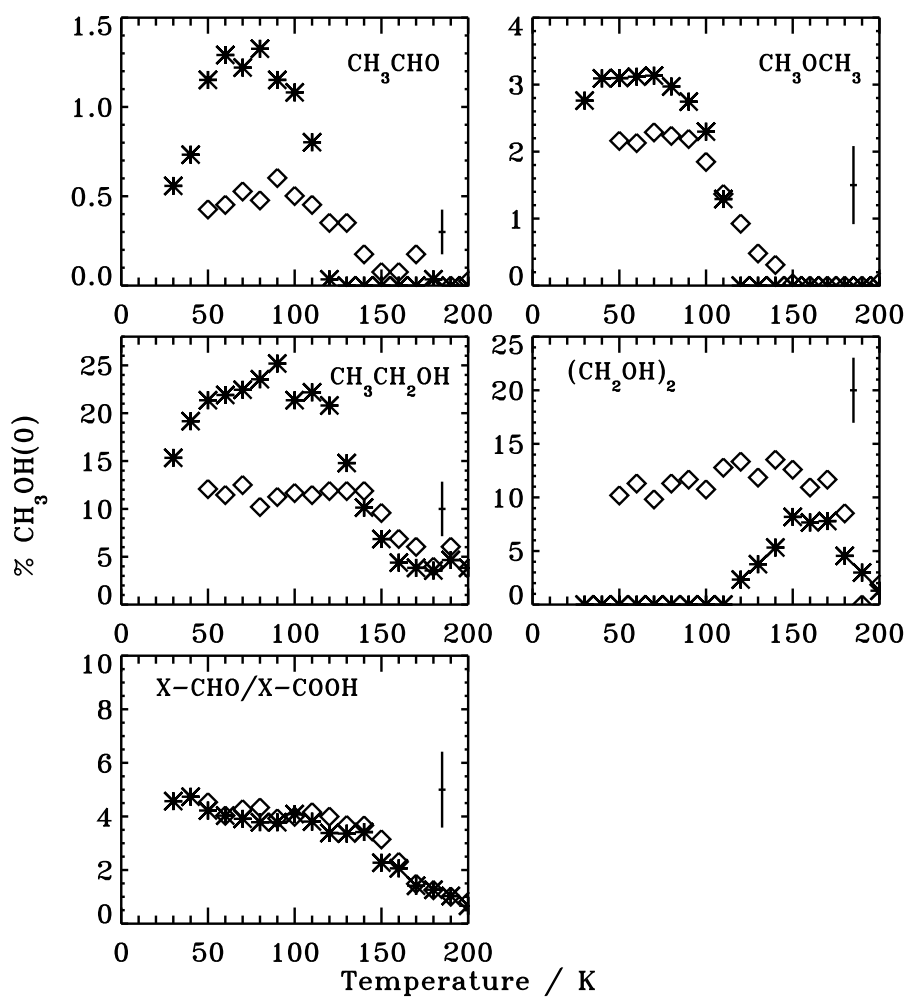

Fig. B.6. The evolution of small photo-products, in $\%$ of the initial $\mathrm{CH}_{3} \mathrm{OH}$ ice abundance, with respect to temperature following irradiation of $\mathrm{CH}_{3} \mathrm{OH}: \mathrm{CH}_{4}$ 1:2 ice mixtures at 30 (stars) and $50 \mathrm{~K}$ (diamonds). The average uncertainties are indicated by the error bar to the right in each panel.

scribes the formation and destruction rates in fluence space in $10^{-17} \mathrm{~cm}^{2}$ (Tables C.1 and C.2). The experiments include all pure 6-20 $\mathrm{ML} \mathrm{CH}_{3} \mathrm{OH}$ experiments irradiated with the normal flux setting, two $20 \mathrm{ML}$ pure $\mathrm{CH}_{3} \mathrm{OH}$ experiments irradiated with the higher flux setting, and all ice mixture experiments except for the $\mathrm{CH}_{3} \mathrm{OH}$ :CO 1:10 experiment. The 1:10 experiment is excluded since the formation of any molecules is too low to detect during irradiation itself. The fitted experiments are numbered as in Table 1.

It is important to note that the fitted formation "cross sections" cannot be used directly in astrophysical models, but rather should be used to compare models of the experiments with the experimental results. The quoted uncertainties in the tables are the fit error and do not include systematic uncertainties, in particular the conversion error between integrated band strength and abundances of $\sim 20 \%$ and the fluence uncertainty of $\sim 30 \%$. 
K. I. Öberg et al.: Formation of complex organics in $\mathrm{CH}_{3} \mathrm{OH}$ ice. I., Online Material p 5

Table C.1. Photoproduct crosssection coefficents for pure $\mathrm{CH}_{3} \mathrm{OH}$ experiments $1-6$ as listed in Table 1.

\begin{tabular}{|c|c|c|c|c|c|c|c|}
\hline & & 1 & 2 & 3 & 4 & 5 & 6 \\
\hline \multirow{3}{*}{$\mathrm{CH}_{4}$} & $\overline{A_{1}}$ & $11.1[0.5]$ & $9.6[0.6]$ & $7.2[0.5]$ & $6.1[0.3]$ & $14.7[0.3]$ & $9.0[0.2]$ \\
\hline & $A_{2}$ & $0.69[0.06]$ & $0.78[0.08]$ & $0.80[0.10]$ & $0.98[0.11]$ & $0.39[0.02]$ & $0.61[0.06]$ \\
\hline & $A_{3}$ & 0.0 & 0.0 & 0.0 & 0.0 & 0.0 & 0.0 \\
\hline \multirow[t]{3}{*}{$\mathrm{CO}$} & $A_{1}$ & $<99$ & $<99$ & $<99$ & $1.81[6.45]$ & $<99$ & $<99$ \\
\hline & $A_{2}$ & $0.021[0.001]$ & $0.016[0.001]$ & $0.02[0.16]$ & $0.12[0.49]$ & $0.015[0.001]$ & $0.006[0.001]$ \\
\hline & $A_{3}$ & $0.16[0.02]$ & $0.14[0.03]$ & $0.07[0.09]$ & 0.0 & $0.36[0.05]$ & $0.17[0.17]$ \\
\hline \multirow[t]{3}{*}{$\mathrm{HCO}$} & $A_{1}$ & $0.32[0.04]$ & $0.29[0.07]$ & $0.16[0.03]$ & $0.13[0.14]$ & $0.37[0.02]$ & - \\
\hline & $A_{2}$ & $0.99[0.29]$ & $0.88[0.37]$ & $1.78[0.81]$ & $0.53[0.87]$ & $0.76[0.21]$ & - \\
\hline & $A_{3}$ & 0.0 & 0.0 & 0.0 & 0.0 & 0.0 & - \\
\hline \multirow[t]{3}{*}{$\mathrm{H}_{2} \mathrm{CO}$} & $A_{1}$ & $9.1[0.4]$ & $10.3[0.5]$ & $4.6[0.5]$ & $1.1[0.3]$ & $11.1[0.3]$ & $7.5[0.4]$ \\
\hline & $A_{2}$ & $2.2[0.3]$ & $2.0[0.3]$ & $1.9[0.6]$ & $3.5[3.9]$ & $1.5[0.4]$ & $2.3[1.4]$ \\
\hline & $A_{3}$ & 0.0 & 0.0 & 0.0 & 0.0 & 0.0 & 0.0 \\
\hline \multirow[t]{3}{*}{$\mathrm{CH}_{2} \mathrm{OH}$} & $A_{1}$ & $1.52[0.04]$ & $1.17[0.04]$ & $1.05[0.04]$ & $0.77[0.03]$ & - & - \\
\hline & $A_{2}$ & $9.0[1.5]$ & $13.6[3.8]$ & $12.9[3.7]$ & $20.8[9.9]$ & - & - \\
\hline & $A_{3}$ & 0.0 & 0.0 & 0.0 & 0.0 & - & - \\
\hline \multirow[t]{3}{*}{$\mathrm{CO}_{2}$} & $A_{1}$ & $<99$ & $<99$ & $<99$ & $<99$ & $<99$ & $<99$ \\
\hline & $A_{2}$ & $0.008[0.025]$ & $0.014[0.099]$ & $0.015[0.117]$ & $0.008[0.095]$ & $0.002[0.001]$ & $0.003[0.006]$ \\
\hline & $A_{3}$ & $0.17[0.05]$ & $0.17[0.08]$ & $0.08[0.11]$ & $0.22[0.18]$ & $1.13[0.09]$ & $1.00[0.10]$ \\
\hline \multirow[t]{3}{*}{$\mathrm{CH}_{3} \mathrm{CHO}$} & $A_{1}$ & $<99$ & $0.9[3.5]$ & $<99$ & $0.47[0.18]$ & $<99$ & $0.82[0.18]$ \\
\hline & $A_{2}$ & $0.009[0.075]$ & $0.10[0.46]$ & $0.014[0.153]$ & $0.51[0.32]$ & $0.004[0.026]$ & $0.19[0.08]$ \\
\hline & $A_{3}$ & $0.23[0.10]$ & 0.0 & $0.30[0.11]$ & $0.11[0.08]$ & $0.54[0.25]$ & $0.09[0.33]$ \\
\hline \multirow[t]{3}{*}{$\mathrm{CH}_{3} \mathrm{OCH}_{3}$} & $A_{1}$ & $1.5[0.3]$ & $1.6[0.3]$ & $1.9[0.2]$ & $1.40[0.09]$ & - & - \\
\hline & $A_{2}$ & $0.86[0.38]$ & $1.04[0.46]$ & $1.50[0.38]$ & $3.01[0.82]$ & - & - \\
\hline & $A_{3}$ & $0.10[0.08]$ & $0.05[0.08]$ & $0.03[0.05]$ & $0.00[0.04]$ & - & - \\
\hline \multirow[t]{3}{*}{$\mathrm{CH}_{3} \mathrm{CH}_{2} \mathrm{OH}$} & $A_{1}$ & $4.7[0.3]$ & $5.4[0.3]$ & $4.8[2.1]$ & $6.9[3.5]$ & $7.4[0.6]$ & $12.9[2.4]$ \\
\hline & $A_{2}$ & $4.4[1.3]$ & $10.2[3.6]$ & $0.63[0.47]$ & $0.46[0.34]$ & $0.50[0.14]$ & $0.22[0.08]$ \\
\hline & $A_{3}$ & 0.0 & 0.0 & 0.0 & 0.0 & 0.0 & 0.0 \\
\hline \multirow[t]{3}{*}{$\left(\mathrm{CH}_{2} \mathrm{OH}\right)_{2}$} & $A_{1}$ & $4.9[0.5]$ & $10.5[2.0]$ & $14.6[0.7]$ & $18.8[0.6]$ & $6.2[0.5]$ & $12.0[0.6]$ \\
\hline & $A_{2}$ & $3.0[1.1]$ & $0.88[0.31]$ & $2.1[0.3]$ & $2.6[0.3]$ & $3.9[6.9]$ & $3.0[2.3]$ \\
\hline & $A_{3}$ & 0.0 & 0.0 & 0.0 & 0.0 & 0.0 & 0.0 \\
\hline $\mathrm{X}-\mathrm{CHO} /$ & $A_{1}$ & $12.5[7.8]$ & $6.1[2.0]$ & $4.5[0.8]$ & $8.4[3.7]$ & $13.5[1.1]$ & $16.8[3.2]$ \\
\hline \multirow[t]{2}{*}{$\mathrm{X}-\mathrm{COOH}$} & $A_{2}$ & $0.16[0.12]$ & $0.37[0.17]$ & $0.50[0.14]$ & $0.21[0.11]$ & $0.12[0.02]$ & $0.10[0.03]$ \\
\hline & $A_{3}$ & $0.03[0.06]$ & $0.04[0.06]$ & 0.0 & 0.0 & 0.0 & $0.12[0.14]$ \\
\hline
\end{tabular}


K. I. Öberg et al.: Formation of complex organics in $\mathrm{CH}_{3} \mathrm{OH}$ ice. I., Online Material $p 6$

Table C.2. Photoproduct crosssection coefficents for ice mixture experiments 7-11, 13, 14 as listed in Table 1.

\begin{tabular}{|c|c|c|c|c|c|c|c|c|}
\hline & & 7 & 8 & 9 & 10 & 11 & 13 & 14 \\
\hline \multirow[t]{3}{*}{$\mathrm{CH}_{4}$} & $A_{1}$ & $8.7[0.9]$ & $7.0[1.6]$ & $3.7[0.6]$ & - & - & $10.7[0.8]$ & $5.6[0.8]$ \\
\hline & $A_{2}$ & $0.79[0.14]$ & $0.54[0.19]$ & $0.89[0.25]$ & - & - & $1.27[0.22]$ & $1.34[0.47]$ \\
\hline & $A_{3}$ & 0.0 & 0.0 & 0.0 & - & - & 0.0 & 0.0 \\
\hline \multirow[t]{3}{*}{$\mathrm{CO}$} & $A_{1}$ & - & - & - & $<99$ & $2.9[2.4]$ & $<99$ & $1.2[0.3]$ \\
\hline & $A_{2}$ & - & - & - & $0.02[0.01]$ & $0.29[0.31]$ & $0.03[0.01]$ & $1.6[1.2]$ \\
\hline & $A_{3}$ & - & - & - & $0.11[0.05]$ & 0.0 & 0.0 & 0.0 \\
\hline \multirow[t]{3}{*}{$\mathrm{HCO}$} & $A_{1}$ & $0.98[0.02]$ & $0.67[0.02]$ & - & $0.34[0.04]$ & $0.12[0.03]$ & - & - \\
\hline & $A_{2}$ & $18.2[3.7]$ & $17.2[4.9]$ & - & $2.9[1.2]$ & $6.2[7.8]$ & - & - \\
\hline & $A_{3}$ & 0.0 & 0.0 & - & $0.03[0.06]$ & $0.01[0.10]$ & - & - \\
\hline \multirow[t]{3}{*}{$\mathrm{H}_{2} \mathrm{CO}$} & $A_{1}$ & $15.2[0.6]$ & $12.8[0.7]$ & $9.5[0.4]$ & $7.1[0.7]$ & $6.0[0.8]$ & $5.4[0.9]$ & - \\
\hline & $A_{2}$ & $3.3[0.5]$ & $2.4[0.5]$ & $6.4[1.5]$ & $3.7[1.6]$ & $2.1[0.9]$ & $7.3[7.8]$ & - \\
\hline & $A_{3}$ & $0.03[0.02]$ & $0.02[0.03]$ & $0.01[0.02]$ & 0.0 & 0.0 & 0.0 & - \\
\hline \multirow[t]{3}{*}{$\mathrm{CH}_{2} \mathrm{OH}$} & $A_{1}$ & $2.08[0.08]$ & $1.37[0.08]$ & $0.81[0.10]$ & $1.46[0.07]$ & $0.91[0.06]$ & - & $0.82[0.13]$ \\
\hline & $A_{2}$ & $4.4[0.7]$ & $5.1[1.3]$ & $1.8[0.6]$ & $10.8[4.4]$ & $17[12]$ & - & $12[15]$ \\
\hline & $A_{3}$ & 0.0 & 0.0 & 0.0 & 0.0 & 0.0 & - & 0.0 \\
\hline \multirow[t]{3}{*}{$\mathrm{C}_{2} \mathrm{H}_{6}$} & $A_{1}$ & - & - & - & $13.8[7.4]$ & - & - & - \\
\hline & $A_{2}$ & - & - & - & $1.2[1.5]$ & - & - & - \\
\hline & $A_{3}$ & - & - & - & 0.0 & - & - & - \\
\hline \multirow[t]{3}{*}{$\mathrm{CO}_{2}$} & $A_{1}$ & $<99$ & $<99$ & $8[23]$ & $<99$ & $<99$ & $<99$ & $<99$ \\
\hline & $A_{2}$ & $0.01[0.02]$ & $0.01[0.05]$ & $0.05[0.17]$ & $0.01[0.06]$ & $0.01[0.08]$ & $0.01[0.11]$ & $0.01[0.13]$ \\
\hline & $A_{3}$ & $0.10[0.03]$ & $0.10[0.04]$ & $0.07[0.07]$ & $0.13[0.10]$ & 0.0 & $0.26[0.07]$ & $0.16[0.09]$ \\
\hline \multirow[t]{3}{*}{$\mathrm{CH}_{3} \mathrm{CHO}$} & $A_{1}$ & $<99$ & $<99$ & $<99$ & $<99$ & $0.90[0.93]$ & $<99]$ & $0.33[0.05]$ \\
\hline & $A_{2}$ & $0.01[0.16]$ & $0.03[0.30]$ & $0.01[0.37]$ & $0.01[0.05]$ & $0.31[0.43]$ & $0.04[0.59]$ & $6.4[5.0]$ \\
\hline & $A_{3}$ & $0.36[0.14]$ & 0.0 & 0.0 & $0.32[0.09]$ & $0.11[0.13]$ & 0.0 & 0.0 \\
\hline \multirow[t]{3}{*}{$\mathrm{CH}_{3} \mathrm{OCH}_{3}$} & $A_{1}$ & $1.2[0.3]$ & $1.5[0.3]$ & $1.6[0.2]$ & $2.8[0.3]$ & $2.3[0.2]$ & $2.1[0.6]$ & $0.8[0.3]$ \\
\hline & $A_{2}$ & $1.4[0.9]$ & $1.4[0.8]$ & $1.5[0.5]$ & $1.8[0.6]$ & $3.1[0.8]$ & $1.4[1.0]$ & $6[12]$ \\
\hline & $A_{3}$ & $0.09[0.12]$ & $0.03[0.11]$ & 0.0 & 0.0 & 0.0 & $0.06[0.14]$ & $0.01[0.13]$ \\
\hline \multirow[t]{3}{*}{$\mathrm{CH}_{3} \mathrm{CH}_{2} \mathrm{OH}$} & $A_{1}$ & $10.0[0.4]$ & $7.3[0.7]$ & $5.2[0.6]$ & $14.9[0.9]$ & $10.0[0.9]$ & $5.7[0.8]$ & $8.1[6.2]$ \\
\hline & $A_{2}$ & $8.4[2.3]$ & $2.6[0.8]$ & $2.0[0.7]$ & $1.9[0.3]$ & $1.8[0.5]$ & 12[14] & $0.8[1.1]$ \\
\hline & $A_{3}$ & 0.0 & 0.0 & 0.0 & 0.0 & 0.0 & $0.01[0.04]$ & $0.10[0.23]$ \\
\hline \multirow[t]{3}{*}{$\left(\mathrm{CH}_{2} \mathrm{OH}\right)_{2}$} & $A_{1}$ & $5.4[0.8]$ & $5.5[3.3]$ & $12.4[0.8]$ & - & $11.4[0.9]$ & $6.4[1.7]$ & $14.6[2.8]$ \\
\hline & $A_{2}$ & $5.6[4.1]$ & $0.9[1.3]$ & $2.7[0.6]$ & - & $3.8[1.2]$ & $3.7[3.7]$ & $1.9[1.1]$ \\
\hline & $A_{3}$ & $0.02[0.06]$ & $0.01[0.28]$ & 0.0 & - & 0.0 & 0.0 & $0.02[0.12]$ \\
\hline X-CHO/ & $A_{1}$ & $12.1[0.7]$ & $9.7[0.8]$ & $17.2[7.3]$ & $<99$ & $11.3[8.3]$ & $11.6[4.7]$ & $8.3[3.1]$ \\
\hline \multirow[t]{2}{*}{$\mathrm{X}-\mathrm{COOH}$} & $A_{2}$ & $0.75[0.07]$ & $0.64[0.09]$ & $0.21[0.11]$ & $0.02[0.01]$ & $0.20[0.17]$ & $0.41[0.25]$ & $0.47[0.26]$ \\
\hline & $A_{3}$ & 0.0 & 0.0 & $0.05[0.04]$ & $0.16[0.07]$ & 0.0 & 0.0 & 0.0 \\
\hline
\end{tabular}

